$12-4-2020$

\title{
Reproductive health care in the time of COVID-19: Perspectives of poor women and service providers from Rahim Yar Khan, Punjab
}

\author{
Iram Kamran \\ Population Council \\ Tahira Parveen \\ Population Council \\ Rehan M. Niazi \\ Population Council \\ Irfan Masood \\ Population Council
}

Follow this and additional works at: https://knowledgecommons.popcouncil.org/departments_sbsr-rh

Part of the Health Services Research Commons, Public Health Education and Promotion Commons, and the Women's Health Commons

How does access to this work benefit you? Let us know!

\section{Recommended Citation}

Kamran, Iram, Tahira Parveen, Rehan M. Niazi, and Irfan Masood. 2020. "Reproductive health care in the time of COVID-19: Perspectives of poor women and service providers from Rahim Yar Khan, Punjab."

Islamabad: Population Council. 


\section{REPRODUCTIVE HEALTH CARE IN THE TIME OF COVID-19:}

PERSPECTIVES OF POOR WOMEN AND SERVICE PROVIDERS

\section{FROM RAHIM YAR KHAN, PUNJAB}

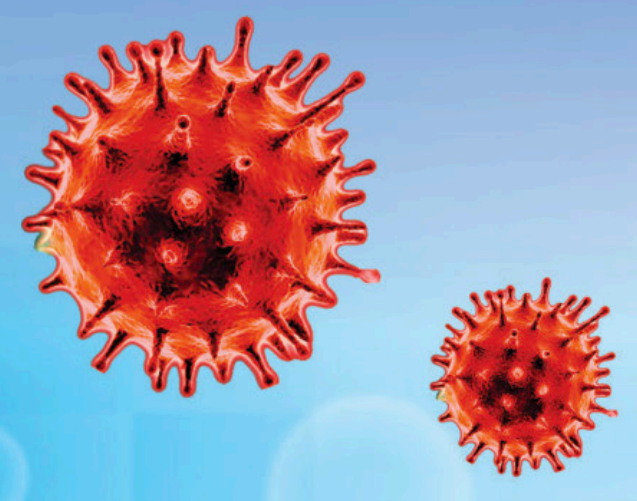





\section{POPULATION COUNCIL}

\section{REPRODUCTIVE HEALTH CARE}

IN THE TIME OF COVID-19:

PERSPECTIVES OF POOR WOMEN AND SERVICE PROVIDERS

FROM RAHIM YAR KHAN, PUNJAB 


\title{
POPULATION
}

COUNCIL

Ideas. Evidence. Impact.

The Population Council confronts critical health and development issues-from stopping the spread of HIV to improving reproductive health and ensuring that young people lead full and productive lives. Through biomedical, social science, and public health research in 50 countries, we work with our partners to deliver solutions that lead to more effective policies, programs, and technologies that improve lives around the world. Established in 1952 and headquartered in New York, the Council is a nongovernmental, non-profit organization governed by an international board of trustees.

Population Council

Third Floor, NTC Building (North), Sector F-5/1

Islamabad, Pakistan

Tel: +9251920 5566

Fax: +92512821401

Email: info.pakistan@popcouncil.org

www.popcouncil.org

\author{
Authors: \\ Iram Kamran \\ Tahira Parveen \\ Rehan Niazi \\ Irfan Masood
}

Suggested citation: Kamran, I., T. Parveen, R. Niazi, and I. Masood. 2020. Reproductive Health Care in the Time of COVID-19: Perspectives of Poor Women and Service Providers from Rahim Yar Khan, Punjab. Islamabad: Population Council.

(C) 2020 The Population Council, Inc. 


\section{TABLE OF CONTENTS}

LIST OF ACRONYMS

ACKNOWLEDGMENTS Vi

EXECUTIVE SUMMARY

INTRODUCTION AND METHODOLOGY 6

Background

Research Objectives

$\begin{array}{ll}\text { Study Methodology } & 7\end{array}$

KNOWLEDGE, CHALLENGES, AND NEEDS OF POOR WOMEN DURING THE COVID=19 PANDEMIC 9

Findings 9

Knowledge and Perception of COVID-19 9

Sources of Information 9

Origins of the Disease 10

Symptoms

Transmission 11

$\begin{array}{ll}\text { High Risk Groups } & 11\end{array}$

\begin{tabular}{l} 
Protective Measures \\
\hline
\end{tabular}

Care for Breastfed Babies 13

Impacts of COVID-19 on the Lives of Poor Women 13

Economic Challenges 14

Food Insecurity 16

Domestic Violence 16

Accessing General and Reproductive Health Services 17

Mental Health 19

KNOWLEDGE, ATTITUDES, PRACTICES AND CHALLENGES OF HEALTH CARE WORKERS DURING COVID-19 PANDEMIC 21

$\begin{array}{ll}\text { Findings } & 21\end{array}$

Knowledge of COVID-19 22

Provider Attitudes $\quad 25$

Practice
Training

Training
25

Availability of Personal Protective Equipment 25

Provision of COVID-19 Services 26

Impact of Pandemic on Routine Service Provision 27

\begin{tabular}{l} 
Discrimination \\
\hline
\end{tabular}

DISCUSSION AND RECOMMENDATIONS 29

\begin{tabular}{l} 
Discussion \\
\hline Recommendations
\end{tabular}

Recommendations $\quad 32$

APPENDICES

Appendix A: Guideline for focus group discussions with BISP beneficiaries 34

Appendix B: Guideline for in-depth interviews with BISP beneficiaries 35

Appendix C: Structured questionnaire for interviews with women 36

Appendix D: Structured questionnaire for interviews with service providers 43 


\section{List of Tables}

Table 1.1: Socio-demographic characteristics of women in structured interviews ( $n=164)$

Table 1.2: Profile of service providers who participated in two rounds of structured interviews ( $n=60)$

Table 1.3: Mean and maximum calls per respondent and response rates

Table 2.1: Distribution of new FP users since COVID-19 outbreak, by status at 2019 survey and method choice ( $\mathrm{n}=20$ )

Table 2.2: Psychological stress scores based on Psychological Stress Assessment Tool and proposed treatment actions

Table 3.1: Number of service providers to whom personal protection equipment is available, by type of equipment

\section{List of Figures}

Figure S.1: Distribution of respondents' sources of information on COVID-19 $(n=164)^{\star}$

Figure S.2: Percentage of women reporting domestic violence under usual circumstances and lockdown ( $n=164)$

Figure S.3: Distribution of respondents' psychological stress levels $(n=164)$

Figure S.4: Distribution of challenges in working in pandemic conditions reported by service providers who were operational in May 2020 and September 2020 ( $\mathrm{N}=39)$

Figure S.5: Distribution of adverse effects of COVID-19 on provision of routine services at facilities reported by service providers who were operational in May 2020 and September 2020 (N=39)

Figure 1.1: Rapid Study Components

Figure 2.1: Key areas assessed in the study

Figure 2.2: Distribution of respondents' sources of information on COVID-19 ( $n=164)$

Figure 2.3: Respondent perceptions of COVID-19 etiology among women $(n=164)$

Figure 2.4: Distribution of COVID-19 symptoms mentioned by respondents $(n=164)$

Figure 2.5: Knowledge of COVID-19 transmission among respondents $(n=164)$

Figure 2.6: Knowledge of specific protective measures against COVID-19 among respondents $(n=164)$

Figure 2.7: Key adverse effects of COVID-19 in the lives of women

Figure 2.8: Occupations preceding the COVID-19 outbreak among respondents' husbands $(n=164)$

Figure 2.9: Distribution of cash or food rations, by source, among respondents $(n=164)$

Figure 2.10: Distribution of effects of lockdown on respondents' lives ( $n=164)$

Figure 2.11: Percentage of women who reported experiencing domestic violence under usual circumstances

and lockdown $(n=164)$, and distribution of types of violence experienced during lockdown reported by women ( $\mathrm{n}=62$ )

Figure 2.12: Percentages of FP use-current, past, never-in 2019 and 2020 after COVID-19 outbreak reported by women $(n=164)$

Figure 2.13: Distribution of contraceptive method in 2019 survey and 2020 COVID-19 survey

Figure 2.14: Percentage of respondents affirming stress symptoms included in psychological assessment statements $(n=164)$

Figure 2.15: Distribution of psychological stress levels among respondents $(n=164)$

Figure 3.1: Distribution of specific possible symptoms of COVID-19 identified by service providers in

May and September $2020(n=60)$

Figure 3.2: Distribution of COVID-19 transmission means identified by service providers in

May and September $2020(n=60)$

Figure 3.3: Distribution of potential COVID-19 health issues identified by service providers in

May and September $2020(n=60)$

Figure 3.4: Distribution of specific measures for preventing transmission of COVID-19 identified by

service providers in May and September $2020(n=60)$

Figure 3.5: Distribution of COVID-19 care and treatment options mentioned by service providers in

May and September $2020(n=60)$

Figure 3.6: Proportions of service providers correctly responding to true or false statements about COVID-19, by category in May and September $2020(n=60)$

Figure 3.7: Distribution of challenges in working in pandemic conditions reported by service providers who were operational in both May and September $(n=39)(n=21)$

Figure 3.8: Distribution of reasons for non-provision of COVID-19 services mentioned by service providers who were operational in both May and September $(n=39)$

Figure 3.9: Distribution of adverse effects of COVID-19 on provision of routine services at facilities reported by service providers who were operational in May and September $(n=39)$

Figure 3.10: Main reasons for decline in clientele at health facilities reported by service providers

who were operational in May and September $(n=39)$

7

10

10

10

11

11

12

14

14

14 


\section{LIST OF ACRONYMS}

\begin{tabular}{ll} 
ANC & Antenatal Care \\
BISP & Benazir Income Support Programme \\
CHW & Community Health Worker \\
COVID & Coronavirus Disease \\
DoH & Department of Health \\
FGD & Focus Group Discussion \\
FP & Family Planning \\
FWC & Family Welfare Center \\
IDI & In-Depth Interview \\
LARC & Long-Acting Reversible Contraceptive \\
LHV & Lady Health Visitor \\
LHW & Lady Health Worker \\
NGO & Non-Governmental Organization \\
PHQ-9 & Patient Health Questionnaire 9 \\
PPE & Personal Protection Equipment \\
PWD & Population Welfare Department \\
RH & Reproductive Health \\
SRH & Sexual and Reproductive Health \\
SOGP & Society of Obstetricians and Gynaecologists of Pakistan \\
TV & Television \\
UN & United Nations \\
UNFPA & United Nations Population Fund \\
WHO & World Health Organization \\
& \\
\hline
\end{tabular}




\section{ACKNOWLEDGMENTS}

We gratefully acknowledge the United Nations Population Fund (UNFPA) for commissioning the Population Council

Pakistan to conduct this study of Reproductive Health Care in the Time of COVID-19: Perspectives of Poor Women and Service Providers from Rahim Yar Khan, Punjab. We also thank colleagues from UNFPA for their guidance and technical support including Dr. Yilma Melkamu Alazar, International Advisor on Family Planning, and Dr. Jameel Ahmed, Program Specialist, Sexual Reproductive Health (SRH).

We are indebted to Dr. Zeba A. Sathar (T.I.), Country Director of the Population Council Pakistan, for her guidance and encouragement to the research team, and to Dr. Ali Mohammad Mir, Senior Director of Research and Programs, for his leadership, insight, and technical guidance at every stage of the research and report writing. This study could not have been completed without his invaluable guidance. We acknowledge and thank Ms. Samia Shah, Project Director, for her oversight and support. We also express our gratitude to Michelle J. Hindin, Director of Reproductive Health at the Population Council, and Leah Jarvis, Program Manager, for their technical reviews.
We deeply appreciate the dedication and hard work of our field team, which collected data by telephone and transcribed it against a stringent timeline. Our sincere thanks are due to Mr. Haider Abbasi for his outstanding support in training field staff for data collection. We also appreciate the important contributions of Ms. Arfa Ahmad and Ms. Faryal llyas, who supported analysis of the qualitative data.

We extend our special gratitude to the beneficiaries of the Benazir Income Support Program and health care providers who participated in this study, and so generously shared their time and experiences during the challenging time of the COVID-19 pandemic.

We are extremely grateful to Ms. Kiren Khan, whose meticulous editing helped shape this report and greatly facilitated its dissemination.

Our special thanks are due to Mr. Muhammad Khalil, Senior Program Manager (IT), whose immense support made it possible for us to successfully conduct focus group discussions via telephone. We also thank Mr. Ali Ammad for formatting this report. 


\section{EXECUTIVE SUMMARY}

This study was conducted by the Population Council in Rahim Yar Khan district of Punjab, with the support of the United Nations Population Fund (UNFPA), to uncover urgently needed evidence about the challenges and needs of poor women and health care providers during the COVID-19 pandemic. Over 200 poor womenbeneficiaries of the Benazir Income Support Programme (BISP), one of the largest social protection programs in the world-and 60 public and private sector health care providers participated in this investigation of BISP beneficiaries' knowledge of COVID-19, the effects of the pandemic on their lives, mental health and wellbeing, and their access to reproductive health $(\mathrm{RH})$ and family planning (FP) services, as well as the knowledge, attitudes, practices, and challenges of service providers during the COVID-19 pandemic.

The study comprised 164 structured interviews with BISP beneficiaries, in-depth interviews (IDIs) with 20 women, three focus group discussions (FGDs) with women (a total of 18 respondents), as well as interviews with 60 health care providers. All of these women and health care providers were interviewed in 2019 for a project in Rahim Yar Khan evaluating an innovative model for FP services to women in the poorest wealth quintile who are BISP beneficiaries.

This study conducted interviews with service providers in two rounds, the first in May 2020 and the second in September 2020. To preserve social distancing, all discussions and interviews were conducted by telephone.

\section{FINDINGS AMONG BISP BENEFICIARY WOMEN}

\section{Knowledge of COVID-19}

All women surveyed were aware of COVID-19 and commonly refer to it as "Corona," "Virus," "Virus Disease," or "Waba," the Urdu term for pandemic, and most were aware of preventative measures (82\%) and a majority knew how it is transmitted (67\%).

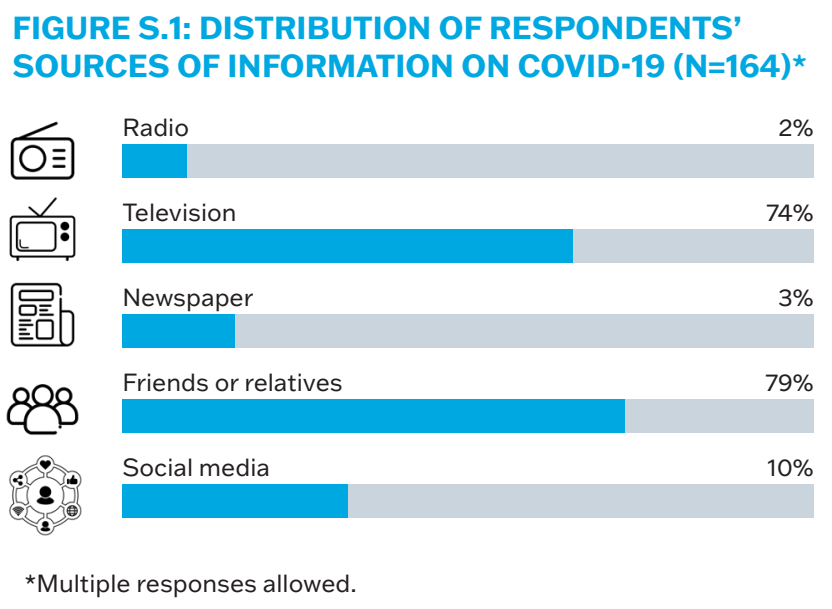

Sources of information: Women primarily learn about COVID-19 from friends, relatives, and television (Figure S.1). They believe television to be a more reliable, faster, and important source of information.

Origins of the disease: In qualitative discussions, most respondents mentioned China as the source of the virus, and some were even able to recall Wuhan (in China) as its place of origin. Most women believe COVID-19 reached Pakistan through people entering the country from abroad. Half of women surveyed perceive the pandemic as divine punishment and a warning.

Symptoms: Surveyed women generally knew at least some symptoms of COVID-19, mainly citing cough, fever, and influenza-like symptoms, but only a small proportion knew about possible sore throat and shortness of breath, and hardly any were aware of fatigue as a symptom.

Transmission: Most women (75\%) were aware that COVID-19 can be transmitted though close contact with infected persons. Smaller proportions identified airborne droplets (25\%), coughing (36\%), and sneezing (30\%) as means of infection.

High risk groups: A majority of women believe young children and older adults are at higher risk of contracting COVID-19; in qualitative discussions, women defined young children as those under five years of age and older adults 
as those older than 50, and believe these groups have less immunity. A few women were aware that individuals with pre-existing medical conditions such as diabetes or hepatitis are more susceptible to COVID-19. The fact that women reported young children as of higher risk is a misperception not substantiated by evidence at this point in time.

Protective measures: Most women consider staying at home a protective measure-many are avoiding visits to neighbors, relatives, and even parents. They are also aware of the need to avoid close contact with others, and the need for frequent handwashing. While not confirmed whether they use soap, women did mention common brands of soap and disinfectant, in addition to affordable alternatives.

Care for breastfed babies: Women are aware of major protective measures against COVID-19, but they do not have accurate knowledge about what breastfeeding mothers should do if they contract the virus. All women who participated in FGDs and IDIs revealed the erroneous impression that an infected mother should not continue to breastfeed, due to a belief of transferal of the virus through breastmilk. Women suggested that breastfeeding mothers with COVID-19 should isolate themselves from their breastfeeding children.

\section{Impact of COVID-19}

Economic challenges: Women report that COVID-19 and its lockdown have drastically changed their lives. Comparison of the 2019 survey with the same panel of women a dramatic rise in women whose husbands are unemployed: from 13 percent in 2019 to 58 percent after the lockdown. Women's own jobs and small scale homebased work, like sewing, have also been affected. It is hard for them to fulfill even basic material needs.

Food insecurity: Nearly all women are distressed by the decline in food availability and resultant hunger within their families, due to loss of work and income. They are worried about the effects on their children's health, and about the lack of economic resources for other necessities.

Domestic violence: One third of women reported domestic violence during the lockdown, with a majority experiencing psychological violence, yet some have experienced physical violence, perpetrated by their husbands (Figure S.2).
FIGURE S.2: PERCENTAGE OF WOMEN REPORTING DOMESTIC VIOLENCE UNDER USUAL CIRCUMSTANCES AND LOCKDOWN ( $\mathrm{N}=164)$

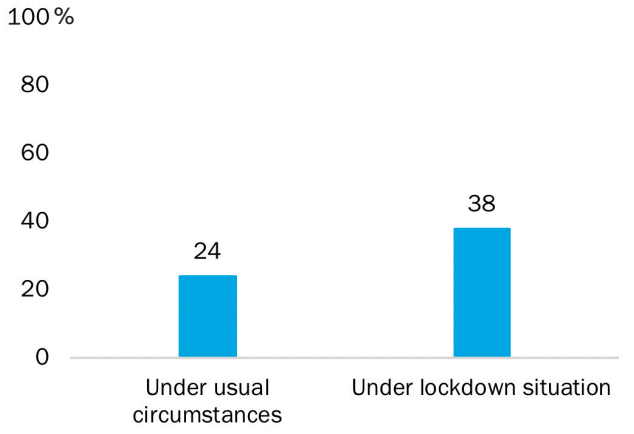

\section{FIGURE S.3: DISTRIBUTION OF RESPONDENTS' PSYCHOLOGICAL STRESS LEVELS ( $\mathrm{N}=164)$}

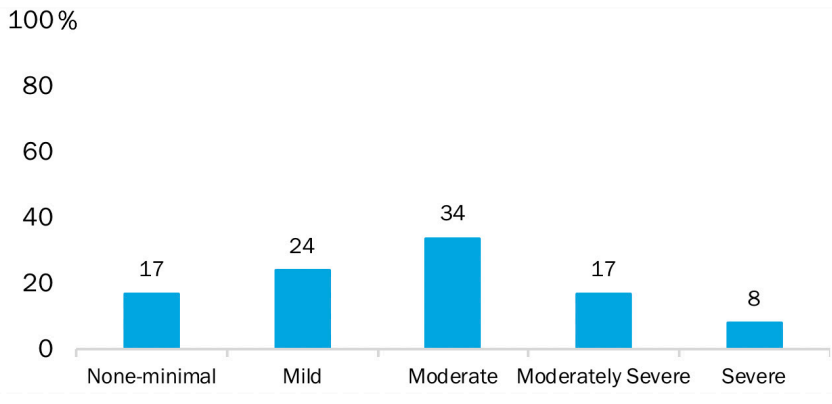

Access to FP and RH services: At the time of the 2019 survey, 63 percent of women were current users of contraception, and 68 percent were current users in 2020. During qualitative discussions, women expressed desire to avoid pregnancy due to the current circumstances. During COVID-19, some women switched from short term, modern methods to less reliable, traditional methods. Qualitative findings suggest the main reasons are financial constraints and suspension of home care services by Lady Health Workers (LHWs).

During FGDs, women described challenges in obtaining antenatal care (ANC) and delivery services due to the COVID-19 lockdowns. They reported service providers wanting to maintain physical distance from clients and not examining patients properly, and even avoiding delivery cases by sending women home, or to other facilities. Women believe delivery cases are not being accepted and admitted upon first visit, and that these delays are leading to poor outcomes including stillbirths. 
Interrupted schooling: Women with schoolchildren are also stressed about the disruption of educational activities, and the possible adverse effects on their children, of being idle or roaming outdoors. They want to arrange home tutoring but cannot afford it.

\section{Psychological stress: Economic} pressures leading to food insecurity are a major contributing factor to women's stress. This study assessed women's stress with a universally recognized and tested assessment tool, PHQ-9, comprising nine statements, with each representing a symptom of stress. For every PHQ-9 statement presented to the surveyed women, at least one third responded affirmatively, with higher proportions for some indicators, especially fatigue, feeling "down," or sleep disturbance.

Only 17 percent of respondents expressed no or minimal stress, whereas 34 percent expressed moderate degrees of stress, and 17 percent had moderately severe levels of stress (Figure S.3).

\section{FINDINGS AMONG SERVICE PROVIDERS}

Interviewed service providers included medical doctors, Lady Health Visitors (LHVs), male and female health technicians, Family Welfare Counselors, Family Welfare Assistants, nurses, midwives, and dispensers. Of these, 42 were employed at public facilities - of either the departments of Health or Population Welfare (PWD)and 18 working for private entities, including large and small hospitals, and LHV maternity clinics. Each health facility provided $\mathrm{RH}$ services, including maternal health and at least one FP method, in addition to general health services. During the first round of interviews, in May, only 39 of the 60 facilities were operational. Eighteen of the 21 closed facilities were PWD Family Welfare Centres (FWCs), which had been closed by the department because their continued operation was considered non-essential during the initial phase of COVID-19. The three private facilities were closed due to lack of capacity for enacting protective measures. During the second round of interviews in September, all 60 facilities were operational.

\section{Knowledge of COVID-19}

Questions about symptoms and health issues associated with COVID-19, and its transmission and treatment, were asked of all 60 service providers. In the first round of interviews, about 85 percent of respondents identified only a few symptoms of COVID-19, and in September 95 percent could do so-providers could, however, identify specific measures of care for COVID-19 patients (97 percent in May and 98 percent in September). Eightyseven percent of service providers in May were aware that a COVID-19 patient should be kept in isolation, yet in September only 80 percent were. In both surveys, the proportion of service providers who understood that a COVID-positive woman can use modern contraceptives as well as continue to breastfeed remained low: at 38 percent in the first round of and 40 percent in the second, for continued contraceptive use, and 37 percent and 43 percent, respectively, for safe breastfeeding.

\section{Attitudes and Challenges}

In May, fear of contracting COVID-19 among the 39 service providers at operational facilities was pervasive, while in September slightly more than two thirds of those same 39 providers reported persisting COVID issues (Figure S.4). Fear of transmitting the infection to their own families was generally prevalent in both surveys and among both categories of service providers, the 39 working in September as well as May, and the 21 operational only in September. In May over one third of service providers were acutely challenged by lack of 
FIGURE S.5. DISTRIBUTION OF ADVERSE EFFECTS OF COVID-19 ON PROVISION OF ROUTINE SERVICES AT FACILITIES REPORTED BY SERVICE PROVIDERS WHO WERE OPERATIONAL IN MAY 2020 AND SEPTEMBER 2020 ( $\mathrm{N}=39)^{\star}$

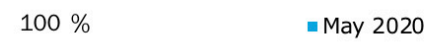

(1)
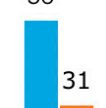

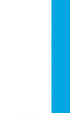
care

*Multiple responses allowed.

\section{Of the 39 facilities that were}

operational in May, 38\% faced

disruption in contraceptive supply in May and $21 \%$ in September.
Impact of COVID-19 on Routine Services

Most (79\%) service providers working in May reported at least one adverse impact of COVID-19 and its lockdown on either general or $\mathrm{RH}$ services at their facilities

(Figure S.5). Of the 39 service providers working in both rounds of interviews, 60 percent reported adverse effects on antenatal care (ANC) in May, which fell to 23 percent in September; 46 percent reported adverse effects on delivery services in May, which declined to 26 percent in September; 54 percent reported that postnatal care (PNC) services were adversely affected in May, which reduced to 21 percent in September; 44 percent reported adverse effects on general health services in May, which was recorded at 31 percent in September; and finally those reporting adverse effects on FP services represented 56 percent of functioning health care workers in May and 31 percent in September. Unsurprisingly, the majority $(n=19)$ of the other 21 service providers reported that FP services were affected by COVID-19, with lower proportions reporting adverse effects on ANC and general health care services.

One third of the 39 service providers working in May reported disruptions in contraceptive supply at their facilities, while in September, the proportion was 21 percent. Among the 21 service providers who were not working in May (primarily PWD staff), during the second survey round in September, a majority $(n=15)$ reported disruptions in contraceptive supplies. During stock outs, most service providers refer their clients to other facilities or to pharmacies.

While most service providers said they had not encountered any social discrimination due to COVID fears, in May 10 percent of providers who were then working reported experiencing some form COVID prejudice or fear, which increased to 18 percent in September among the same 39 service providers.

By September, only 19 of all 60 service providers had received official training on COVID-19 and 33 percent of them had not yet received PPE. 


\section{RECOMMENDATIONS}

- Broadcast public service media messages on TV to widely disseminate accurate information about COVID-19 and RH and child health issues and dispel pervasive misconceptions and myths. Provide information about health facilities that are open and can be visited by women and couples for $\mathrm{RH}$ services. Publicize established helplines to both support families and educate the public on how to contact trained doctors by telephone for advice for $\mathrm{RH}$ issues.

- Immediately provide additional income support and nutrition packages to all eligible BISP beneficiaries, to help meet poor families' basic food needs, either in the form of ration packages or vouchers. In addition to helping address food insecurity, it will help reduce child malnutrition.

- Provide parents emergency educational subsidies for school fees to keep children enrolled, or for community or home tuition, so children can continue their lessons at or close to home. School administrations should liaise with the postal system for home delivery and exchange of study materials and homework lessons between students and teachers.

- To restore access to RH and general health services, reopening PWD facilities and resuming community health services is crucial, not only for addressing couples' unmet FP needs but in contributing to critical efforts to raise COVID-19 awareness. Inclusion of RH and maternal health in essential services, in the case of any type of emergency situation, should be included in intense advocacy efforts with the government and relevant decision-makers.
- Use mHealth or telemedicine to avoid burdening facilities and minimize patient access issues. Community health workers (CHWs) should provide their clients with toll-free telephone numbers to contact doctors for advice on $\mathrm{RH}$ and general health needs.

- All service providers should be trained on COVID-19 protocols and procedures to eliminate critical knowledge deficiencies, help them deal safely with clients, and improve COVID awareness in local communities.

- All service providers should be provided PPE at work to reduce their fears of coronavirus infection and combat absenteeism. COVID-19 testing at service providers' workplaces will not only increase their confidence but ensure that only uninfected staff is working at facilities.

- Provide mental health support for service providers, and periodically assess their mental health, and then provide any help or rehabilitation support they need.

- Allocate resources to implement the COVID-19 Emergency Support Plan of the Primary and Secondary Healthcare Department of Punjab-it will address the majority of supply issues identified in this study. 


\section{INTRODUCTION AND METHODOLOGY}

\section{BACKGROUND}

The coronavirus disease COVID-19 is an unprecedented global crisis. As its myriad societal effects continue to emerge, there is growing recognition that women and girls, especially those who are poor and especially vulnerable, are bearing the brunt of the fractures in health care systems along with the economic pressures. The United Nations Secretary General emphasized this risk in his 7 April 2020 global statement on the pandemic response, stressing the need to pay attention to continued delivery of sexual and reproductive health $(\mathrm{SRH})$ services, and to closely monitor the situation by collecting sex-disaggregated data.' In her statement on World Population Day 2020, UNFPA executive director Dr. Natalia Kamen also emphasized the urgent need to safeguard the health and rights of women and girls, that "sexual and reproductive health care is a right, and like pregnancies and childbirth, human rights don't stop for pandemics."2 As part of the COVID-19 response, the World Health Organization (WHO) has also emphasized the need for social science research on the impacts of the pandemic on SRH systems, especially qualitative research on women's reproductive and psycho-social health issues, and assessments of health facilities. ${ }^{3}$

There is tremendous need for such research in Pakistan, which has an under-resourced health care system, and generally poor health indicators in comparison with the rest of South Asia, and where women's vulnerability to risks such as unwanted pregnancies, unsafe deliveries at home, pregnancy-related deaths, pre-term births and low infant birth weights, gender-based violence (GBV), nutritional neglect, as well as psychological issues, is already high. The COVID-19 crisis is putting enormous pressure on Pakistan's health system, and diverting attention and resources from regular health care.
Both the public and private health care sector providers in Pakistan are finding it difficult to provide services due to lack of training for pandemic conditions, lack of personal protective equipment (PPE), and supply disruptions. International evidence indicates that primary health care (PHC) providers treating patients with COVID-19 face greater risks of mental health issues, and those with no infectious disease expertise face additional challenges as they adjust to an entirely new, highly stressful work environments.

Meanwhile, protracted lockdowns have reduced households' access to health services, resulting from rapid declines in income and ability to pay for goods and services, lack of public transportation, and the general fear of becoming infected.

This rapid study was conducted by the Population Council, beginning in May 2020, to contribute urgently needed evidence on the challenges to health and well-being among the poorest women in Pakistan, as well as the difficulties faced by service providers in health care provision. Further data collection was in September 2020 captured changes in service providers' knowledge, attitudes, and practices. In conjunction with the research agenda of the United Nations, and UNFPA in particular, this study aims to inform effective strategies for maintaining women's access to health care services in Pakistan during the COVID-19 pandemic.

\section{RESEARCH OBJECTIVES}

This study principally examines elements of Punjab's poorest women's experiences during COVID-19:

- Knowledge and perceptions of COVID-19, its modes of transmission, prevention and protection strategies, and perceived personal vulnerability to viral infection;

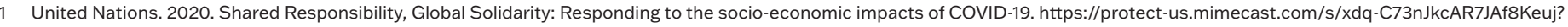
domain=nam01safelinks.protection.outlook.com

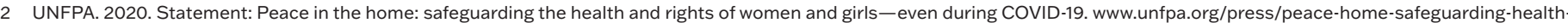
and-rights-women-and-girls-\%E2\%80\%93-even-during-covid-19

3 IBP Network. 2020, Covid-19 and its implications for family planning services (webinar). https://ibpnetwork.org/news/271558

4 Chen, H., J. Guo, C. Wang, F. Luo, X. Yu, W. Zhang, J. Li, D. Zhao, D. Xu, Q. Gong, and J. Liao. 2020. Clinical characteristics and intrauterine vertical transmission potential of COVID-19 infection in nine pregnant women: A retrospective review of medical records. The Lancet 395(10226): 809-815. 
- Additional reproductive health $(\mathrm{RH})$ and family planning (FP) needs;

- Impact on household nutrition and care-seeking behaviors;

- Mental health issues or experiences of domestic violence associated with the stressful circumstances created by the pandemic; and

- Coping strategies, particularly for changes and shocks to household economics, and for meeting nutritional and $\mathrm{RH}$ needs, including FP.

This study further assesses public and private sector health care providers' COVID-19 knowledge, attitudes, and practices and identifies noteworthy challenges to continuing provision of $\mathrm{RH}$ and child health services.

\section{STUDY METHODOLOGY}

The study was conducted in Khanpur, a sub-district of Rahim Yar Khan in southern Punjab province. The Population Council, with the support of UNFPA, was already evaluating an innovative model for FP services to the sub-district's women in the poorest wealth quintile, who are beneficiaries of the Benazir Income Support Programme (BISP), one of the largest social protection programs in the world.

Before the pandemic, in September and October 2019, the Population Council completed a survey in Khanpur of 1,640 female BISP beneficiaries, along with all public and private health facilities that provide at least one FP method. Those voluntary informed consent forms, with participants' contact details, from that survey permitted the Council to again contact those respondents for urgently needed evidence of their experiences with the COVID-19 pandemic and lockdowns. These individuals made possible this rapid study that is founded on a strong, established knowledge base. Non-probability sampling selected 10 percent of the women from the 2019 survey who were married, age 18 to 45 , and from the poorest wealth quintile.

We attempted to include all 67 service providers from the initial survey in 2019, and of those, 60 agreed to contribute, two declined to participate, and five did not respond to our telephone calls, after multiple attempts at different
FIGURE 1.1. RAPID STUDY COMPONENTS

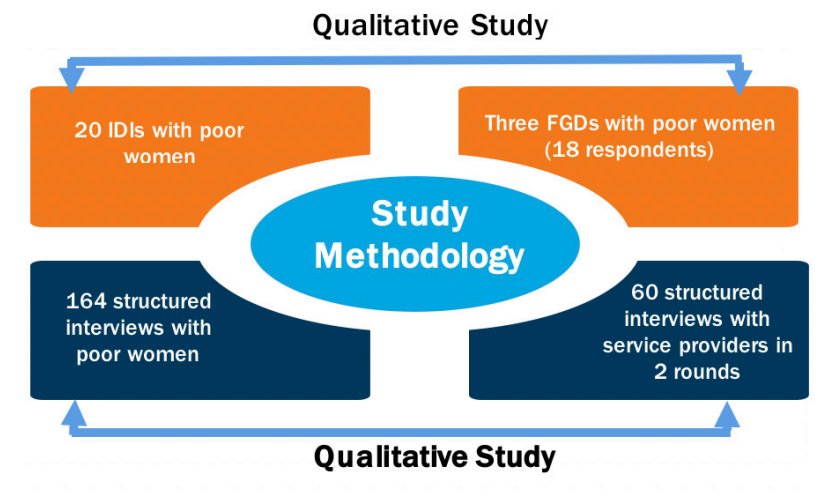

dates and times. Service providers in the public and private sectors, including medical doctors, Lady Health Visitors (LHVs), male and female health technicians, Family Welfare Counselors (FWCs), assistants, nurses, midwives, and dispensers are all represented. All service providers who participated in the first round of interviews for this rapid study also participated in the second round-except one male doctor from a private health facility who could not make time for an interview but assigned another staff member to participate on behalf of their health facility.

TABLE 1.1. SOCIO-DEMOGRAPHIC CHARACTERISTICS OF WOMEN IN STRUCTURED INTERVIEWS ( $\mathrm{N}=164)$

\begin{tabular}{|c|c|c|}
\hline & $\%$ & $\mathbf{N}$ \\
\hline \multicolumn{3}{|l|}{ Age group } \\
\hline $25-30$ years & 13 & 21 \\
\hline 31-35 years & 26 & 43 \\
\hline $36-40$ years & 39 & 64 \\
\hline $41-45$ years & 22 & 36 \\
\hline \multicolumn{3}{|c|}{ Educational attainment } \\
\hline No schooling & 77 & 127 \\
\hline Primary & 15 & 24 \\
\hline $\begin{array}{l}\text { Middle and } \\
\text { above }\end{array}$ & 8 & 13 \\
\hline \multicolumn{3}{|c|}{ Contraceptive use status } \\
\hline Current user & 68 & 112 \\
\hline Never user & 10 & 16 \\
\hline Past user & 22 & 36 \\
\hline \multicolumn{3}{|c|}{ Current pregnancy status } \\
\hline Yes & 3 & 5 \\
\hline No & 97 & 159 \\
\hline
\end{tabular}


TABLE 1.2. PROFILE OF SERVICE PROVIDERS WHO PARTICIPATED IN TWO ROUNDS OF STRUCTURED INTERVIEWS ( $\mathrm{N}=60)$

\begin{tabular}{|l|c|c|}
\hline & $\begin{array}{c}\text { N } \\
\text { (Round 1: } \\
\text { May 2020) }\end{array}$ & $\begin{array}{c}\text { N } \\
\text { (Round 2: } \\
\text { September 2020) }\end{array}$ \\
\hline Gender & 18 & 18 \\
\hline Male & 42 & 42 \\
\hline Female & 1 & 1 \\
\hline Type of provider & 15 & $14^{\star}$ \\
\hline Gynecologist & 20 & 20 \\
\hline Doctor & \multicolumn{2}{|c|}{} \\
\hline $\begin{array}{l}\text { Lady Health Visitor/ } \\
\text { Female Health } \\
\text { Technician }\end{array}$ & 18 & 18 \\
\hline $\begin{array}{l}\text { Family Welfare Workers/ } \\
\text { Councilors/ Assistants** }\end{array}$ & 2 & $3^{\star}$ \\
\hline $\begin{array}{l}\text { Dispenser/Male Health } \\
\text { Technician }\end{array}$ & 4 & 4 \\
\hline $\begin{array}{l}\text { Nurse/Midwife/ } \\
\text { Community Midwife }\end{array}$ & 13 & 11 \\
\hline Professional Experience (years) & & \\
\hline Mean & 10 & \\
\hline Median & & \\
\hline
\end{tabular}

*One male doctor who was interviewed in May was not available for the interview in September. In his place, a dispenser working at the same health facility participated in the study in September. ${ }^{* *}$ All three cadres are staff of the Population Welfare Department.

TABLE 1.3. MEAN AND MAXIMUM CALLS PER RESPONDENT AND RESPONSE RATES

\begin{tabular}{|l|c|c|l|}
\hline $\begin{array}{l}\text { Type } \\
\text { of } \\
\text { Respondent }\end{array}$ & $\begin{array}{c}\text { Number of } \\
\text { Calls per } \\
\text { Respondent } \\
\text { (Mean/Max) }\end{array}$ & $\begin{array}{c}\text { Response } \\
\text { Rate }\end{array}$ & \multicolumn{1}{|c|}{ Refusals } \\
\hline $\begin{array}{l}\text { BISP } \\
\text { Beneficiaries }\end{array}$ & $2.4 / 4$ & $100 \%$ & $\begin{array}{l}\text { None-All } \\
\text { women were very } \\
\text { understanding and } \\
\text { cooperative }\end{array}$ \\
\hline $\begin{array}{l}\text { Service } \\
\text { Providers } \\
\text { (Round 1 in } \\
\text { May) }\end{array}$ & $2.0 / 7$ & $95 \%$ & $\begin{array}{l}\text { Of 67 providers } \\
\text { approached, 2 } \\
\text { refused } \\
\text { and 5 could not } \\
\text { be contacted after } \\
\text { repeated calls }\end{array}$ \\
\hline $\begin{array}{l}\text { Service } \\
\text { Providers } \\
\text { (Round 2 in } \\
\text { September) }\end{array}$ & $1.6 / 4$ & $100 \%$ & \\
\hline
\end{tabular}

This study includes qualitative and quantitative components, outlined in Figure 1.1. Ethical approval for the study was obtained on an expedited basis from the Population Council's Institutional Review Board in New York. The tools for data collection include a guideline for focus group discussions (FGDs, in Appendix A), a guideline for in-depth interviews (IDIs, in Appendix B), a structured questionnaire for interviews with women (Appendix C), and a structured questionnaire for interviews with service providers (Appendix D).

Profiles of the 164 women and 60 service providers who participated in the survey are presented in Tables 1.1 and 1.2 , respectively. The women who participated in IDIs and FGDs did not participate in the survey.

Each of the 60 service providers in this study represented a unique health facility: 42 public (Population Welfare or Health department) facilities and 18 private entities, including large and small hospitals, as well as LHV clinics. Each health facility provides $\mathrm{RH}$ services, including maternal health services, and at least one FP method, in addition to general health services.

At the time of the first round of interviews, only 39 of the 60 facilities were operating, and 18 of the 21 closed facilities were Family Welfare Centres (FWCs) of the Population Welfare Department (PWD), whose exclusive mandate is FP services. These FWCs were closed by the PWD because the public health sector's exclusive focus on COVID-19; in the early stages of the pandemic FP services were not considered essential. The remaining three non-operational health facilities are private, and were closed due to lack of protective measures and infection risks. However, at the time of the second round of data collection, all 60 facilities were open and functional.

Due to the imperative of maintaining social distance, respondents were all contacted, and their data collected, entirely through telephone calls. This is not usual practice in Pakistan, and this experience, summarized in Table 1.3 , tested and confirmed its viability in the country. The study's remote data collection permitted contact and interviews with all 60 service providers, including those employed at facilities that were closed, who were each asked standard, relevant, and applicable questions. 


\section{KNOWLEDGE, CHALLENGES, AND \\ NEEDS OF POOR WOMEN DURING THE COVID-19 PANDEMIC}

\section{FINDINGS}

- BISP beneficiaries have good knowledge about how COVID-19 is transmitted and prevention measures, but they know less about specific symptoms.

- There is a common misperception that a mother who has COVID-19 should not breastfeed.

- More than half of husbands became unemployed or shifted to wage labor, leading to great financial difficulties according to their wives.

- Basic food insecurity has become the overriding challenge for the women's households.

- More women are relying on traditional FP methods due to reduced access to health services and financial constraints.

- Pregnant women are facing problems obtaining antenatal care (ANC) due to facilities being closed or providers' fear of COVID-19, and social distancing during the visit.

- A third of the women reported violence in lockdown situation, and the majority of women who reported domestic violence experienced psychological violence and some experienced physical violence perpetrated by their husbands.

- Most BISP beneficiaries in this study have mild to severe psycho-social stress, and women in FGDs linked their stress with unemployment, inability to feed their children, and inability to leave home.

To understand the effects of the COVID-19 pandemic on the lives of Punjab's poorest women, both qualitative and quantitative techniques apprised BISP beneficiaries' knowledge of the disease and prevention, the challenges of their daily lives due to the pandemic, and necessities for contending with their current predicaments. The qualitative component involved IDIs and FGDs, while the quantitative component comprised a survey employing a structured questionnaire. All of these findings were then triangulated.

FIGURE 2.1: KEY AREAS ASSESSED IN THE STUDY

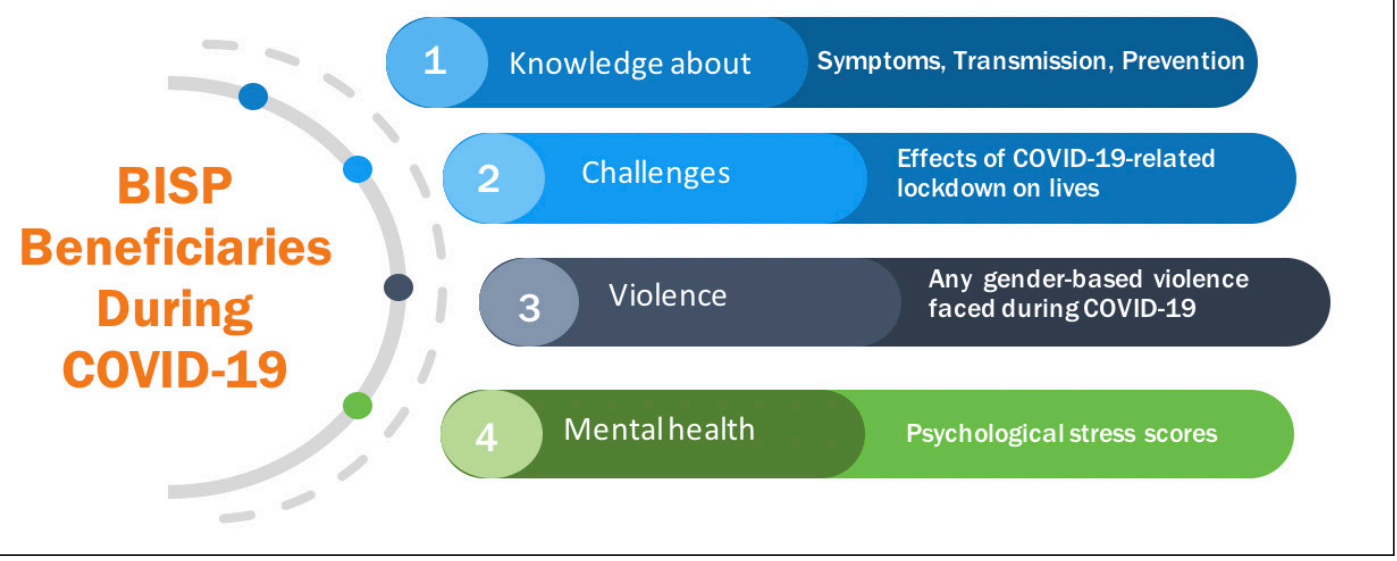




\section{KNOWLEDGE AND PERCEPTION OF COVID-19}

All BISP beneficiaries who participated in the study had at least some knowledge about COVID-19. They all knew about the disease, but referred to it by different names. The majorities of the IDI, FGD, and structured interview respondents were well aware of the illness, its symptoms, how it spreads, and preventative measures.

\section{Sources of Information}

When asked where they had learned about COVID-19, respondents reported primary sources of information as

\section{Terms used by respondents to refer to} COVID-19: Corona, Virus, Virus Disease, Waba (Pandemic).

\section{FIGURE 2.2: DISTRIBUTION OF RESPONDENTS' SOURCES OF INFORMATION ON COVID-19 ( $N=164)$ *}

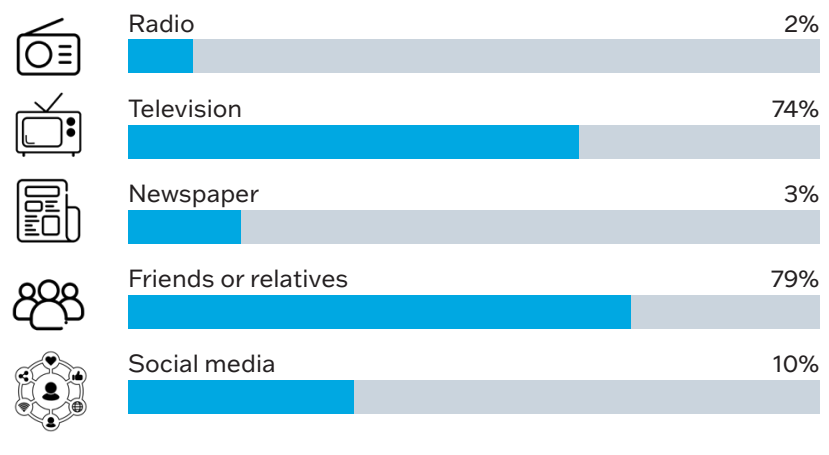

^Multiple responses allowed.

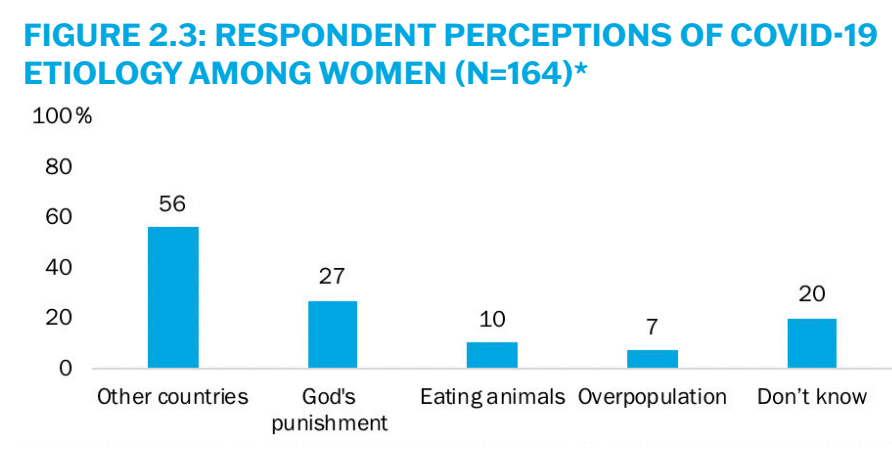

*Multiple responses allowed. friends and relatives, followed by television (TV), with other means of information playing limited roles (Figure 2.2). In qualitative discussions, respondents acknowledged TV as a particularly important source of information.

“We don't trust people; some say one thing while others say something different. We gathered all our information from television."-IDI respondent

Other sources mentioned in qualitative discussions, but less frequently, were doctors, husbands, the Internet, mobile messages, and prayer leaders.

\section{Origins of the Disease}

Quantitative and qualitative findings provide a consistent picture of BISP beneficiary perceptions of why COVID-19 spread around the world. Over half of respondents stated that the virus was transferred from other countries, specifically China, with "punishment from God" the second most frequently mentioned reason, yet one fifth of respondents were unaware of any reason for its spread.

In qualitative discussions, a majority of respondents (34 of 39) referenced China, and a few named the city of Wuhan, as the origin of the virus. Half of these respondents $(n=19)$ stated that it is a punishment and warning from God due to bad deeds now prevalent in the world. Some respondents $(n=16)$ believe people who entered the country from abroad were the main source.

"I have heard that this disease has come from foreign countries [i.e. China], where people were eating bats and snakes in soups as well as frogs." -FGD respondent

“This is Allah's warning-because we do not pray five times a day, so our sins have increased." -IDI respondent

“Those who came from foreign countries met everyone and that resulted in people contracting this disease."-IDI respondent

"This disease is also spreading because people do not clean their hands as much as they should. They do not keep their houses clean." IDI respondent 


\section{Symptoms}

BISP beneficiaries were aware of some COVID-19 symptoms, mainly cough, fever, and influenza-like symptoms. As Figure 2.4 shows, only a limited proportion of respondents knew that the disease can involve sore throat and shortness of breath. Hardly any respondents knew about fatigue, a common symptom of COVID-19.

\section{Transmission}

Figure 2.5 shows that only one third of survey respondents were aware that COVID-19 can spread through coughing and sneezing, and only one quarter were aware the virus could be contracted from airborne droplets, while three fourths were aware of the dangers of close contact with infected persons.

During qualitative discussions, women talked at length about possible ways the virus can be transmitted. All 18 FGD participants and 15 of 20 women in IDIs knew the virus spreads through:

- Shaking hands;

- Close contact or failing to maintain a proper distance with others; and

- Droplets produced by coughing or sneezing.

"This is a germ that transmits from person to person through handshaking, hugging, and sitting closely, so it is necessary to maintain a gap of one to two meters."-IDI respondent

A small number of respondents noted that the disease also spreads through crowded places such as markets, and that one infected individual could affect many other people by shaking hands, sneezing in a crowd, or eating and sharing utensils with others. A few individuals also mentioned that the virus can be transmitted via surfaces like doors and monetary currency, and when people from different areas gather at one place.

“This disease spreads through sitting in a crowd, using each other's clothes, eating together, drinking in someone else's cup, and breathing near others."-IDI respondent

"We have heard that it also spreads through currency notes as money is exchanged, so it results in [the virus] being passed from one person to another."-FGD respondent
FIGURE 244: DISTRIBUTION OF COVID-19 SYMPTOMS MENTIONED BY RESPONDENTS $(\mathrm{N}=164)$ *

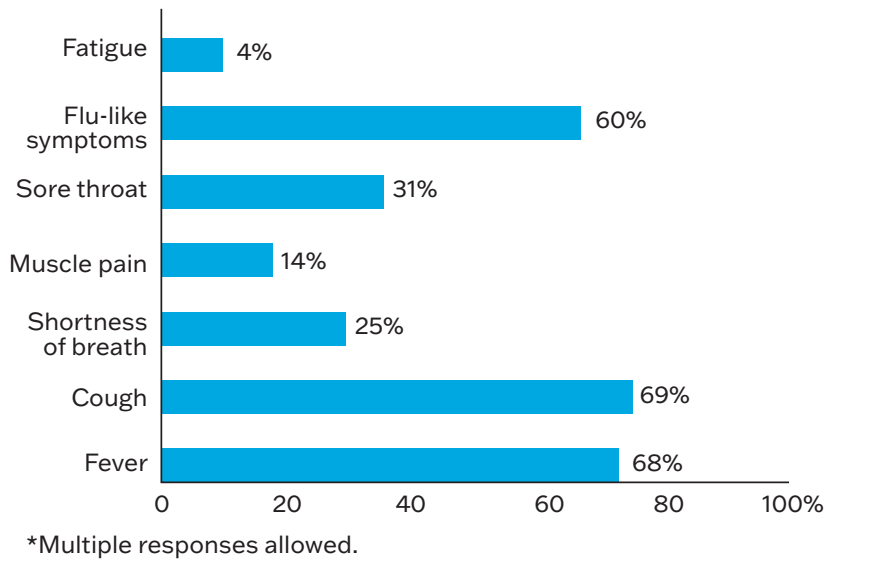

FIGURE 2.5: KNOWLEDGE OF COVID-19 TRANSMISSION AMONG RESPONDENTS ( $\mathbf{N = 1 6 4 ) \star ~}$

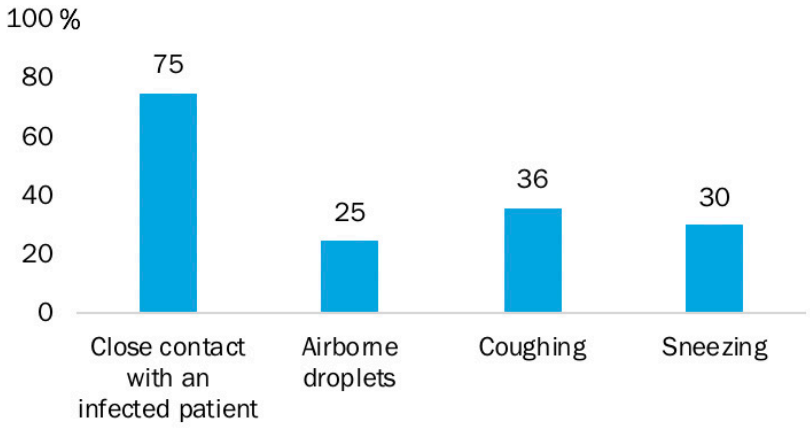

*Multiple responses allowed.

"People visit markets and hold currency notes, and this becomes a main source of this illness."IDI respondent

\section{High Risk Groups}

In both IDIs and FGDs, as well as the structured survey, respondents identified two groups at higher risk of COVID-19: young children and older adults. Over 80 percent of survey respondents considered children and older adults at higher risk, revealing a common misperception of young children's risk.

"Older people catch this (infection) due to deficiency of blood, and children....are developing new blood, which makes them catch this disease quickly."-IDI respondent 
FIGURE 2.6: KNOWLEDGE OF SPECIFIC PROTECTIVE MEASURES AGAINST COVID-19 (N=164)*

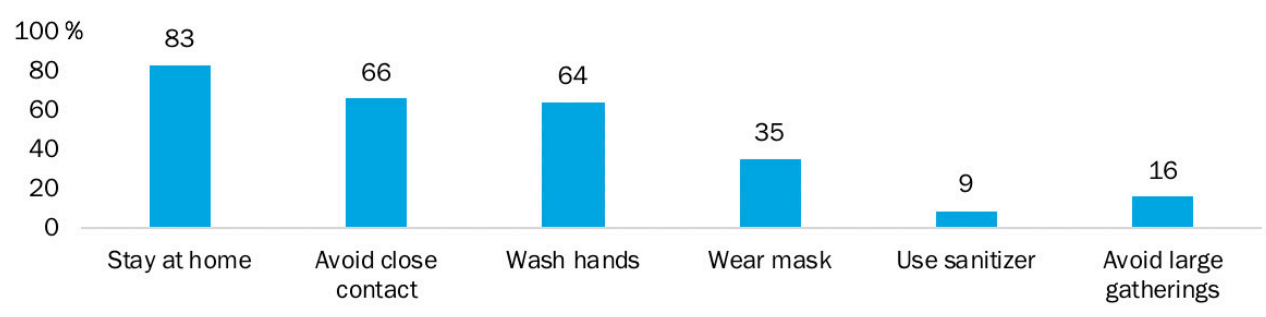

*Multiple responses allowed.

Few women used the word "sanitizer," while the majority is familiar with "mask" and "gloves."

Women are aware of the concept of social distancing and perceive it important for avoiding infection.

Many women are observing social distancing by not visiting neighbors, relatives, and even parents.

Where costs hinder them, the women also know about affordable alternatives to common brands of soaps and disinfectant.

"As the years pass, adults become weak-this leads to them catching this disease."-IDI respondent

A few respondents mentioned that individuals with pre-existing medical conditions such as diabetes or hypertension are more susceptible to COVID-19. One respondent also believed women to be at higher risk during delivery.

In qualitative discussions, women explained that children younger than age five and those older than 50 are at higher risk because they have less immunity and cannot fight diseases. Some also mentioned that young children have higher chances of contracting the virus because they do not wash their hands and frequently put things in their mouths. There were no clear distinctions between contracting the virus and the illness that results from the virus.

"People who have weak immune systems catch this virus very swiftly. Patients with hepatitis and diabetes have weak immune systems and so this [virus] affects their lungs."-IDI respondent

\section{Protective Measures}

The majority of survey respondents considered staying at home a protective measure. They were also aware of the need to avoid close contact with others and to wash hands frequently, although it was not confirmed whether they were using soap when washing hands.

Respondents in qualitative discussions were vocal about protective measures against COVID-19 and could list several. Measures most frequently mentioned included social distancing and minimizing contact with others, avoiding crowded areas, using masks and gloves, washing hands with soap, and using Dettol ${ }^{\circledR}$ to disinfect clothes.

\section{“Wear gloves, use a mask, wash hands as much as possible, and keep a distance."-IDI respondent \\ "If you have a light cough then drink warm water, use Dettol ${ }^{\circledR}$ soap, wash the children's hands with Dettol ${ }^{\circledR}$ water, and stay clean."-IDI respondent}

Some BISP beneficiaries were more aware and knowledgeable than others, and those women either had some education or were raised in cities and moved to villages after marriage. 
"Use a sanitizer, a disinfectant in your homes. The objects that you use frequently-like the $T V$ remote-keep them free of germs. While coughing, cover your face with your elbow. Wear a mask. If you have a common cold, then sit further away from people. When you come home from outside, iron the clothes you were wearing or place them in the sun."-IDI respondent

"We heard on TV that keeping at a distance of one to three feet is necessary to protect against this virus."-IDI respondent

Most women not only knew protective measures but were also observing them. In some cases, they were too poor to afford the popular brands of soap for handwashing, sanitizers, and disinfectant sprays, but were careful and committed enough to have identified alternatives.

"Sit far apart from each other. If you have the money, use Dettol ${ }^{\circledR}$. If you don't, then use lal [red, inexpensive brand] soap. Protect your life as much as you can-you only get it once!"-IDI respondent

“Don't go outside. Don't visit your relatives. If you do go outside, wear a mask so the outside air does not enter you-masks help us against this virus. Use a sanitizer. Those who don't have sanitizer should put two drops of Dettol ${ }^{\circledR}$ in water and spray it on their clothes."-IDI respondent

Some respondents mentioned additional protective measures, albeit with less frequency, including avoiding drinking cold water, inhaling steam, drinking black or herbal tea, avoiding people who have recently traveled, and sitting in the sun.

"My husband takes our kids and sits in the sun every day; we have heard that sitting in the sun kills the virus due to the heat."-IDI respondent

Interestingly, while FGD and IDI respondents often spoke about use of masks or sanitizers, and avoiding large gatherings, these were barely mentioned by survey respondents.

\section{Care for Breastfed Babies}

While BISP beneficiaries are well-informed about major protection measures against COVID-19, they do not have accurate knowledge about what breastfeeding mothers should do if they contract the virus. All women who participated in FGDs and IDIs shared the erroneous impression that an infected mother should not continue to breastfeed because the virus could be transferred through her milk. Women suggested that if a breastfeeding mother contracts COVID-19, she should isolate herself from her child.

"An infected mother should stay away from her child so that it doesn't get affected by the virus. The virus might pass from mother to baby. The mother must be placed in isolation and someone should look after her."-IDI respondent

Mothers who were breastfeeding were conscious of the risks, were worried, and took extra safety precautions to avoid even common fever or cold that might be transferred to their children. A few mentioned that they had restricted their own mobility and were keeping themselves especially clean, so nothing harmful could be transferred to their children.

"A mother should wash her hands before holding her baby. She should wear clean clothes because if she keeps herself clean, then she can take good care of her child. If a mother is ill, her germs will pass to her baby through breastmilk."-IDI respondent

\section{IMPACTS OF COVID-19 ON THE LIVES OF POOR WOMEN}

The lockdown imposed in Pakistan in response to COVID-19 has had adverse effects on the lives of BISP beneficiaries, who are already poor and marginalized. Findings of IDIs and the structured survey reveal complex, inter-related challenges. The core issue is increased economic challenges due to the lockdown that has threatened food security for BISP beneficiary households and made it difficult to afford other essentials such as health services. In these straitened circumstances, domestic violence has increased, and together these issues are a source of often severe psychological stress. 
FIGURE 2.7: KEY ADVERSE EFFECTS OF COVID-19 IN THE LIVES OF WOMEN
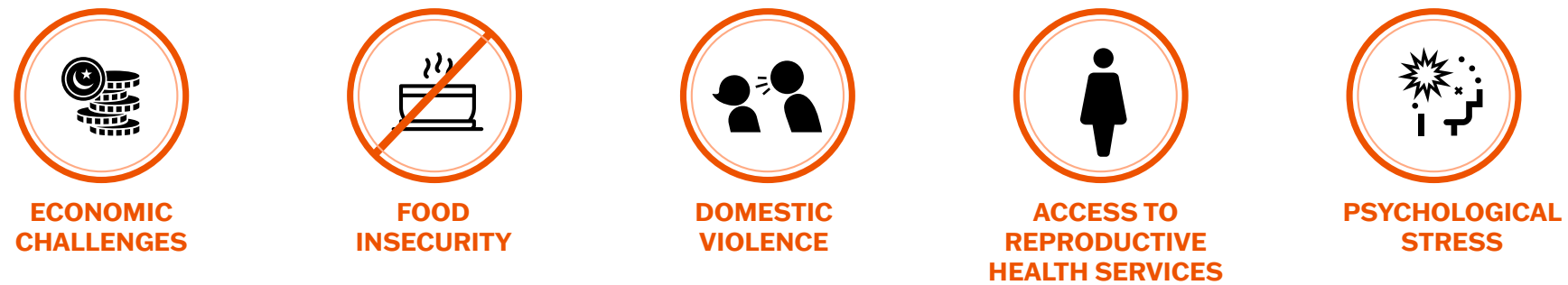

FIGURE 2.8: OCCUPATIONS PRECEDING THE COVID-19 OUTBREAK AMONG RESPONDENTS' HUSBANDS (N=164)

$100 \%$

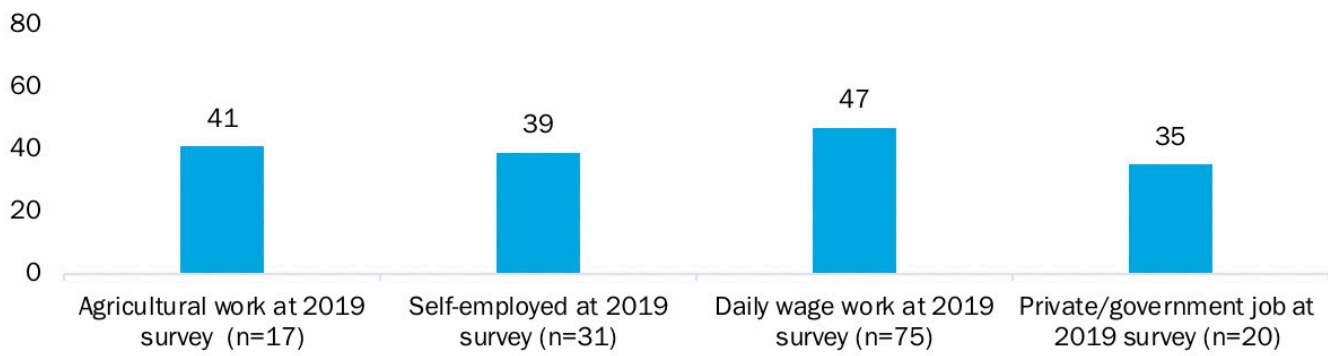

\section{Economic Challenges}

COVID-19 has drastically changed lives, especially for BISP beneficiaries whose circumstances are compounded by poverty. Comparison of data from the 2019 survey and the current study shows that unemployment among the 164 women's husbands increased from 13 percent to 58 percent following the lockdown, and some men had to change occupations entirely.

Figure 2.8 charts survey respondents' husbands' occupations before the pandemic. These men were principally engaged in daily wage work $(n=75)$, agricultural labor $(n=17)$, or were self-employed $(n=31)$. In most cases, they were unemployed due to the lockdown.

In discussions, respondents referred to their husbands' returns from cities due to lack of work. Women's own jobs and small scale, home-based work, such as sewing, have also been affected. Overall, the lockdown has pushed women into extreme poverty whereby even their families' basic needs are hard to meet.

"Due to this virus, factories have closed, labor has stopped. Those who used to work in Lahore or Rahim Yar Khan have come back to their homes. My husband who used to work in city is now also stuck at home."-FGD respondent
FIGURE 2.9: DISTRIBUTION OF CASH OR FOOD RATIONS, BY SOURCE, AMONG RESPONDENTS $(\mathrm{N}=164)^{\star}$

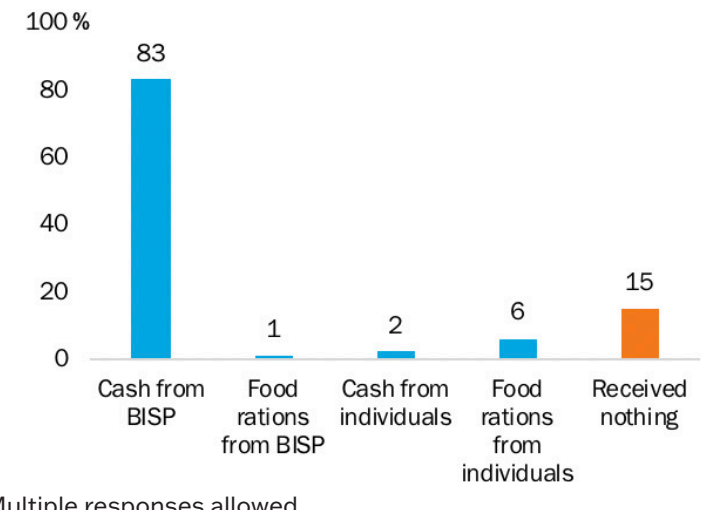

*Multiple responses allowed.

"I used to stitch clothes on payment. That money enabled me to buy household items and clothes for my children. Now my work has ended. It feels like, earlier, the world was moving, and now it has stopped."-IDI respondent

A prevalent, consistent finding is that BISP support is crucial for survival but is not sufficient. To alleviate the economic hardships for poor households associated with the lockdown, the government of Pakistan launched 
the Ehsaas Emergency Cash Programme. Beneficiaries of BISP, who are provided allowances of Rs. 2,000 per month, disbursed quarterly, are included in the Ehsaas program, through which they have been provided financial assistance of Rs. 12,000 (\$72) to ensure they do not go hungry. (This amount includes four months' routine BISP assistance, i.e. Rs. 8,000, and Rs. 4,000 in additional aid.) ${ }^{5}$

Figure 2.9 shows that the majority of survey respondents received this extra financial support. Qualitative findings indicate that recipients were able to buy necessary household items such as food and clothes, and even repay prior loans, and they felt relieved and fortunate to receive this support.

\section{"The 12,000 rupees that Imran [Khan, Prime Minister] gave us have been keeping us alive!"- IDI respondent}

There is, however, confusion and uncertainty among respondents about the nature of this extra support, whether it represents a combined advance for three payment periods, is a discrete payment of additional support, or will be provided every month during the lockdown. There is also ambiguity about food rations, which the government is trying to facilitate through the Ehsaas Ration Portal. ${ }^{6}$ Barely five percent of respondents were able to receive food rations, while two percent received both cash and food from the government (data not shown).

\section{“The situation in this country is bad. We don't know what will happen next. Of the 12,000 rupees that the government gave us, we are using as little as we can manage so we have something saved for later." -IDI respondent}

Women who received neither cash nor food support (15\%) feel helpless and complained about being overlooked.

\section{"Widows are getting rations, but where should the 'safed posh' [those who do not generally take charity] go? All those who do not have any business are poor-now do we have to kill our husbands to fill our stomachs?" IDI respondent}

\section{FIGURE 2.10: DISTRIBUTION OF EFFECTS OF LOCKDOWN ON RESPONDENTS' LIVES ( $\mathrm{N}=164)$ *}

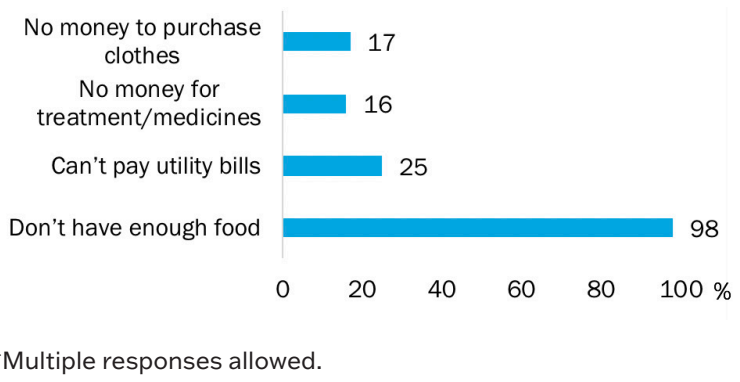

\section{MY CHILDREN GO TO BED CRYING, WITH EMPTY STOMACHS}

"We are a family of eight living under one roof. My father-in-law is paralyzed, and my husband can only see from one eye. He works at a wheat shop where he earns 400 rupees a day. I have young children and the money my husband makes is not enough to feed us all. Sometimes we don't have anything to eat for two or more days. People give us food out of pity. And sometimes my children go to bed crying, with empty stomachs."

"We are very poor. The other day, I bought two kilograms of wheat on loan. It was infested with bugs, but we will still have to eat it. I even had to take a loan of 10 rupees from someone to break our fast. We cry and we don't know who to turn to. Once my husband had to go to the shop but he had no shoes, so he had to borrow them from our neighbor."

"We do not have wheat or flour at home. I sit here and cry, not knowing what I will feed my children today."

"This whole situation means a lot of worry for both me and my husband. My husband especially gets very stressed-so much that I worry we might lose him. This virus is a torment upon us from Allah. It has deeply upset our family."

-BISP beneficiary

5 Further information about this initiative available at www.pass.gov.pk/Detailf90ce1f7-083a-4d85-b3e8-60f75ba0d788

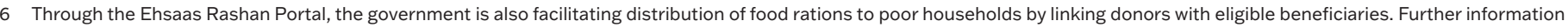
available at www.pass.gov.pk/Detail71f369ce-7579-447a-a6af-bee4c1305537 


\section{Food insecurity}

Among the effects of the lockdown reported by women, Figure 2.10 shows that food insecurity was by far the most frequently mentioned, and virtually universal. Nearly all women are distressed by the decline in food availability for their families.

In qualitative discussions, almost all respondents stated that the biggest problem they are facing during the pandemic is hunger. Families do not have enough money to buy food and prevent their children from going to bed hungry. Women were worried about the effect of inadequate food on their children's health, and about the lack of resources for other necessary expenses.

\section{“Corona might not kill us, but hunger will. We cook whatever we can find. Sometimes, we just end up eating roti with chili and chutney."-FGD respondent}

Almost every woman spoke of distress in having nothing for their children to eat, and watching them cry from hunger. Women asserted that their household incomes had declined since the pandemic, forcing drastic changes. They are coping with food shortages by reducing the number of daily meals from two to one, serving roti (bread) with just water or chilies, rather than usual curries of lentils or vegetables, buying sub-standard food, borrowing money, or receiving meal donations from neighbors or relatives.

"We sometimes make lentils and sometimes potatoes. At times we prepare food for the morning and start worrying about what to make in the evening. When it grows dark, the children ask us for dinner. Where do we bring it from? We just pray to Allah and go to sleep."-IDI respondent
"Before the lockdown, we would sometimes buy fruit or milk. Now, we are living on water. Sometimes we cook vegetables, and other times, we just eat roti."-FGD respondent

An important concern raised by some respondents is that their young children are becoming weak from limited food availability, but they are unable to afford any healthy food for them.

"Due to lack of food, the children are becoming weak. When we took them to the doctor, he said they are not eating enough food which is causing iron deficiency."-IDI respondent

In one FGD, some women mentioned having to feed one year old children the same food as the rest of the family because they could not afford appropriate food for them.

\section{Domestic Violence}

During the survey, women were asked about their personal experience of domestic violence, both under normal circumstances and during lockdown. As shown in Figure 2.11, 24 percent of women reported experiencing domestic violence under normal circumstances, while 38 percent reported violence during the lockdown period, but the difference is not statistically significant. In most cases, domestic violence was in the form of humiliation and insults with emotional effects. There were limited instances of physical violence; in almost all cases, perpetrators were the women's husbands.

FIGURE 2.11: PERCENTAGE OF WOMEN WHO REPORTED EXPERIENCING DOMESTIC VIOLENCE UNDER USUAL CIRCUMSTANCES AND LOCKDOWN ( $\mathrm{N}=164)$, AND DISTRIBUTION OF TYPES OF VIOLENCE EXPERIENCED DURING LOCKDOWN REPORTED BY WOMEN (N=62)*
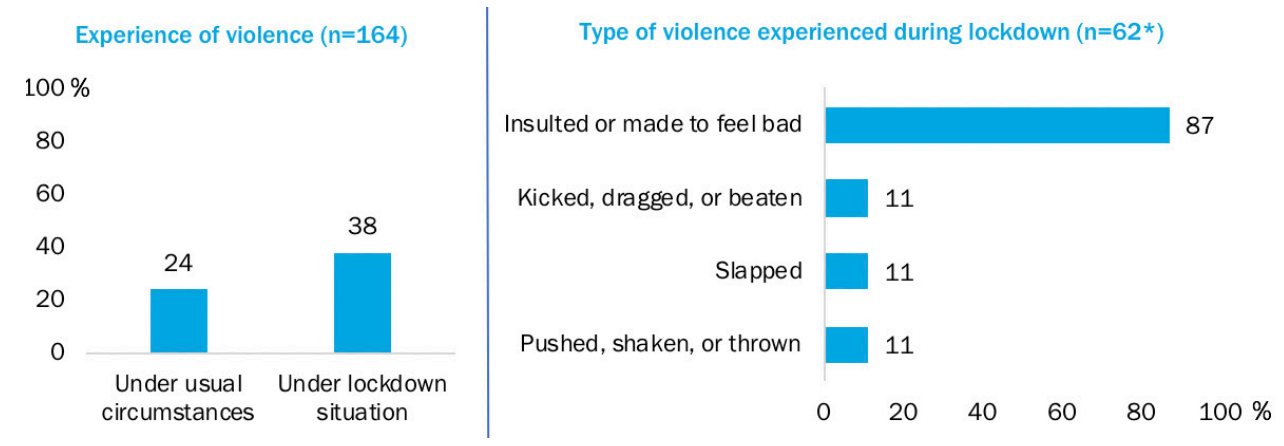

*Multiple responses allowed. 
During IDIs and FGDs, women repeatedly emphasized that becoming unemployed or having limited work created numerous financial problems for their families. In this adverse economic situation, parents are unable to afford basic meals, and feel especially stressed due to their children's wellbeing. Both women and their husbands feel depressed, and the stressful situation has led to clashes and quarrels at home.

Most discussion of domestic violence took place during FGDs; few women mentioned any personal experience of violence during IDIs.

According to these women, their husbands feel stressed due to their inability to earn, while women themselves are distraught at seeing their children go hungry. Children frequently demand food, increasing their parents' feelings of stress and helplessness. Living in constant anxiety makes couples tense and leads to fighting.

"When there is nothing left in the house to eat, the children start getting on their mothers' nerves! How do we explain this to them? When we ask our husband, a quarrel ensues. If this lockdown persists any longer, violence will start in the home."-FGD respondent

"All these worries are due to the lockdown. If there was no lockdown, businesses would be open and there would be fewer worries."-FGD respondent

Another reason for domestic violence that emerged in qualitative discussions is that men spend time idle at home due to the lockdown. This unusual and forced restriction on their mobility aggravates their frustration: Not being able to leave the home means no earned wages and no money to meet food needs. In this complicated situation, men vent their frustration and anger on their wives, mainly in abusive language, humiliating remarks, or by telling them to leave the home-but sometimes through physical violence. Women are concerned that continued lockdown will mean increased financial problems and increased violence.

"When I ask my husband for money, he says you should go to your parent's house for Eid celebrations. When the lockdown ends, you can come back. We have neither money nor clothesthat is why we end up fighting."-FGD respondent
FIGURE 2.12: PERCENTAGES OF FP USE-CURRENT, PAST, NEVER-IN 2019 SURVEY AND 2020 SURVEY AFTER COVID-19 OUTBREAK REPORTED BY WOMEN $(\mathrm{N}=164)$

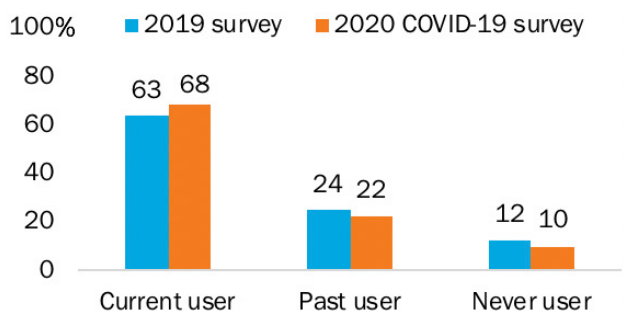

FIGURE 2.13: DISTRIBUTION OF CONTRACEPTIVE METHOD IN 2019 SURVEY AND 2020 COVID-19 SURVEY ( $\mathrm{N}=164)$

$100 \%$

80

60

40

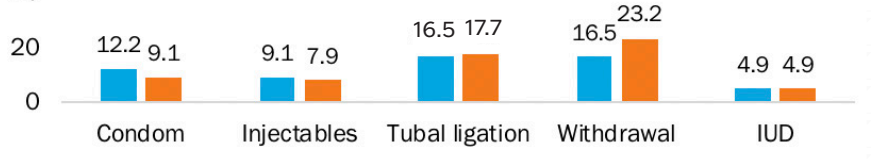

"Due to this lockdown, many problems have arisen in our home. Just asking for rations or ghee [clarified butter] can result in a fight. Whenever I ask my husband for money, he responds with harsh words. If the lockdown goes on like this and there is no employment, [physical] violence will begin." FGD respondent

\section{Accessing General and Reproductive Health Services}

Respondents were asked about their access and use of both RH services as well as immunization services for their children. Where possible, findings were compared with available 2019 survey data, to assess changes in women's practices from before the COVID-19 pandemic and lockdown.

\section{Family Planning Services}

Figure 2.12 shows a slight potential shift in current use, but the differences are not statistically significant. The majority of women at both time points were currently using a FP method. 
TABLE 2.1: DISTRIBUTION OF NEW FP USERS SINCE COVID-19 OUTBREAK, BY STATUS AT 2019 SURVEY AND METHOD CHOICE $(\mathrm{N}=20)$

\begin{tabular}{|l|l|c|c|}
\hline $\begin{array}{l}\text { Status during } \\
\text { 2019 survey }\end{array}$ & $\begin{array}{l}\text { Method choice at the } \\
\text { 2020 COVID-19 survey }\end{array}$ & $\%$ & N \\
\hline \multirow{4}{*}{ Past user } & Tubal ligation & 13.3 & 2 \\
\cline { 2 - 4 } & $\begin{array}{l}\text { Short-term modern } \\
\text { methods }\end{array}$ & 33.3 & 5 \\
\cline { 2 - 4 } & Traditional methods & 53.4 & 8 \\
\cline { 2 - 4 } & Total & 100 & 15 \\
\hline \multirow{2}{*}{ Never user } & Traditional methods & 100 & 5 \\
\cline { 2 - 4 } & Total & 100 & 5 \\
\hline
\end{tabular}

At the same time, comparison of method-specific current use among respondents during the 2019 and current survey suggests a slight switch in pattern for most commonly used methods, from modern to less reliable traditional methods (Figure 2.13). Qualitative findings suggest this is due partly to financial constraints and partly to suspension of home services by Lady Health Workers (LHWs).

Fifteen of the 20 women who started using contraception since COVID emerged were past users, while five were new users. Most new users (65\%) adopted traditional methods, which may not have required a visit to the health facility or from a health worker (Table 2.1).

During qualitative discussions, respondents were asked whether contraceptive availability has been affected by the lockdown. Most respondents stated that women who use condoms and injectables are facing problems because LHWs are not visiting homes for services. These women are anxious to continue contraceptive use to avoid pregnancy - which is particularly difficult during the economic crisis. In the absence of $\mathrm{CHWs}$, FP clients are forced to buy contraceptives from pharmacies, switch to traditional methods, or practice abstinence.

“My daughter's age is five months. The Lady Health Worker used to provide us condoms before the lockdown. Now, because of the virus, she doesn't visit our homes. In this situation, my husband and I are very worried, and we are now practicing withdrawal."-IDI respondent

"Yes, condoms are not available because of the present situation. Even LHWs don't have them. It is a real inconvenience and my husband has to buy them from the medical store, because that is open."-IDI respondent
"We can only abstain-what else can we do? It is hard enough to feed our family."-IDI respondent

"We are avoiding each other during this lockdown...We don't go near each other because there is no source of condoms since the LHW is not visiting us and we are short of money too."-IDI respondent

\section{Maternal Health Services}

The effects of the lockdown on maternal health services were explored in both the qualitative discussions and structured, quantitative survey. Only five of the women who participated in the survey were currently pregnant, and all five reported problems in obtaining ANC services due to lack of transportation, lockdown restrictions on general mobility, and financial issues (data not shown). This topic was discussed in FGDs, where women described challenges in obtaining ANC and delivery services due to the lockdown and COVID-19.

Respondents stated that service providers are not examining women properly because they want to maintain physical distance from clients. Women also reported that service providers try to avoid delivery cases and send women home or to other facilities. The general view is that delivery cases are not being accepted or admitted upon first visit, due to service providers' fear of contracting the virus, and that delays are creating problems for women. There was also a perception among women that, at the current time, most stillbirths are associated with delayed services.

\section{"My sister-in-law was pregnant. We took her for delivery to the civil hospital. The doctors did not pay any attention to her and did not check her properly. So we took her to a private hospital. By the time we got there, her child had died. We lost both money and the baby."-FGD respondent}

\section{Immunization services}

Of the 164 women interviewed, 69 had children of immunization age, and nearly half $(n=30)$ reported a disruption in their children's immunization schedule. The most frequently reported reason-by all 30 womenwas that immunization teams were not visiting them. Thirteen of these women visited health facilities but service providers were not available, or the facilities were closed (data not shown). 


\section{Mental Health}

These challenges naturally are associated with mental stress. Due to the array of challenges reported by BISP beneficiaries, and pervasive reports of their stress, we attempted to measure respondents' psychological stress levels using a universally tested assessment tool, PHQ-9, ${ }^{8}$ which utilizes nine statements for evaluation. This tool was administered to all 164 BISP beneficiaries.

As Figure 2.14 shows, at least one third of women responded affirmatively to every symptom, with much higher proportions for particular indicators, especially feeling "down," depressed, or hopeless, fatigue or little energy, and sleep disturbance. About 40 percent of women admitted that they had thought they would be better off dead or had thought about hurting themselves, indicative of a severe level of stress.
Individual psychological stress scores were also assessed based on responses to the PHQ-9 tool. The results, depicted in Figure 2.15, show that only 17 percent of survey respondents had minimal or no stress, while 34 percent expressed moderate stress, and 17 percent revealed moderately severe stress.

The Approved PHQ-9 Treatment and Follow Up Guideline ${ }^{9}$ proposes treatment actions for individuals experiencing different levels of psychological stress. Table 2.2 summarizes these actions and indicates the number and proportion of survey respondents for whom these treatments are indicated, based on their psychological stress scores. Over half of women were found to need counseling or pharmacotherapy, implying a need for focused efforts to support the mental health and wellbeing of poor women during the COVID-19 pandemic.

\section{FIGURE 2.14: PERCENTAGE OF RESPONDENTS AFFIRMING STRESS}

SYMPTOMS IN ASSESSMENT STATEMENTS ( $\mathbf{N = 1 6 4 )}$

Little interest or pleasure in doing things

Feeling down, depressed, or hopeless

Trouble falling or staying asleep, or sleeping too much Feeling tired or having little energy Feeling bad about self, or like a failure, or having let self or family down Poor appetite or overeating

Trouble concentrating on normal routine

Moving or speaking noticeably slowly, or being unusually fidgety or restless Thoughts of being better off dead, or hurting self

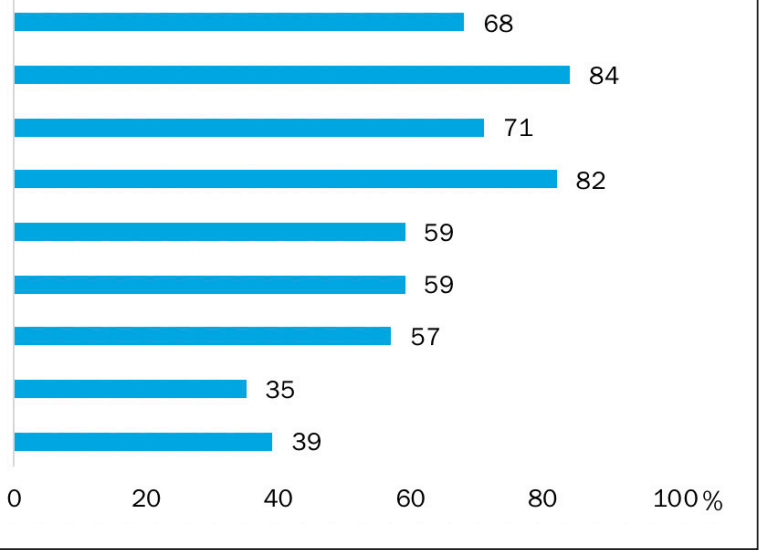

TABLE 2.2: PSYCHOLOGICAL STRESS SCORES BASED ON PSYCHOLOGICAL STRESS ASSESSMENT TOOL AND PROPOSED TREATMENT ACTIONS ( $=164)$

\begin{tabular}{|l|l|l|l|}
\hline Stress Level & $\begin{array}{l}\text { No. of Cases } \\
\text { (\% of } \\
\text { Respondents) }\end{array}$ & Proposed Treatment Actions \\
\hline 1 & None-Minimal & $28(17 \%)$ & None \\
\hline 2 & Mild & $40(24.4 \%)$ & Watchful waiting, repeat PHQ-9 at follow up \\
\hline 3 & Moderate & $55(33.5 \%)$ & Consider counseling, follow-up and/or pharmacotherapy \\
\hline 4 & Moderately severe & $28(17 \%)$ & Active treatment with pharmacotherapy and/or psychotherapy \\
\hline 5 & Severe & $13(8 \%)$ & Immediate pharmacotherapy/referral to mental health specialist \\
\hline
\end{tabular}

8 The depression module of the Patient Health Questionnaire-9 (PHQ-9) is a widely used depression screening instrument in nonpsychiatric settings. (Manea, L., Gilbody, S. and McMillan, D., 2015. A diagnostic meta-analysis of the Patient Health Questionnaire-9 (PHQ-9) algorithm scoring method as a screen for depression. General hospital psychiatry, 37(1), pp.67-75.)

9 https://dev.carecompassnetwork.org/wp-content/uploads/sites/4/2017/03/CGC-CG-05-Approved-PHQ-9-Treatment-and-Follow-Up-Guideline.pdf 
In IDIs and FGDs, most women expressed feelings of depression and mental stress, clearly indicating this study's findings of pervasive stress due to the pandemic. During discussions respondents emphasized that economic pressure leading to food insecurity was their major source of stress, which is in turn linked with increased friction at home and domestic violence. Women's inability to access $\mathrm{RH}$ and general health services also contributes to their increased anxiety.
“Schools are closed. We don't let our children out of the house out of fear. If they do go out, we have to go after them. This is hindering their studies and has made them upset."-IDI respondent

"The children are stuck at home, schools are closed, and their studies are being affected. They will be promoted to the next grade, but their minds will not have the knowledge that they were supposed to obtain practically."-IDI respondent

\section{FIGURE 2.15: DISTRIBUTION OF PSYCHOLOGICAL STRESS LEVELS AMONG RESPONDENTS ( $\mathrm{N}=164)$}

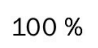

80

60

40

20

0
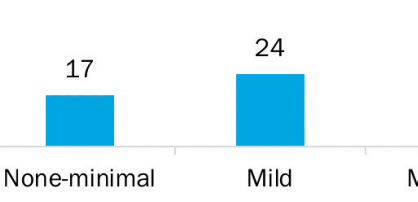

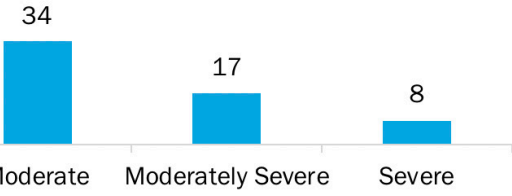

"Schools are closed, and the children's studies have ended. They are stuck at home and don't leave the house, even to learn to recite the Quran."-IDI respondent

During these difficult times, when their need for emotional support has increased, some women mentioned feeling more removed from their loved ones than ever: They cannot visit their
"I don't have enough money to buy the children milk or fruits, and often, I go to bed crying."-IDI respondent

"I get stressed when the children refuse to eat roti with chilies. So to comfort them, I tell them that we will eat proper food when your father goes back to work."-IDI respondent

"In facing this situation I feel like I have lost all tears. May Allah have mercy on us all."-FGD respondent

In addition, women are concerned about the disruption of their children's education. With schools closed during the lockdown, and no remedial arrangements, children are now disengaged from any educational activity and are largely idle, with nothing constructive to do. According to respondents, older boys roam aimlessly outside and do not abide by parents' instructions to stay home. Young boys are upset at being confined at home, while girls have nothing to do either. Parents worry that their children are disturbed and diverted, and will forget what they had learned at school. They wish they could arrange home tutoring but cannot afford to do so. parents due to the lockdown, nor attend the funerals of loved ones, and this degree of isolation particularly depresses them.

"To prevent people from gathering, we have been instructed not to announce funerals, although we have yet to see a case of Corona."-IDI respondent

"The disease will spread when people gather. People do not understand that everything is up to God; they are more scared of people than God. They have closed the mosques due to this disease and now we cannot pray, nor can we offer the Friday prayer. Children cannot recite the Quran either."-IDI respondent
“A person's death no longer has any significance-people can't even offer their funeral, nor can they cry for them."-IDI respondent 


\section{KNOWLEDGE, ATTITUDES, PRACTICES AND CHALLENGES OF HEALTH CARE WORKERS DURING COVID-19 PANDEMIC}

\section{FINDINGS}

- Most service providers retain the misconception that a woman who has COVID-19 cannot continue a modern contraceptive method nor breastfeed.

- A majority - 55 of 60 service providers in May and 41 of 60 in September 2020-have received no training on COVID-19.

- Service providers lack PPE: Among the 39 service providers still working in May, 22 did not have available PPE, but this number reduced to 13 by September. Among the 21 service providers whose facilities were closed in May but were operational in September, seven had no PPE available at their place of work.

- Among the 39 service providers who were working during both rounds of interviews, in May almost all (92\%) were afraid of contracting COVID-19, while only 67 percent reported such fear in September. Fear of transmitting COVID-19 to their families was voiced by roughly the same proportions in both surveys: 31 percent in May and 33 percent in September.

- All RH services, including both FP and maternal health care, were reported to be affected by the pandemic in May, and while maternal health care services have improved, FP services remained affected in September.

- In May, contraceptive availability was low in operational health facilities, while all PWD facilities were closed. Three months later, all facilities were open and functional, but contraceptive availability remained an issue.

- In May, 35 of 39 service providers at functioning health facilities reported experiencing no discriminatory behavior, while in September, 32 of those 39 reported continued lack of discrimination. Of the 21 service providers who resumed work after the first round of interviews, 16 reported no discrimination.

This study also addressed health service providers' knowledge of COVID-19, and their attitudes and service practices during the pandemic. The two rounds of interviews, the first in May 2020 and the second in September 2020, involved a panel of 60 service providers that included medical doctors, Lady Health Visitors (LHVs), male and female health technicians, family welfare counselors (FWCs), assistants, nurses, midwives, and dispensers. Of these service providers, 42 of 60 were employed at public facilities, and 18 at private entities.

During the first round of interviews, only 39 of the 60 service providers' affiliated health care facilities were operational, and 18 of the 21 closed facilities were PWD Family Welfare Centres (FWCs), all of which had been closed by PWD, while three were private facilities closed due to apparent lack of protective measures. During the second round of data collection, all 60 facilities were open and functioning. In both interview rounds, no facilities were providing in-patient COVID-19 services.

Because of the small numbers of providers in each category-public or private, and doctors or other cadresall responses are considered part of one general category of health care providers. Health care respondents are differentiated by one important aspect: Only 39 of the panel of 60 were actively serving patients during both rounds of interviews, in May and September 2020. The health care facilities of the remaining 21 service providers were closed in May, but all had re-opened by the second 
FIGURE 3.1: DISTRIBUTION OF SPECIFIC POSSIBLE SYMPTOMS OF COVID-19 IDENTIFIED

BY SERVICE PROVIDERS IN MAY 2020 AND SEPTEMBER $2020(\mathrm{~N}=60)$ *

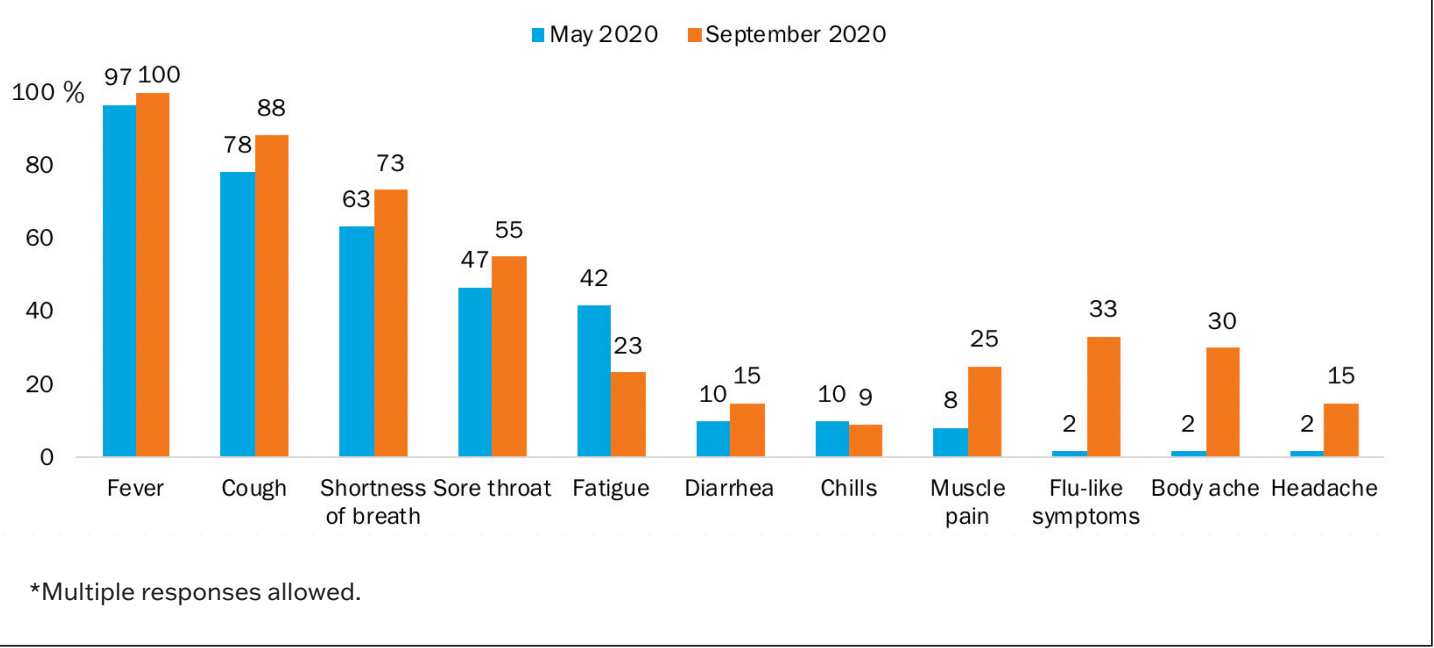

FIGURE 3.2: DISTRIBUTION OF COVID-19 TRANSMISSION MEANS IDENTIFIED BY SERVICE PROVIDERS IN MAY 2020 AND SEPTEMBER 2020 ( $\mathrm{N}=60)^{*}$

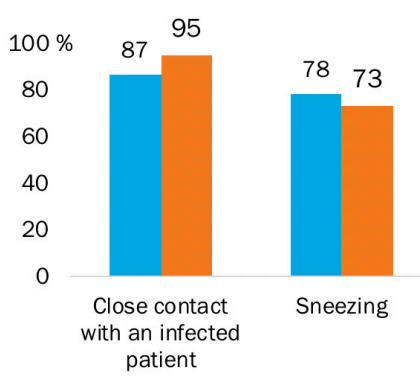

- May 2020 September 2020

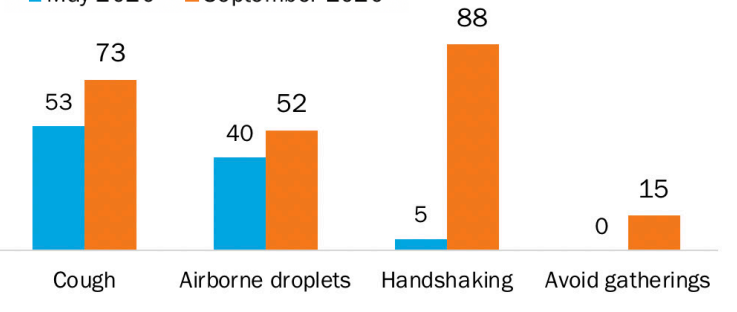

*Multiple responses allowed.

round of interviews in September. Some parts of this analysis, such as assessment of attitudes and practices in May, and identification of changes between May and September, were only possible based on data from the 39 service providers who were active in both May and September. We have therefore considered these two categories of service providers separately in many instances.

\section{KNOWLEDGE OF COVID-19}

All health care providers must have accurate, basic knowledge about COVID-19 to safely treat and advise their patients. Service providers were asked a series of questions that assessed their knowledge of COVID-19 symptoms, how it spreads, associated health complications, and prevention and treatment measures. An exhaustive list of possible answers is contained in the data collection tool, but respondents were not prompted with any potential answers.
During the survey in May, most respondents could identify only a few symptoms of COVID-19, chiefly fever, cough, shortness of breath, and sore throat. Only six of 60 service providers mentioned diarrhea or chills, and even fewer mentioned muscle pain, loss of smell or taste, headache, or body ache. As Figure 3.1 shows, in September more service providers were aware of symptoms like muscle pain, flu-like symptoms, body ache, and headache, which were barely reported in the earlier round.

As Figure 3.2 shows, the majority of service providers identified the common, major sources of the virus's spread, such as sneezing and close contact with an infected person, in both rounds of data collection. Only 40 percent of providers were aware that COVID-19 can be transmitted by airborne droplets in May, and 52 percent were in September. Only five percent of providers identified shaking hands as a possible transmission route in May, but 88 percent cited it during the September round of interviews. 
FIGURE 3.3: DISTRIBUTION OF COVID-19 TRANSMISSION MEANS IDENTIFIED BY

SERVICE PROVIDERS IN MAY 2020 AND SEPTEMBER 2020 ( $\mathrm{N}=60$ )*

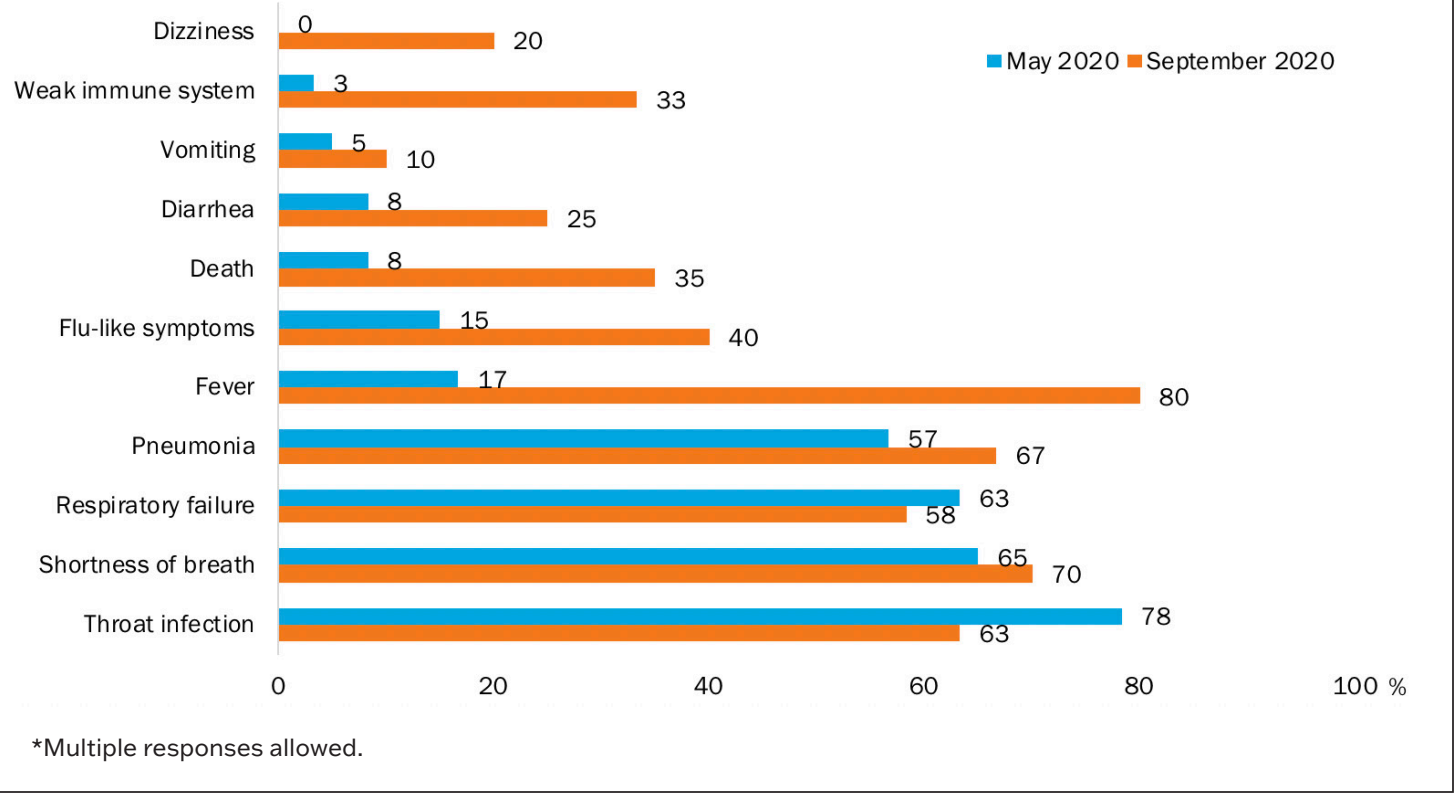

\section{FIGURE 3.4: DISTRIBUTION OF SPECIFIC MEASURES FOR PREVENTING TRANSMISSION OF COVID-19 IDENTIFIED BY SERVICE PROVIDERS IN MAY AND SEPTEMBER $2020(\mathrm{~N}=60)$}

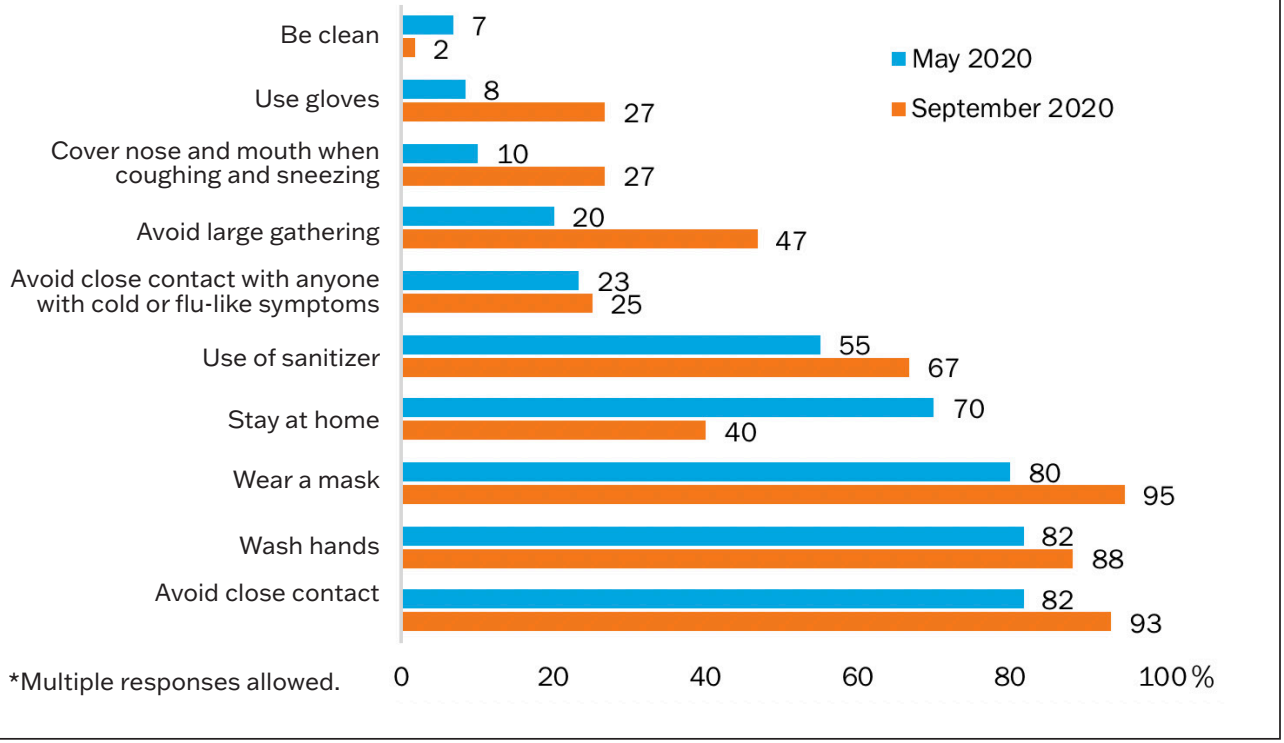

Service providers were also asked what health issues a COVID-19 patient might develop after infection. In May, this question revealed the greatest deficiency in COVID knowledge than any other question. As Figure 3.3 shows, service providers generally mentioned shortness of breath, throat infection, pneumonia, and respiratory failure, but barely mentioned dizziness, diarrhea, and fever in the earlier round. In September, those health issues were mentioned by at least one quarter of respondents.
Prevention measures most commonly mentioned by respondents at both points in time were avoiding close contact, wearing a mask, washing hands, and staying home (Figure 3.4). In May, generally lower proportions of service providers identified other specific measures such as avoiding large gatherings (20\%), avoiding contact with a person with cold or flu-like symptoms (23\%), and covering nose and mouth when coughing or sneezing (10\%), while in September these proportions rose to 47 


\section{FIGURE 3.5: DISTRIBUTION OF COVID-19 CARE AND TREATMENT OPTIONS MENTIONED \\ BY SERVICE PROVIDERS IN MAY 2020 AND SEPTEMBER $2020(\mathrm{~N}=60)$ *}

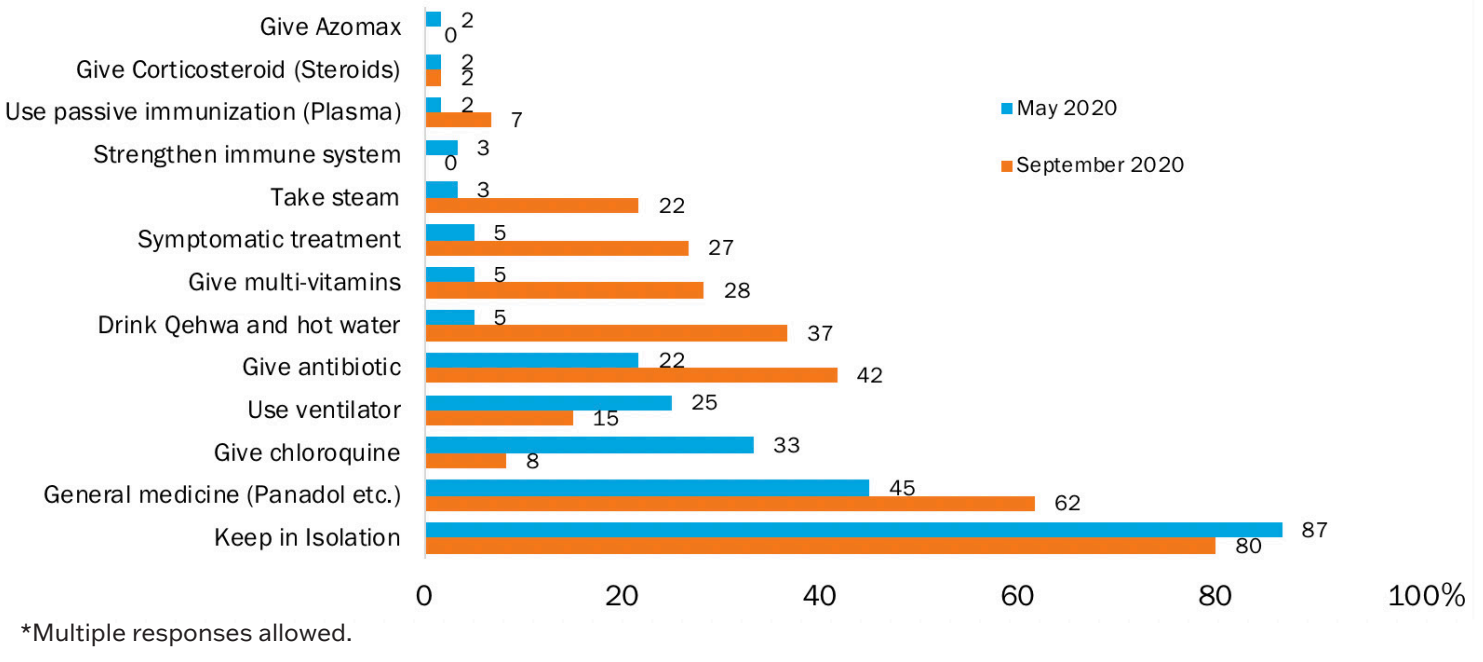

\section{FIGURE 3.6: PROPORTIONS OF SERVICE PROVIDERS CORRECTLY RESPONDING TO TRUE OR FALSE STATEMENTS ABOUT COVID-19, BY CATEGORY IN MAY 2020 AND SEPTEMBER 2020 ( $\mathrm{N}=60)$}

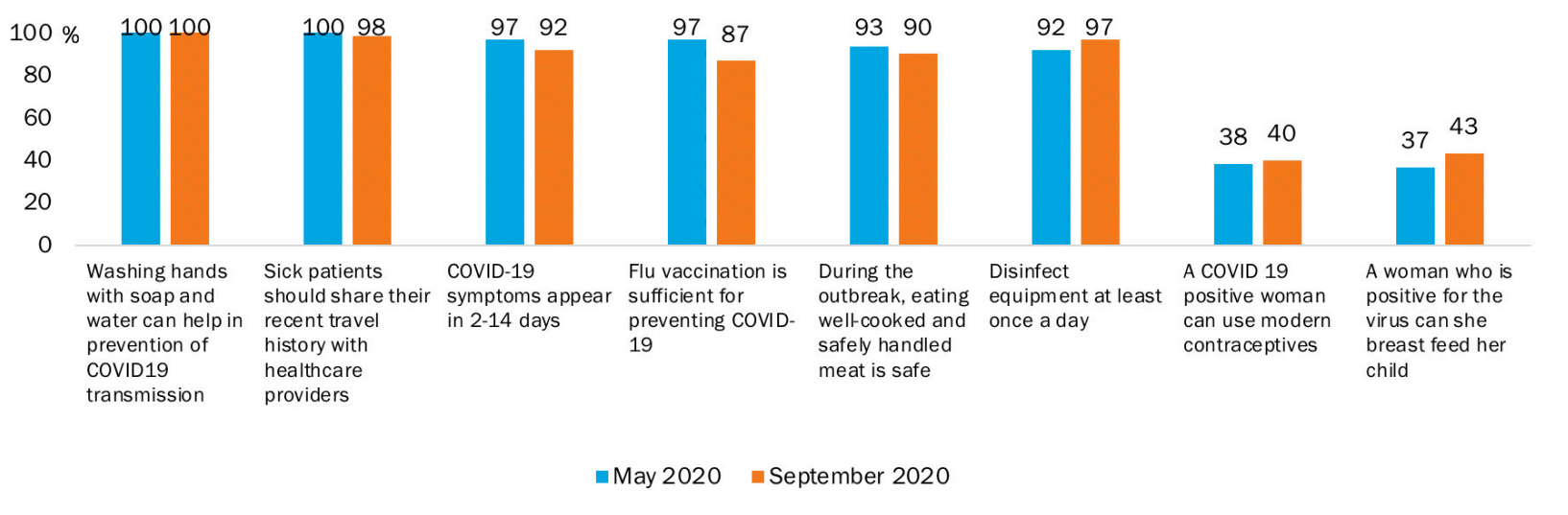

percent, 25 percent, and 27 percent, respectively, while still less frequently cited than other measures. Interestingly, the proportion of service providers mentioning staying at home as a transmission prevention measure was 70 percent in May, when the lockdown was in place, but declined to 40 percent in September, when the lockdown had been lifted and services resumed.

As Figure 3.5 shows, service providers' responses about care and management of COVID-19 were different in May and September. Most respondents reported that a patient should be kept in isolation in both rounds, with smaller proportions mentioning treatment with antibiotics, general medicines, or symptomatic treatment in May. Notably, 33 percent of service providers mentioned giving chloroquine to COVID-19 patients in May, but only eight percent did in September, indicating that knowledge about the disease is time-bound and continually changing as a result of evolving medical research.
In addition to open-ended questions about COVID-19, eight true or false statements about COVID protocols and symptoms were posed to all service providers.

Figure 3.6 shows that in both rounds of interviews, the majority of service providers answered six of the eight statements correctly. Notably, all providers were aware of the importance of handwashing, and that sick patients should share their travel history with service providers. The two statements that resulted in incorrect answers focused on contraceptive use and breastfeeding by a woman with COVID-19, with a drop in correct responses in both rounds: Only slightly more than one third of service providers knew that a COVID-19 positive woman can use modern contraceptives as well as breastfeed in both May and September.

All service providers responded correctly to at least two of the eight statements. The gaps in knowledge identified among service providers are likely due to lack of training on COVID-19. 


\section{PROVIDER ATTITUDES}

We asked the service providers whose facilities were open and functional-39 of the 60 service providers in May, and all 60 in September-about their challenges in providing services during the pandemic, especially whether they experienced any stress while providing services. Responses from service providers whose facilities were operational in both rounds are shown in Figure 3.7. Comparison indicates that fear of infection was by far the most common challenge: Among the 39 service providers who were active during both rounds of interviews, 92 percent in May and over two thirds in September expressed fear of COVID infection. One third of the 21 service providers who resumed work after the first round of interviews mentioned this fear in September. Among the 39 service providers working in May, the other two most frequently cited challenges at that time were closely related: fear of infecting their own families, and lack of PPE. In September, lack of PPE was mentioned by one fifth of the 39 service providers working since May, and by about half of the 21 service providers who resumed service later. Fear of infecting their own families persisted for service providers working in May, and was shared by a quarter of the other 21 service providers. In September, about half of all service providers cited diminished clientele as a present challenge.

Despite the widespread fear of becoming infected or transmitting it to their families, relatively small proportions of active service providers reported stress or depression, at either point in time. Among the 39 who were actively serving during both rounds of interviews, only five percent felt challenged by the long hours of services and transportation issues in May, and those proportions were 13 percent and 23 percent, respectively, in September.

In May, the 21 service providers whose facilities were closed were experiencing some measure of anxiety, with all 18 public service providers reporting stress about sitting idle and not attending clients, while the three private sector service providers reported financial uncertainty. By September, however, all health facilities were open and these stresses were no longer active concerns.

\section{PRACTICE}

A number of questions assessed service providers' preparation for dealing with patients who might have COVID-19, specifically their training and PPE, whether their facilities are treating COVID-19 patients, and how RH and general health services offered at their facilities were affected by the pandemic. All 60 service providers were asked about their COVID training in both rounds of the survey; the remaining questions were posed only to the service providers whose facilities were operational, so to 39 in May and all 60 in September.

$92 \%$ of 60 service providers in May and $68 \%$ in September reported they have no training on COVID-19.

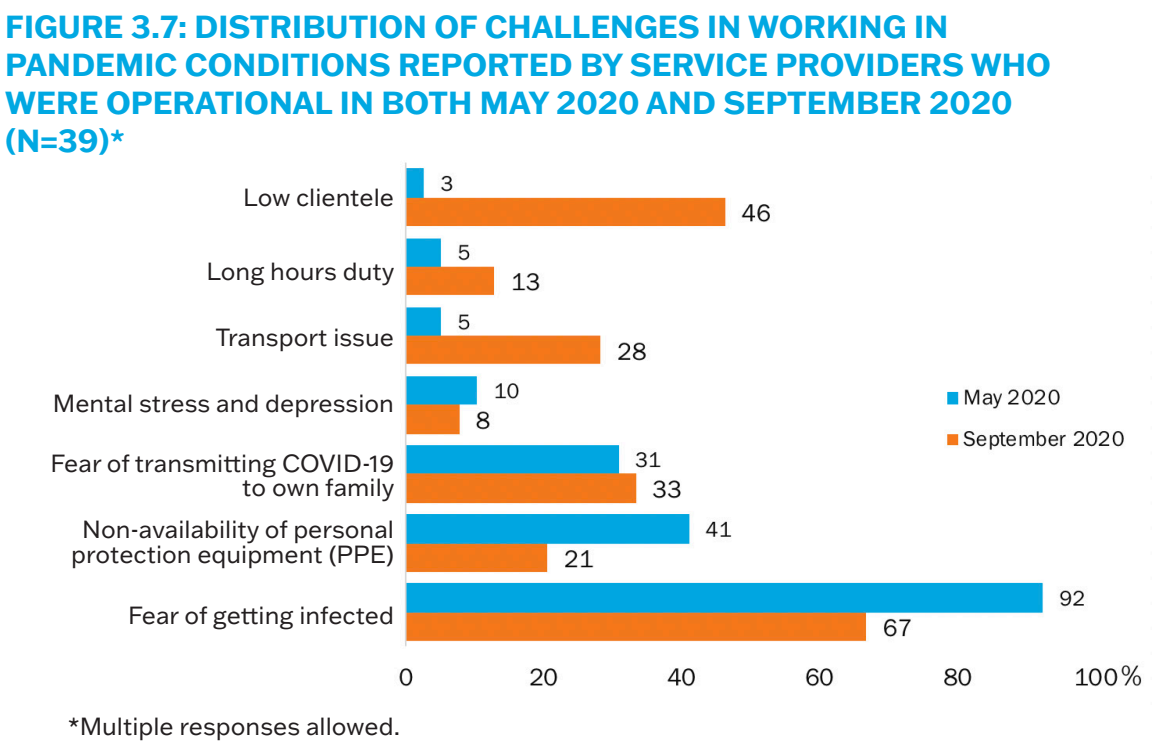

\section{Training}

In May, only five of the 60 service providers had received any training on COVID-19: Four attended a training organized by the Department of Health, and one attended a training organized by a non-governmental organization (NGO). In September only 19 of the 60 service providers had received COVID-19 training.

\section{Availability of Personal Protective Equipment} In May, only 17 (44\%) of the 39 active service providers reported PPE available at work; the remaining 22 active 
FIGURE 3.1: NUMBER OF SERVICE PROVIDERS TO WHOM PERSONAL PROTECTION EQUIPMENT IS AVAILABLE, BY TYPE OF EQUIPMENT ( $\mathrm{N}=39)$

\begin{tabular}{|l|c|c|c|}
\hline Type of equipment & $\begin{array}{c}\text { Had PPE among } \\
\text { providers operational } \\
\text { in May 2020 (n=39) }\end{array}$ & $\begin{array}{c}\text { Had PPE in September among } \\
\text { providers operational in May } \\
\text { and September 2020 } \\
(\mathbf{n = 3 9 )}\end{array}$ & $\begin{array}{c}\text { Became operational after } \\
\text { Round 1 and had PPE in } \\
\text { September 2020 } \\
\text { (n=21) }\end{array}$ \\
\hline Corona kit (Preventive suit) & 4 & 6 & 1 \\
\hline Mask N-95 & 3 & 9 & 0 \\
\hline Surgical gloves & 15 & 21 & 13 \\
\hline Disposable mask & 8 & 15 & 5 \\
\hline Disposable gloves & 9 & 19 & 2 \\
\hline Sanitizer & 15 & 23 & 7 \\
\hline $\begin{array}{l}\text { Number of service } \\
\text { providers with any PPE }\end{array}$ & 17 & 26 & 14 \\
\hline
\end{tabular}

respondents had no access to any PPE while providing health services. In September, 26 (67\%) of those 39 service providers reported available PPE at work, and 14 of the 21 service providers whose facilities opened after the first round of interviews also reported available PPE.

As Table 3.1 shows, most service providers who had PPE available only had a limited assortment of PPE items: even sanitizer was not available to all of them. Among the 17 of 39 active service providers who had PPE in May, only four had a complete coronavirus kit (prevention suit), only three had the more effective N95 masks, and eight out of the 17 had surgical gloves, with greater numbers having disposable masks, gloves, and sanitizer. Among those 39 service providers surveyed in May, data collected in September show that all service providers still do not have all PPE items available. The 21 service providers who resumed work after the first round of interviews are of particular concern: Little equipment is available to them besides surgical gloves, and Corona kits and N-95 masks are essentially not available.

In May, seven out of 17 service providers obtained PPE from the government, while eight purchased PPE items on their own, and two received it from a private organization.

By September, 26 service providers who had been working in May had PPE, of whom 20 received the equipment from the Department of Health. Among the 21 service providers who resumed work after the first round of interviews, in September 14 had PPE, and of those, 11 had received PPE from PWD, indicating improved government support to its facilities and staff

\section{Provision of COVID-19 Services}

As mentioned, no facilities were providing in-patient COVID-19 services in May or September, which could be attributed to the fact most facilities in the sample are small or medium in size, with limited resources to adapt to pandemic conditions. Service providers working at health facilities cited multiple reasons for not treating coronavirus cases; Figure 3.8 shows the reason most commonly mentioned, in both rounds of data collection, is lack of space for keeping patients in isolation. Lack of adequately trained staff is the second most frequently mentioned reason, followed by lack of PPE, which was reported by a relatively smaller number of service providers in September. Another major reason reported in September is non-availability of test kits, which was rarely mentioned prior. Among the 21 service providers who were inactive during the first round of interviews, but had resumed work by the second round in September, the most frequently mentioned reason for lack of COVID patient treatment

\section{FIGURE 3.8: DISTRIBUTION OF REASONS FOR NON- PROVISION OF COVID-19 SERVICES MENTIONED BY SERVICE PROVIDERS WHO WERE OPERATIONAL IN BOTH MAY 2020 AND SEPTEMBER 2020 ( $\mathrm{N}=39)$ *}

$$
\text { - May } 2020 \text { - September } 2020
$$

$100 \%$

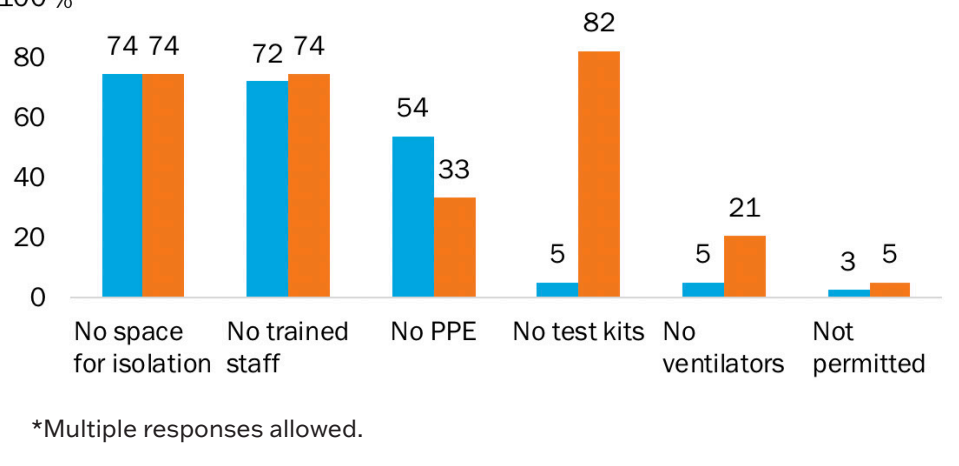


was non-availability of trained staff, followed by lack of authorization-mainly from PWD (18 of these 21 service providers are PWD staff) - as well as non-availability of PPE and testing kits.

\section{IMPACT OF PANDEMIC ON ROUTINE SERVICE PROVISION}

Health care respondents were asked in both rounds of interviews whether the COVID-19 pandemic had affected provision of $\mathrm{RH}$ and general health services at their facilities. In May, this question was only posed to the 39 service providers whose facilities in operation, and in September they were also asked to compare general and $\mathrm{RH}$ service provision with their statuses in May; the other 21 service providers, whose facilities had only recently reopened, were asked in September to compare general and $\mathrm{RH}$ services to times before the pandemic.

The majority (31 of 39) of respondents in May reported that COVID-19 and its lockdown had adverse effects on services, while in September, only 15 of those same respondents reported that services were still noticeably affected; the remaining 24 reported that services were either less affected or even returning to normal, compared to the situation in May. Among the 21 service providers who resumed work after the first round of interviews, 19 reported negatively affected $\mathrm{RH}$ and general health services compared to the pre-COVID-situation.
As shown in Figure 3.9, about half of the 39 active respondents in May reported that general health services were affected; these respondents did not report any change in September. $\mathrm{RH}$ services seemed to be returning to normal in September. The impacts on FP services reported by the 21 service providers whose facilities have recently opened are of particular importance, as most of those respondents are employed by PWD, which is mandated to focus on FP services. Seventeen of those 21 respondents reported that FP services have been adversely affected by COVID-19, mainly due to disrupted contraceptives supplies, while fewer of them reported effects on ANC and general services.

A large proportion of service providers reported declines in clientele at their facilities, particularly in May. Figure 3.10 presents details of service disruptions due to COVID-19. In May, about one quarter of service providers referenced low stocks of medicines, and over one tenth mentioned low contraceptive stocks. Respondents attributed disruptions in their services to clients to these shortages of medicines and contraceptives, as a result to the lockdown situation, leading to a decline in clientele. In September, only five percent and eight percent of the 39 service providers who were active in May reported limited stocks of contraceptives and medicines, respectively. The 21 service providers who resumed work after May, who generally work for PWD, mentioned that, to address any lingering effects of earlier facility closures, staff is being sent out to local

\section{FIGURE 3.9: DISTRIBUTION OF ADVERSE EFFECTS OF COVID-19 ON PROVISION OF ROUTINE SERVICES AT FACILITIES REPORTED BY SERVICE PROVIDERS WHO WERE OPERATIONAL IN MAY 2020 AND SEPTEMBER $2020(\mathrm{~N}=39)^{*}$}

$100 \%$

- May 2020 - September 2020

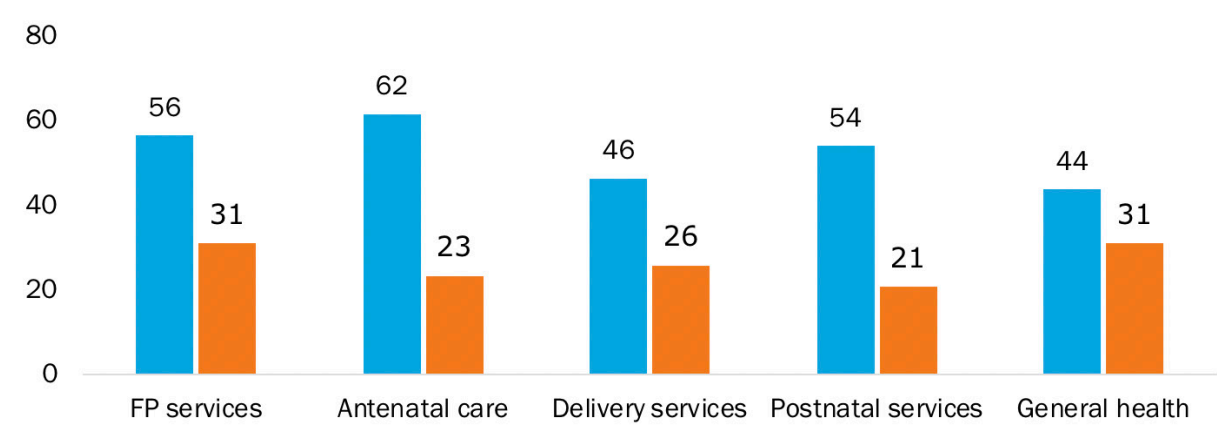

*Multiple responses allowed. 


\section{FIGURE 3.10: MAIN REASONS FOR DECLINE IN CLIENTELE AT HEALTH \\ FACILITIES REPORTED BY SERVICE PROVIDERS WHO WERE OPERATIONAL \\ IN MAY 2020 AND SEPTEMBER $2020(\mathrm{~N}=39)^{*}$}

100\% May 2020 - September 2020

80

60

40

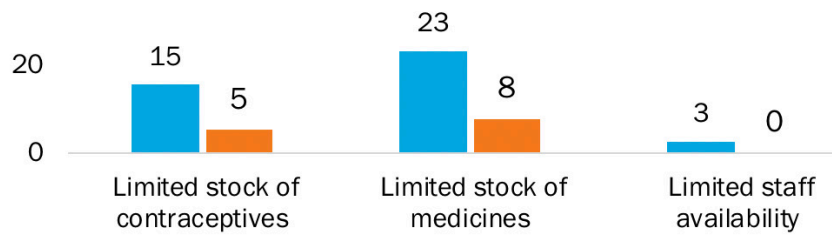

*Multiple responses allowed.

communities to inform them that these facilities have reopened, encouraging them to resume their patronage. Service providers were asked whether their facilities are receiving regular contraceptive supplies, and how providers respond when a client requests unavailable FP services or contraceptive methods. In May, over one third of facilities were reportedly not receiving regular supplies, that figure had declined to 21 percent in September, according to the same respondents. A few service providers mentioned purchasing contraceptives for their clients or referring them to other facilities (data not shown). Among the 21 service providers who were not active in May, primarily PWD employees, the majority (15) reported disruptions in contraceptive supplies when interviewed in September. Under normal circumstances, health care facilities refer FP clients to PWD facilities, and when PWD facilities were closed in May, many clients were unable to procure any FP methods. This risk was reduced in September, as by then PWD facilities had re-opened, and their staffs were taking proactive steps to contact clients in their communities.

A few service providers reported advising their clients to purchase contraceptives from pharmacies due to stock outs, but that is not feasible for many poor women. Contraceptive availability and stock management practices suggest that many clients, especially those who are poor, may be finding it difficult to maintain their pre-COVID FP status, despite motivation to seek contraceptive aid.

\section{DISCRIMINATION}

Under continuing pandemic conditions, it is possible that service providers could be regarded by the general public as potential infection agents, and even targeted with discriminatory behaviors. When asked, only four of the 39 working service providers reported any sort of discrimination in May. In September, seven of those 39 providers reported experiencing some form of discrimination, along with five of the 21 service providers who resumed work after the first round of interviews.

Service providers who reported discrimination stated that their relatives began avoiding interactions, and one stated that she believed her neighbors perceived her as a possible source of infection in the neighborhood.

The majority of service providers

who were operational in both rounds

of interviews-90\% in May and $82 \%$

in September-did not report any discriminatory behavior. 


\section{DISCUSSION AND RECOMMENDATIONS}

\section{DISCUSSION}

COVID-19 has introduced multifaceted complications in the lives of poor women and their households. These detailed findings about their plight-which includes hunger and severe stress as a result of their inability to feed their children, plummeting incomes, domestic violence, and an unreliable health system during a pandemic, even for infant delivery services-reveal their vulnerability and lack of resilience. More affluent segments of the population can access private health care, have insurance plans that protect them from economic shocks, often have options to work from home, and can afford schools that continue their children's education online through an indefinite lockdown. A financial assessment of the implications of COVID-19 for various socio-economic groups in Pakistan found that negative impacts of the pandemic can be up to 10 times more catastrophic for the poor.

The overriding concern is food insecurity. Benazir Income Support Programme (BISP) beneficiaries are unable to properly eat or feed their children even once a day, and the impact on their nutritional status, already compromised by poverty, could be extraordinarily serious. An estimated 36.43 million people are persistently and chronically vulnerable to food insecurity in Pakistan, and extremely vulnerable to natural hazards, including a pandemic. Even assuming that the current pandemic produces medium shock effects - and it very well could be greater-it is expected to make an additional 2.45 million people food insecure. $^{2}$

Not surprisingly, the inability to meet basic household needs, especially for adequately feeding their children, is causing great anxiety and frustration among poor couples. BISP beneficiaries report an escalation in domestic violence, perpetrated primarily by husbands. Presently, the majority of women report psychological violence, while frequently expressing the fear that things could worsen, that a longer-term lockdown may cause their increasing quarrels with their husbands to turn physically violent. This fear is corroborated by a recent study revealing evidence of increasing physical domestic violence linked to loss of livelihoods due to the COVID-19 pandemic in many parts of the country. ${ }^{3}$

A number of local studies and discourse on social media substantiate this study's findings that women's access to most RH services, including ANC, PNC, delivery, and FP services, have been reduced, as health facilities either closed or CHWs ceased household and community visits. ${ }^{4,5}$ COVID-19, its resultant lockdown, and the fear of viral transmission have each disrupted the continuum of care, with complete disruption between communities and $\mathrm{CHWs}$, particularly LHWs and vaccinators. The absence of these critical health care workers has produced a void in in FP and immunization services that are frequently cited by BISP beneficiaries. In their attempts to access health facilities, both the availability and affordability of transportation pose significant problems, compelling current users of short term, modern FP methods to utilize unreliable, traditional methods.

A positive finding from these interviews and discussions with BSIP beneficiaries is that their knowledge about COVID-19 is generally good. Most respondents were well aware of transmission modes and conversant with appropriate preventative measures. These acceptable levels of knowledge about COVID-19 among Punjab's poor women, who have no or little education generally, corresponds with findings from recent cross-sectional study of Pakistan's general population, determining that they are highly knowledgeable of COVID-19 symptoms, transmission, and prevention. ${ }^{6}$ Media, especially television, has been an effective and positive source of information for BISP beneficiaries, and the strong influence of the

\footnotetext{
Shaikh, H. 2020. COVID-19: Pakistan's preparations and response. International Growth Centre (IGC) blog post, www.theigc.org/blog/covid-19-pakistans-preparations-and-response UN Office for Coordination of Humanitarian Affairs. 2020. Pakistan Humanitarian Response Plan for COVID-19 Pandemic 2020.

Shirkat Gah Women's Resource Centre. 2020. Voices from the Field: Living with Covid-19 in Pakistan-Issues \& Needed Actions, Update 28 April 2020. Lahore: Shirkat Gah.

Qureshi, U. 2020. Women and girls must be at the centre of Pakistan's COVID-19 recovery. World Bank blog, Act Now Pakistan series.

Shirkat Gah Women's Resource Centre. 2020. Voices from the Field: Living with Covid-19 in Pakistan_Issues \& Recommended Actions, Update 15 June 2020. Lahore: Shirkat Gah. Muddassir, M.T., R. Ali, K.M. Musarrat. 2020. Knowledge and Perception of COVID-19 and Its Preventive Measures in the Public of Pakistan. Pak Armed Forces Med J 70(2): 338-45.
} 
country's media is manifest in the measures women are taking to remain safe from coronavirus infection. This study in Punjab, however, reveals a widespread misconception that COVID-19 is transmitted via breastmilk and that infected mothers should stop breastfeeding. Media should play a prominent role in efforts to correct misperceptions about breastfeeding that could have ramifications for infant and child health, through public service messages.

BISP beneficiaries' capacities for effectively implementing COVID prevention measures are influenced by: 1) their ability to purchase soap and other commodities for disinfection and cleaning, 2) their access, and ease of access, to water and sanitation facilities, and 3) housing and living conditions. With large families living in small one- or two room homes, sharing a single bathroom, it can be practically difficult or even impossible to maintain any social distance or isolate unwell members. In the current pandemic, these resource constraints can be expected to have multiplied effects on the poorest segments of any population. These same challenges are reported in a study from Kenya that found poor households have inadequate capacities for practicing regular handwashing and social isolation, due to their lack of access to soap or even water, and crowded living conditions. ${ }^{7}$ This study's findings support the likelihood of increased poverty due to COVID-19, with a majority of respondents' husbands newly unemployed or forced to engage in less reliable and lesserpaying daily wage work.

The closing of schools due to the lockdown and its abrupt and indefinite disruptions in children's education is another challenge with potential lasting ramifications for BISP recipients and their families. Children are sitting idle, not engaged in productive activity, while parents are unable to afford substitute arrangements such as tutoring at home. Confronted with a multitude of interrelated challenges, the majority of women surveyed in this study showed signs of psychological stress, ranging from mild to severe, with a significant proportion in urgent need of professional mental health assistance. In designing and deploying a health response to COVID-19, mental health interventions should be a central component.
This study provides important insights about resultant problems in routine as well as $\mathrm{RH}$ services during the COVID-19 pandemic. Service providers are not wellinformed about COVID-19, with important implications for how safely they can treat patients, whether or not they have direct engagement with diagnosed COVID-19 patients. This study reveals that service providers lack accurate knowledge about COVID-19's symptoms, prevention, and treatment, indicating limited access to recent developments in COVID-19 knowledge.

Some COVID-19 effects on health facility service provision are glaring, such as the outright closure in May of PWD facilities, which are mandated to focus on FP provision. Facility closures in combination with disruptions in LHW services that were mentioned in our interviews and discussions with women imply significant declines in FP service availability and accessibility, and the possibility of higher numbers of unwanted pregnancies and abortions in the days ahead.

In both May and September, only a limited number of service providers knew that COVID-19 positive women could safely use modern contraceptives as well as continue to breastfeed. Considering that all study respondents are employed at health facilities that provide $\mathrm{RH}$ services, this has serious implications for the quality of $\mathrm{RH}$ counseling provided to clients. This problem is not specific to Pakistan: Similar knowledge gaps were also identified in a cross-sectional web-based study with service providers from almost all regions of the world. ${ }^{8}$

Pakistan's health service providers' primary sources of COVID-19 information are from media. Only four of 60 service providers in this study population had any training on COVID-19 at the first round of data collection, and four months later, in September, still only 19 had received training. This lack of needed training is likely a principal reason for service providers' lack of adequate COVID-19 knowledge. It is imperative facilities arrange training sessions for all affiliated service providers, even if they do not directly deal with known COVID-19 patients, as any facility client or patient could potentially be infected and infectious.

\footnotetext{
7 Population Council. 2020. Kenya: COVID-19 Knowledge, Attitudes \& Practices. COVID-19: Managing the Outbreak.

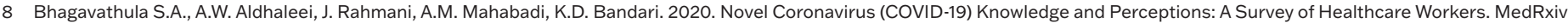
preprint. 
Most service providers surveyed in May had no PPE available through the places of work. Although in September the situation, as reported by those who were working in May, was somewhat improved, it fell short of desired levels of PPE provision. Moreover, both rounds of data collection reveal that even those who have PPE do not have complete kits for proper health service provision. This is a serious concern, as it reveals high risk of COVID-19 infection for service providers, as well as their families, in addition to their patients. Service providers are fearful of coronavirus infection while serving clients, and transmitting it to their own families. Some service providers also confessed that they do not know how to protect themselves against infection; while that proportion of respondents was small, it is worrisome due to their position in the public health system and potential as nexuses of transmission among their patients. This lack of PPE and COVID training are particularly concerning, as they imply unsafe levels of risks of infection among service providers, in addition to preventing their optimal contribution to fighting the pandemic. It is vitally important to both train and equip service providers with PPE for their own protection as well as that of their patients, and to improve their confidence in interacting with patients.

Measures should be introduced to assess the psychological stress among health care providers and provide them with support when necessary. Discussions about psychological challenges for service providers, especially primary care workers, during the COVID-19 pandemic are now universal, ${ }^{9}$ and several countries offer examples of strategies for rehabilitative services that can be adapted for service providers in Pakistan, including those who do not deal directly with COVID-19 patients. ${ }^{10}$

Our findings indicate that the burdens of COVID-19 are affecting the entire health system, from community services to PHC clinics to hospitals, with health facilities continuing patient care performing sub-optimally and service providers reporting disruptions in $\mathrm{FP}, \mathrm{RH}$, and general health services. Service providers identify diminished clientele as a primary concern, which could be a result, in addition to obvious fears of viral infection, from client access issues, including transportation and economic exigencies. Disruptions in contraceptive supplies and medicines discourage clients from returning. Pakistan is not alone in facing these problems, as studies show that the COVID-19 pandemic is adversely affecting contraceptive commodity supply chains in other parts of the world due to disruptions in manufacturing and transportation delays. ${ }^{11}$

The findings of this study reveal urgent need for action to alleviate the challenges of poor and marginalized households and their communities, besides restoring routine health services that ensure the safety of their service providers. ${ }^{12}$ These findings about the difficulties endured by BISP beneficiaries during the COVID-19 epidemic both confirm and elucidate issues reported in the other Pakistan studies. While those studies were concerned with the general population and urban areas, this study is unique in focusing on, and providing evidence from, the poorest women in rural areas, for whom universal challenges of the pandemic can be expected to be compounded by economic, geographic, and gender disparities. These findings about poor rural women in Pakistan are substantiated by similar studies in other parts of the world.

The Pakistan Humanitarian Response Plan for COVID-19, 2020 identifies priority areas for action, such cash support through the Ehsaas program and measures to address food insecurity, nutrition, health services, and GBV. This study's findings from BISP beneficiaries substantiate that these plans correlate to actual, expressed needs, but they must be implemented with immediacy, with all stakeholders, from the public as well as private sectors, coordinating efforts and combining resources for collective and focused interventions. ${ }^{13}$

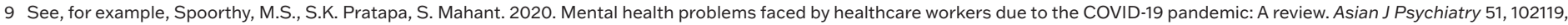

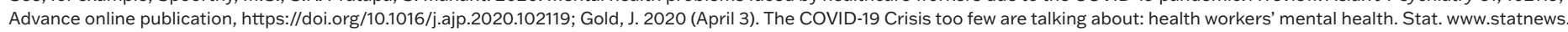
com/2020/04/03/the-covid-19-crisis-too-few-are-talking-about-health-care-workers-mental-health; and WHO. 2020 (July 13). Frontline workers and COVID-19: Coping with stress. www.emro.who.int/images/stories/mnh/documents/1_flyer_flws_covid_coping_with_stress.pdf?ua=1

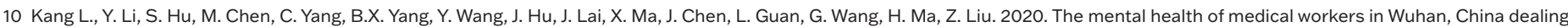
with the 2019 novel coronavirus. The Lancet Psychiatry 7(3): e14. doi: 10.1016/S2215-0366(20)30047-X.

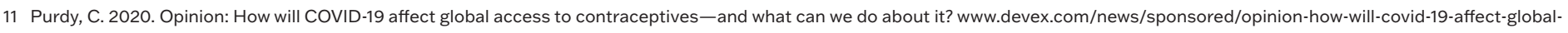
access-to-contraceptives-and-what-can-we-do-about-it-96745

12 Please see footnotes 14-16.

13 United Nations Office for the Coordination of Humanitarian Affairs (OCHA). 2020. Pakistan Humanitarian Response Plan for COVID-19 Pandemic 2020. OCHA.
} 


\section{RECOMMENDATIONS}

\section{Public service media messages with accurate information for households and communities}

Our findings suggest that television has proven to be a good source of information about COVID-19 for BISP beneficiaries. To further utilize this medium, increased public service messaging should:

- Guide households on RH and child health issues, especially in awareness of protective measures for pregnant women, encouraging couples to adopt FP to countenance higher risk of pregnancy during the current pandemic, in addition to dispelling the misconception that mothers who contract COVID-19 should stop breastfeeding.

- Publicize helplines more widely that support families and their health, such as the helpline on $\mathrm{RH}$ issues established by the Population Council with UNFPA support and collaboration with the Aman Foundation and the Society of Obstetricians and Gynaecologists of Pakistan (SOGP), and the helpline established by the Ministry of Human Rights for cases of domestic violence.

- Educate viewers on how to contact trained doctors by telephone for advice for $\mathrm{RH}$ issues.

- Provide information about health facilities that are operational and can be visited by women and couples for $\mathrm{RH}$ services, especially FP, ANC, and delivery, to facilitate and encourage women's access to health facilities, reducing time, travel costs, risks, and stress due to referrals to inaccessible facilities.

\section{Income support and nutritional packages}

Due to the lockdown and general depression in business activity associated with COVID-19, many poor male and female wage earners were either left with no work or shifted to sporadic, unreliable day labor. These individuals and their households are unable to purchase enough food for their families, and routine hunger, especially among their children, creates chronic stress that can lead to domestic violence.
In this critical situation, the government should ensure the additional income support announced from the Ehsaas program is immediately disbursed to all eligible beneficiaries. The government should provide not only additional income support but nutritional packages as well, to meet poor families' basic food needs, either in ration packages or vouchers, which will help reduce child malnutrition and associated psychological stress and domestic violence among their caregivers.

\section{Education subsidies, strategies and partnerships \\ Creative strategies must be devised to re-engage} schoolchildren in educational activities, and rescue them from their current unproductive condition, a source of stress for parents and likely for children themselves. Online learning options are not feasible for poor, rural households, but educational aid or subsidies could help pay school fees to keep children enrolled, so they can continue lessons at, or close to, home. School administrators should liaise with the postal system to arrange home delivery of study materials and exchange of homework lessons between students and teachers.

\section{Reopening PWD facilities and resuming community health services}

Women are facing impediments to $\mathrm{RH}$ services, especially FP, because the manifestation of COVID-19 and its lockdowns in Pakistan led to the closure of PWD facilities. The closure of these facilities throughout Punjab compelled women to either discontinue contraceptive use or switch to unreliable, traditional methods. LHWs suspended their visits to women's homes to provide FP or ANC services. This suspension in home services also affected children's immunization schedules.

This is untenable. To avert unwanted pregnancies and deteriorations in maternal and child health indicators, PWD must keep its facilities open, even during emergency conditions, and it is crucial to resume communitybased services for couples' unmet FP need. In addition, resumption of these necessary routine services will contribute to improved awareness and understanding of COVID-19. Current and future advocacy with the government and relevant decision-makers should argue for the categorization of $\mathrm{RH}$ and maternal health services as essential services, during any emergency situation. 
Use of mHealth or telemedicine to avoid over-burdening facilities and minimize patient access issues

The government should introduce telephone-mediated triage for the health system, as a response to patient difficulties in reaching health facilities as well as safety concerns at facilities and challenges in ensuring service providers' protection. Such issues have led to mHealth solutions worldwide, and these investments are justified by the likelihood of this pandemic's persistence. Toll-free telephone numbers should be provided by $\mathrm{CHWs}$ to their clients for contacting doctors to seek advice on $\mathrm{RH}$ and general health needs. This will not only improve patients' access to health services but will reduce viral infection risks, for both clients and providers, in addition to the added infection risks non-emergency cases pose for doctors and the health system in general.

\section{Training of both public and private sector} service providers on COVID-19

Most service providers have not been trained on COVID-19 and its proper precautions and procedures, and this is directly reflected in their deficient knowledge of not only its prevention and personal protective measures but its symptoms and appropriate patient care. These deficiencies in knowledge contribute to providers' fears of self-infection and further transmission, and discourage even routine services. The government should provide training for both public and private sector providers on safe work practices during the COVID-19 pandemic. Service providers at currently suspended health facilities should be trained to work in pandemic conditions prior to their facilities' re-opening.

\section{Provide PPE and COVID-19 testing at} facilities for service providers

Service providers feel vulnerable to coronavirus infection at health facilities, particularly when no PPE is available, resulting in absenteeism. This can be addressed by providing PPE to all service providers. The government should begin regular testing of service providers-at their places of work--to improve their confidence in providing care to all of their clients, in addition to ensuring that only uninfected staff is working at health facilities.
Mental health support for service providers Health care providers who are currently working are under constant mental and emotional strain due to their fear of virus transmission, especially to their own families, in addition to their other patients. It is important that the government begins periodic assessments of service providers' mental health and provision of any help or rehabilitative support they need.

\section{Allocate resources to implement COVID-19 Emergency Support Plan}

In an encouraging development, under the Primary and Secondary Healthcare Department of Punjab, the Integrated Reproductive, Maternal, Newborn and Child Health and Nutrition Program developed a COVID-19 Emergency Support Plan in April 2020. The program requires additional funds to implement the plan, and the provincial government should allocate the necessary resources for its implementation, as it will address a majority of the supply side issues identified in this study. 


\section{APPENDIX A: GUIDELINE FOR FOCUS GROUP DISCUSSIONS WITH BISP BENEFICIARIES}

\section{INFORMED CONSENT}

\section{Perception and perspectives about COVID-19}

1. What do you and people of your community call this disease, and what do you know about it?

2. How do you think this disease spreads or how it can spread (through droplets from sneezing, coughing, touching, etc.)? (List all means women mention.)

3. Who in your view can contract this disease the most (children, adults, or older people)?

4. How can people protect themselves? Are you at your $\mathrm{HH}$ level following any preventive measures to protect yourself from disease (Probes: washing hands, using masks and hand sanitizers, limited mobility and keeping distance-why is social distancing important in your view)?

5. From where you got this information about this outbreak (Probes: TV, radio, husband, family members, mobile phone, Lady health worker, health care provider, NGO, neighbors, announcements at mosque) Of your mentioned sources grade these from most important source to least important.

6. are you scared about it/ do you think it can affect you, your family, community? Why do you think so?

\section{Lock down implementation and its effects at community}

7. Is there any lockdown implemented in your community by the government?

8. Are people of your community following this lock down and keeping themselves restricted to their homes? If Yes then Why and if no then why not?

9. In your view, has the lockdown affected your community? If yes, then how?

a. Economically (economic opportunities compromised, unemployment increased, shops are closed etc.)

b. Mental health issues and stress level increased

c. Social issues (events and gatherings (private function like wedding and religious) banned, no socializing)

10. What will be the long-term effects on people of your community if this lock down situation continues for some time?

11. Do you think that this situation has impacted women differently than men? If Yes then How?

- Health and reproductive health needs and issues including family planning

- Psychological effects, mental stress

- Economic impact

- Domestic violence

12. In your view, what are special needs of pregnant women in this given lock down situation?

13. What specific information is being provided through these sources that relates to women's health and protection?

14. In your view, can women breast feed their children if they get affected by the virus?

\section{Dealing with Coronavirus positive case}

15. Do you know anyone who has developed this virus from your community or nearby?

16. If yes, then how did it affect your community?

17. How was that person treated by the community? is there any stigma attached to such a person?

18. Were there any means of self-isolation practiced by your community? (for the person infected or suspected to be infected by the virus)? 


\section{APPENDIX B: GUIDELINE FOR IN-DEPTH INTERVIEWS WITH BISP BENEFICIARIES}

\section{INFORMED CONSENT}

1. What is the name of this disease? What do people here refer to it as?

2. How does it spread/ how one can get this disease from others (through droplets from sneezing, coughing, touching, etc.)? (List all means women mention.)

3. In your opinion who can get the illness children, adults, older people?

4. In your opinion how can you protect yourself? (Probes: regularly washing hands, using masks and sanitizers, limited mobility and keeping distance-in your opinion why is social distancing important in your view)

5. From where did you get all this information (Probes: TV, radio, husband, family members, mobile phone, Lady health worker, health care provider, NGO, neighbors, announcements at mosque) Of your mentioned sources grade these from most important source to least important.

6. Do you feel scared about it/ do you think it can affect you, your family, community? Why do you think so?

\section{General health questions}

7. Do you feel well these days?

8. Are you able to perform your routine tasks?

9. How do you think this illness has impacted your life?

10. Do you have any issues regarding your health?

11. For your health issues particularly $\mathrm{RH}$ menstrual hygiene, what options do you have(regarding purchasing pads/napkins) and how have you been coping with them?

12. (If not pregnant) do you feel concerned/ fear about being pregnant in the present situation? What are you doing to avoid it?

13. (If breastfeeding a child) do you feel concerned about feeding your child in this situation? In your opinion or knowledge, what measures mothers should take who are breast feeding their children? Can women breast feed their children if they get affected by the virus?

\section{Contraception}

14. Are you using any form of contraception for voiding pregnancy? If yes

- Currently what method are you using?

- From where are you obtaining your method and how?

- Did you leave your home to visit a provider?

- Are you facing any problems in getting method? What are those problems?

- Has this lock down situation led you to method switching or discontinuation?

- Have you switched to traditional method due to issues in getting method?

\section{Current Pregnancy}

15. As you are pregnant, do you feel concerned due to the current lock down situation?

- Are you in touch with your doctor?

- Did you leave your house for checkup?

- Have you received instructions on ANC?

- During ANC did you receive specific precautions particularly in context of coronavirus

- Are you aware of where your delivery will take place?

- Are you aware that you will be needing special support during the antenatal period and delivery that scares you or concerns you due to the current situation?

- Are you concerned that you or your child might catch the virus if you go to deliver in a health facility? Why and why not?

- During delivery what precautions do you think you should take during the current coronavirus outbreak?

- Because of being pregnant do you face any issues in this situation?

- Is LHW visiting your residence regularly?

- Has the LHW provided you any information regarding the current outbreak

- Do you know the testing place of Coronavirus, do you or any of your family member have visited that place?

16. Has this situation effected your food patterns(time/quantity) in anyway? If yes, how?

17. Did you face any additional problems during this lockdown situation regarding menstrual hygiene? 


\section{APPENDIX C: STRUCTURED QUESTIONNAIRE FOR}

INTERVIEWS WITH WOMEN

SRNO:

$1-1-1$

SRNO from baseline (2019) survey:

Reproductive health needs and access issues

of poor and marginalized women in COVID-19 situation

Interview with women to assess their psychological issues in COVID-19

Currently Married Women of

Reproductive Age (15-45 years - BISP Beneficiaries) 


\section{SECTION A \\ HOUSEHOLD INFORMATION}

A1- Name of Woman:

A2- Phone Number:

A3- Name of Union Council:

-1-

A4- Name of village/Mohalla:

A5- Complete (postal) address of the household:

A6- CNIC: $-$

A7- Duration of telephonic interview:

_____ [in minutes]

[Please write down 24 hours]

A8- Date of interview:

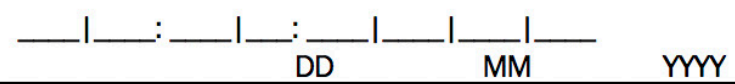

A9- Name of the interviewer:

Code:

A10- Result of interview:

Connected and interview completed 01

Connected and interview incomplete.

Connected but refused to be interviewed ............... 03

Connected but given other time for interview ......... 04

Call not responded ................................................. 05

Number switched off............................................... 06

Number not in use ................................................... 07

Others .................................................................. 77

A11- In case of incomplete interview / refusal, please specify reasons:

A12: Number of total calls made to a woman:

Additional information for reference during interview (Not to be asked)

A13- Pregnancy Status:

A14- Method Usage Status:

A15- Contraceptive Type: 


\section{SECTION B \\ Socio-economic characteristics of the respondent}

\section{Now I would ask few questions about you and your Household}

\begin{tabular}{|c|c|c|}
\hline B1 & What is your name? (Optional) & \\
\hline B2 & How old are you? & [Completed Years \\
\hline B3 & $\begin{array}{l}\text { As you are a BISP beneficiary, when did you receive } \\
\text { your last cash from the BISP? }\end{array}$ & $\begin{array}{l}\text { In this current month } \\
\text { In previous month } \\
\text { Three months ago } \\
\text { More than } 3 \text { months }\end{array}$ \\
\hline B4 & $\begin{array}{l}\text { Did you receive any additional cash or ration from } \\
\text { BISP or any organization/ individual to meet your } \\
\text { needs in this lock down situation? } \\
\text { Multiple responses are allowed }\end{array}$ & 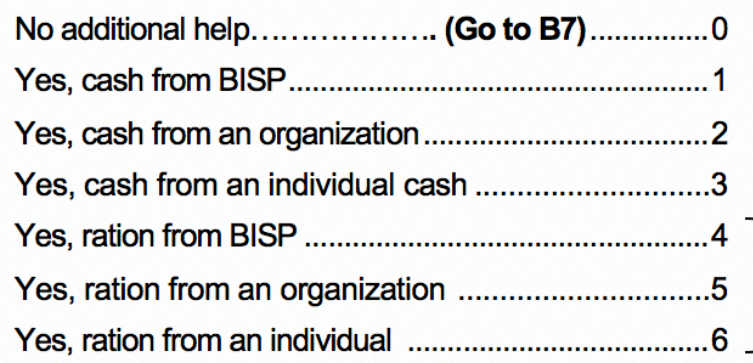 \\
\hline B5 & If yes, how much in cash? & $\begin{array}{l}\text { a. Amount in PKR BISP: } \\
\text { b. Amount in PKR Another } \\
\text { organizations/individual: }\end{array}$ \\
\hline B6 & $\begin{array}{l}\text { Do you feel this support as helpful in meeting your } \\
\text { daily needs in the current situation? }\end{array}$ & Yes \\
\hline B7 & $\begin{array}{l}\text { Does he still do same work these days or is sitting } \\
\text { at home without work or changed the profession } \\
\text { due to lock down? }\end{array}$ & 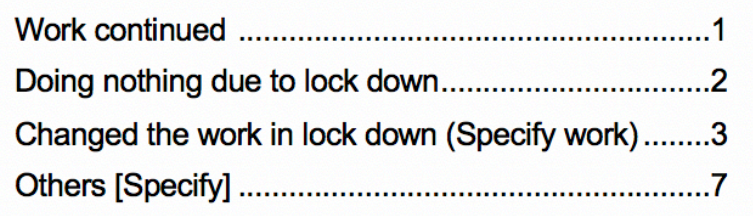 \\
\hline B8 & $\begin{array}{l}\text { Do you still do same work these days or are sitting } \\
\text { at home without work or changed the profession } \\
\text { due to lock down? }\end{array}$ & $\begin{array}{l}\text { Work continued } \\
\text { Doing nothing due to lock down .............................. } \\
\text { Changed the work in lock down (Specify work) ......... } \\
\text { Others [Specify] }\end{array}$ \\
\hline
\end{tabular}

\section{SECTION C}

\section{Impact of lock down in coronavirus}

Today I will be asking you about illness that is spreading across Pakistan. And due to this illness, there is a lock down situation from the government and there is restriction on going out due to which people are facing certain economic, health and other social issues. Now I would like to ask few questions that what do you know about this illness and how this lock down has affected you and your household.

\begin{tabular}{|c|c|c|}
\hline C1 & $\begin{array}{l}\text { Have you heard about the illness that is spreading } \\
\text { everywhere now a days? }\end{array}$ & 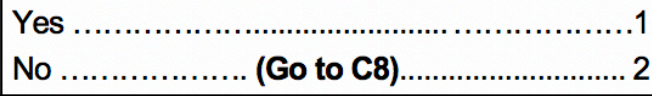 \\
\hline $\mathrm{C2}$ & what it is called? & Coronavirus. \\
\hline
\end{tabular}




\begin{tabular}{|c|c|c|}
\hline & & Virus \\
\hline C3 & $\begin{array}{l}\text { What are your sources of information on Coronavirus? } \\
\text { Multiple responses are allowed }\end{array}$ & 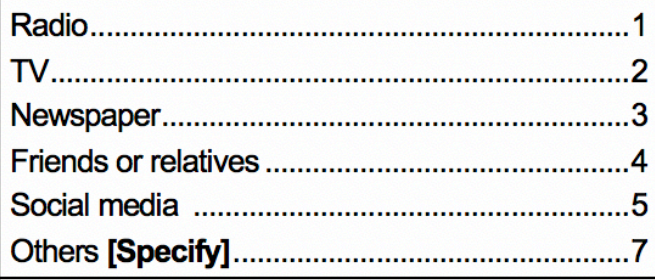 \\
\hline C4 & $\begin{array}{l}\text { What are the main symptoms of Coronavirus? } \\
\text { Multiple responses are allowed }\end{array}$ & 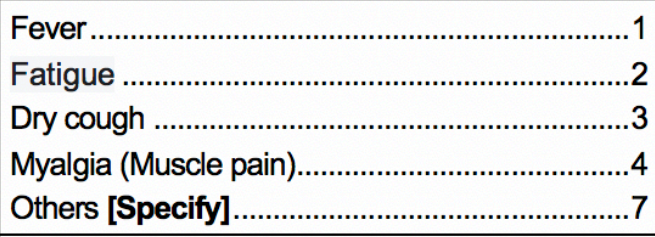 \\
\hline C5 & $\begin{array}{l}\text { How does this illness spread? } \\
\text { Multiple responses are allowed }\end{array}$ & 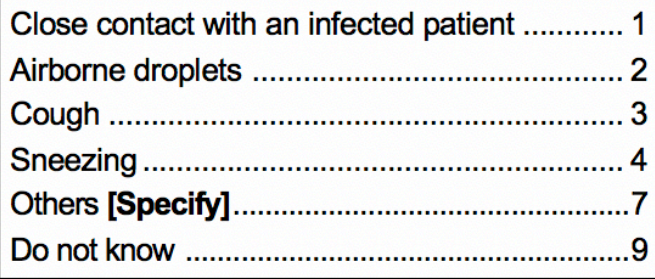 \\
\hline C6 & How can you protect yourself? & 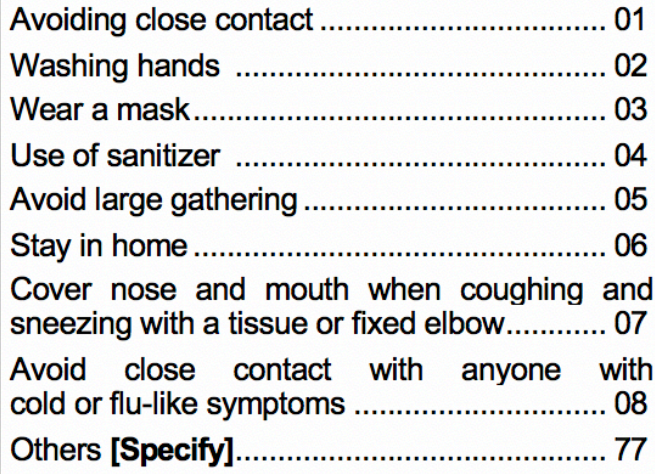 \\
\hline C7 & Do you think you can get effected with this virus? & Yes \\
\hline
\end{tabular}

Now some statements will be read to you, and we would like to know how often each of the things described in the statements happened to you during lockdown. It may be that they Never happened, or that they Happened Sometimes, Happened Often or Happened Very Often.

\begin{tabular}{|c|c|c|c|c|c|c|}
\hline \multicolumn{2}{|c|}{$\begin{array}{l}\text { C8. How likely are you to do the } \\
\text { following practices? } \\
\text { Prompt for each category }\end{array}$} & \multirow{2}{*}{$\begin{array}{c}\text { NEVER } \\
1\end{array}$} & \multirow{2}{*}{$\begin{array}{c}\text { SOMETIMES } \\
2\end{array}$} & \multirow{2}{*}{$\begin{array}{c}\text { OFTEN } \\
3\end{array}$} & \multirow{2}{*}{$\begin{array}{c}\text { VERY } \\
\text { OFTEN } \\
4\end{array}$} & \multirow{2}{*}{$\begin{array}{c}\text { REFUSE TO } \\
\text { ANSWER } \\
6\end{array}$} \\
\hline a. & Wear Masks for going outside & & & & & \\
\hline b. & $\begin{array}{l}\text { Avoid commercial gathering e.g. } \\
\text { Market, Bazar, etc., }\end{array}$ & 1 & 2 & 3 & 4 & 6 \\
\hline c. & $\begin{array}{l}\text { Avoid social gatherings at the } \\
\text { homes of friends and relatives }\end{array}$ & 1 & 2 & 3 & 4 & 6 \\
\hline d. & Avoid religious gathering & 1 & 2 & 3 & 4 & 6 \\
\hline e. & Stay at home & 1 & 2 & 3 & 4 & 6 \\
\hline f. & $\begin{array}{l}\text { Washing Hands frequently with } \\
\text { soap }\end{array}$ & 1 & 2 & 3 & 4 & 6 \\
\hline g. & $\begin{array}{l}\text { Cover nose and mouth when } \\
\text { coughing and sneezing with a } \\
\text { tissue or fixed elbow }\end{array}$ & 1 & 2 & 3 & 4 & 6 \\
\hline h. & $\begin{array}{l}\text { Avoid close contact with anyone } \\
\text { with cold or flu-like symptoms }\end{array}$ & 1 & 2 & 3 & 4 & 6 \\
\hline
\end{tabular}




\begin{tabular}{|c|c|c|}
\hline & Multiple responses are allowed & 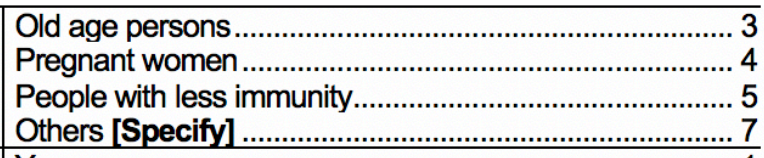 \\
\hline C10 & $\begin{array}{l}\text { Because of the lock down are you restricted to } \\
\text { your home? }\end{array}$ & 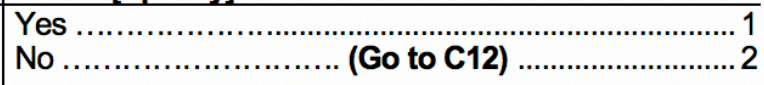 \\
\hline C11 & If yes & Number of days: \\
\hline C12 & $\begin{array}{l}\text { What are the possible reasons of coronavirus? } \\
\text { (Multiple responses allowed) }\end{array}$ & 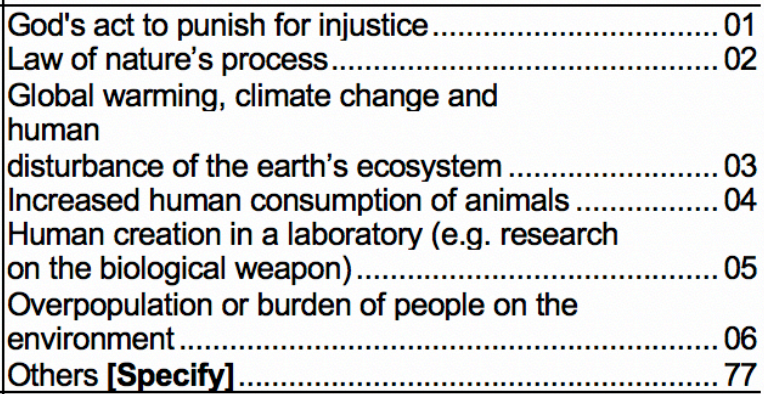 \\
\hline C13 & $\begin{array}{l}\text { Has this lock down affected your household } \\
\text { income? }\end{array}$ & 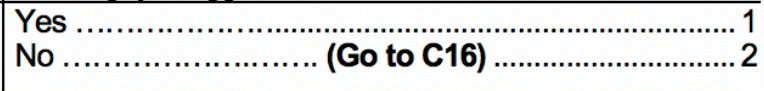 \\
\hline C14 & $\begin{array}{l}\text { If yes, in what ways? } \\
\text { (Multiple responses allowed) }\end{array}$ & 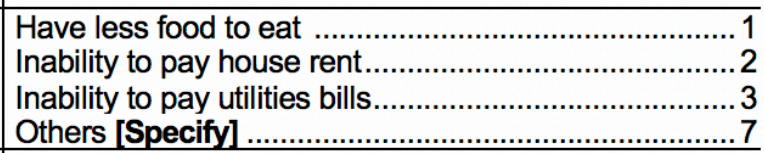 \\
\hline C15 & How you are coping with it? & 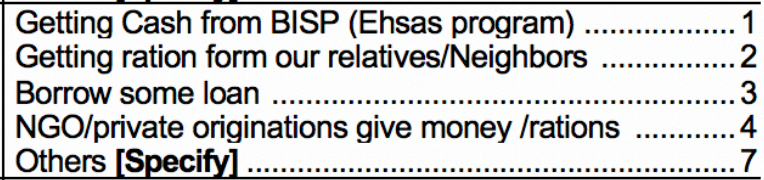 \\
\hline C16 & $\begin{array}{l}\text { How economic stress affects your relationships } \\
\text { at home? } \\
\qquad \text { (Multiple responses allowed) }\end{array}$ & 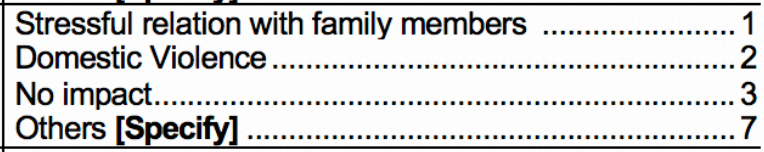 \\
\hline C17 & $\begin{array}{l}\text { How restriction on going out affected your } \\
\text { relationships at home (it can be positive or } \\
\text { negative)? } \\
\text { (Multiple responses allowed) }\end{array}$ & 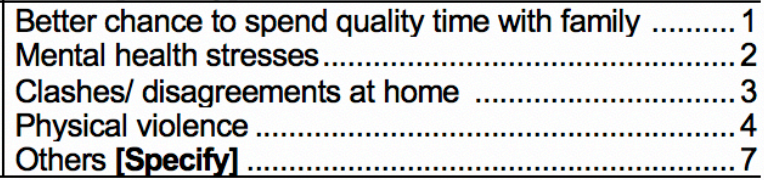 \\
\hline
\end{tabular}

\begin{tabular}{|c|c|c|}
\hline & & \\
\hline C18 & $\begin{array}{l}\text { Usually does it happen with you that you have to face } \\
\text { gender-based violence of any type? }\end{array}$ & Yes \\
\hline $\mathbf{C 1 9}$ & $\begin{array}{l}\text { What type of violence you have to experience during } \\
\text { usual days? }\end{array}$ & 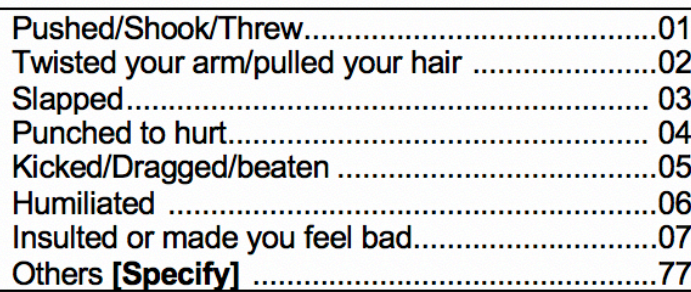 \\
\hline C20 & $\begin{array}{l}\text { Did you experience gender-based violence of any type } \\
\text { during lockdown situation? }\end{array}$ & 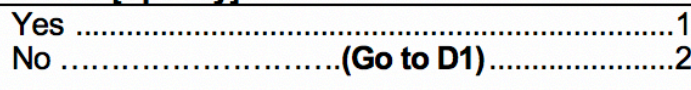 \\
\hline C21 & $\begin{array}{l}\text { What type of violence you experienced during this } \\
\text { lockdown situation? }\end{array}$ & 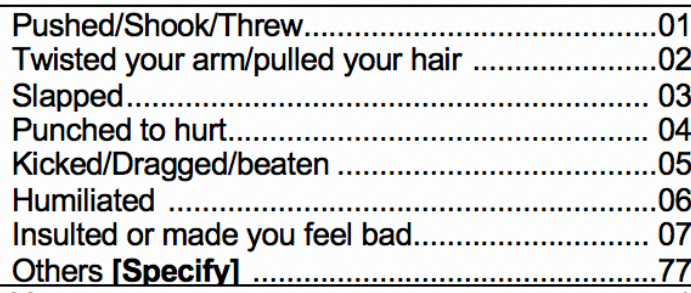 \\
\hline C22 & If yes, has it increased during lockdown situation? & Yes \\
\hline
\end{tabular}




\begin{tabular}{|c|c|c|}
\hline C23 & $\begin{array}{l}\text { Who has hurt you in this way in lockdown situation? } \\
\text { [Multiple responses allowed] }\end{array}$ & 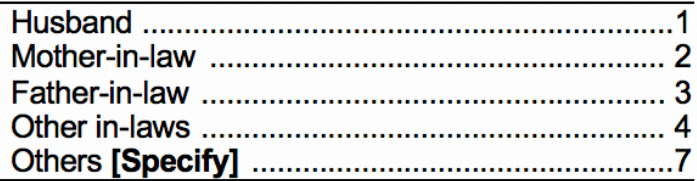 \\
\hline C24 & $\begin{array}{l}\text { How are you dealing with it? } \\
\qquad \text { [Multiple responses allowed] }\end{array}$ & 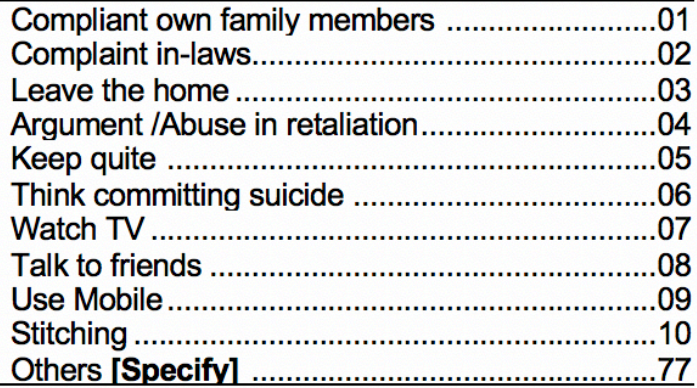 \\
\hline
\end{tabular}

\section{Section D \\ Mother and Child Health}

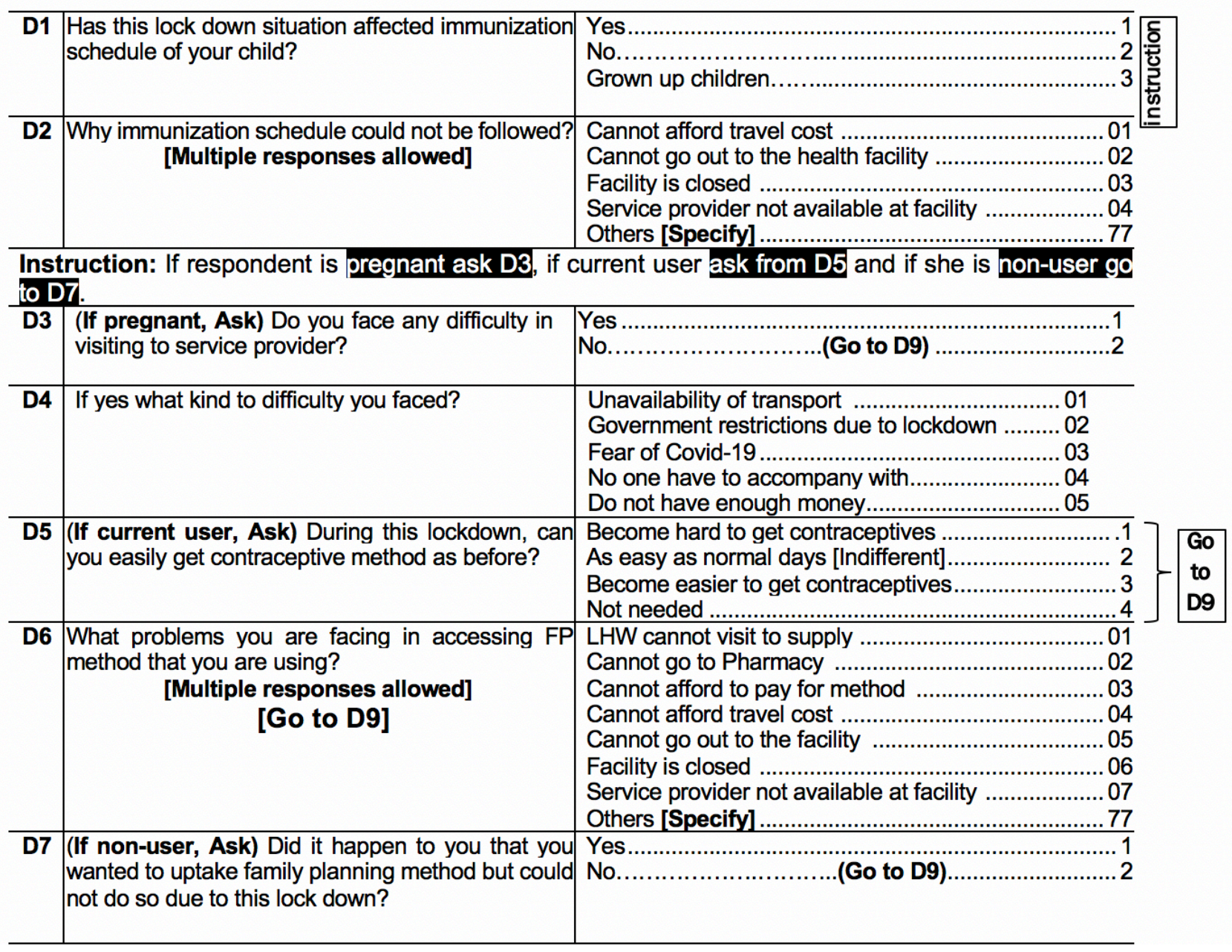




\begin{tabular}{|c|c|c|}
\hline D8 & $\begin{array}{c}\text { What problems you have to face in accessing FP } \\
\text { method that you decided to uptake? } \\
\text { [Multiple responses allowed] }\end{array}$ & 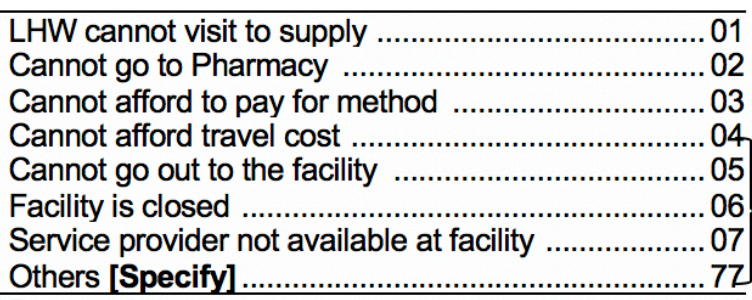 \\
\hline D9 & $\begin{array}{l}\text { Are you easily able to access menstrual hygiene } \\
\text { products (such as sanitary napkins)? }\end{array}$ & 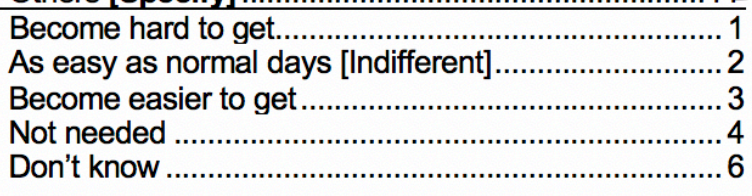 \\
\hline D10 & $\begin{array}{l}\text { What problems you have to face in accessing these } \\
\text { products? }\end{array}$ & 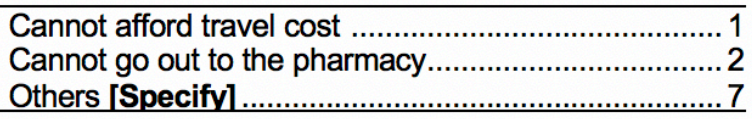 \\
\hline
\end{tabular}

\section{SECTION E}

\section{Psychological stress assessment (PHQ-9)}

Now I would to ask you some questions about your routine, behavior, and feelings during last 2 weeks, how often have you been bothered by any of the following problems?

\begin{tabular}{|c|c|c|c|c|c|c|}
\hline \multicolumn{3}{|c|}{ E1 items: } & \multirow{2}{*}{$\begin{array}{l}\text { Not } \\
\text { at all }\end{array}$} & \multirow{2}{*}{\begin{tabular}{|c|}
$\begin{array}{c}\text { Several } \\
\text { days }\end{array}$ \\
1
\end{tabular}} & \multirow{2}{*}{$\begin{array}{c}\begin{array}{c}\text { More than } \\
\text { half the } \\
\text { days }\end{array} \\
2\end{array}$} & \multirow{2}{*}{$\begin{array}{c}\begin{array}{c}\text { Nearly } \\
\text { every } \\
\text { day }\end{array} \\
3\end{array}$} \\
\hline a) & \multicolumn{2}{|l|}{ Little interest or pleasure in doing things } & & & & \\
\hline b) & \multicolumn{2}{|l|}{ Feeling down, depressed, or hopeless } & 0 & 1 & 2 & 3 \\
\hline c) & \multicolumn{2}{|l|}{$\begin{array}{l}\text { Trouble falling or staying asleep, or sleeping too } \\
\text { much }\end{array}$} & 0 & 1 & 2 & 3 \\
\hline d) & \multicolumn{2}{|l|}{ Feeling tired or having little energy } & 0 & 1 & 2 & 3 \\
\hline e) & \multicolumn{2}{|l|}{ Poor appetite or overeating } & 0 & 1 & 2 & 3 \\
\hline f) & \multicolumn{2}{|l|}{$\begin{array}{l}\text { Feeling bad about yourself or that you are a failure or } \\
\text { have let yourself or your family down }\end{array}$} & 0 & 1 & 2 & 3 \\
\hline g) & \multicolumn{2}{|l|}{$\begin{array}{l}\text { Trouble concentrating on things, such as your } \\
\text { normal routine activities }\end{array}$} & 0 & 1 & 2 & 3 \\
\hline h) & \multicolumn{2}{|l|}{$\begin{array}{l}\text { Moving or speaking so slowly that other people could } \\
\text { have noticed. Or the opposite being so fidgety or } \\
\text { restless that you have been moving around a lot } \\
\text { more than usual }\end{array}$} & 0 & 1 & 2 & 3 \\
\hline i) & \multicolumn{2}{|l|}{$\begin{array}{l}\text { Thoughts that you would be better off dead, or of } \\
\text { hurting yourself }\end{array}$} & 0 & 1 & 2 & 3 \\
\hline \multicolumn{7}{|c|}{$\begin{array}{c}\text { Section } F \\
\text { Permission for revisit/ Re-tele visiting }\end{array}$} \\
\hline \multicolumn{7}{|c|}{ It is possible that we may come/ call back after some time to interview you again. } \\
\hline \multicolumn{2}{|r|}{ F1 Could we call or visit you again? } & \multicolumn{5}{|c|}{ Yes } \\
\hline \multicolumn{7}{|c|}{$\begin{array}{l}\text { F2 Would you like to give us any suggestion or ask } \\
\text { any question? }\end{array}$} \\
\hline
\end{tabular}


APPENDIX D: STRUCTURED QUESTIONNAIRE FOR INTERVIEWS WITH SERVICE PROVIDERS

\$RNO:

SRNO from baseline (2019) survey:

Reproductive health needs and access issues of poor and marginalized women in COVID-19 situation

Interview with Health Care providerl In-charge of the facility 


\section{SECTION - A}

\section{Identification of the Health Facility}

A1- District Name:

Rahim Yar Khan

A2- Tehsil Name: Khanpur

\begin{tabular}{llll}
\hline A3- Name of Union Council: & & & \\
\hline A4- Locality: & Urban $\ldots \ldots \ldots . .1 \quad$ Rural $\ldots \ldots \ldots 2$ & \\
\hline
\end{tabular}

A5- What type of facility is this?

\begin{tabular}{|c|c|}
\hline Government Facilities & Private: \\
\hline THQ & 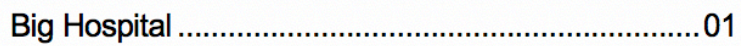 \\
\hline RHC & Small Hospital \\
\hline BHU & Doctors Clinic $(M+F)$ \\
\hline Public dispensary & 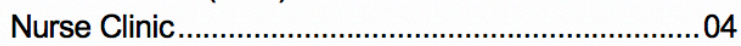 \\
\hline MCH Center & 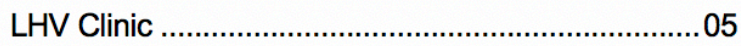 \\
\hline RHS-A FH Center & CMW Clinic \\
\hline FWC & Maternity Home \\
\hline 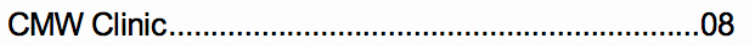 & 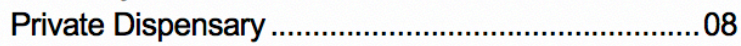 \\
\hline
\end{tabular}

A6- Complete (postal) address of the health facility:

Address:

A7- Contact number of the facility:

Mobile No:

Landline No:

1_1_1_1___

A9- Duration of telephonic interview: [in minutes]

[Please write down 24 hours]

A10- Date of visit for interview: $\quad$ ____ $\quad \frac{\mathrm{L}}{\mathrm{DD}}: \frac{\mathrm{l}}{\mathrm{MM}} \frac{\mathrm{L}}{\mathrm{YYY}}$

A11- Name of the interviewer: Code:

A12- Result of interview:

Connected and interview completed

01

Connected and interview incomplete

02

Connected but refused to be interviewed

03

Connected but given other time for interview

04

Call not responded

05

Number switched off

06

Number not in use

Connected and interview completed with closed facility status.

Others

77

A13- In case of incomplete interview / refusal, please specify reasons:

A14: Number of total calls made to the service provider: 


\section{SECTION - B}

\section{Socio-demographic characteristics of the Service Provider}

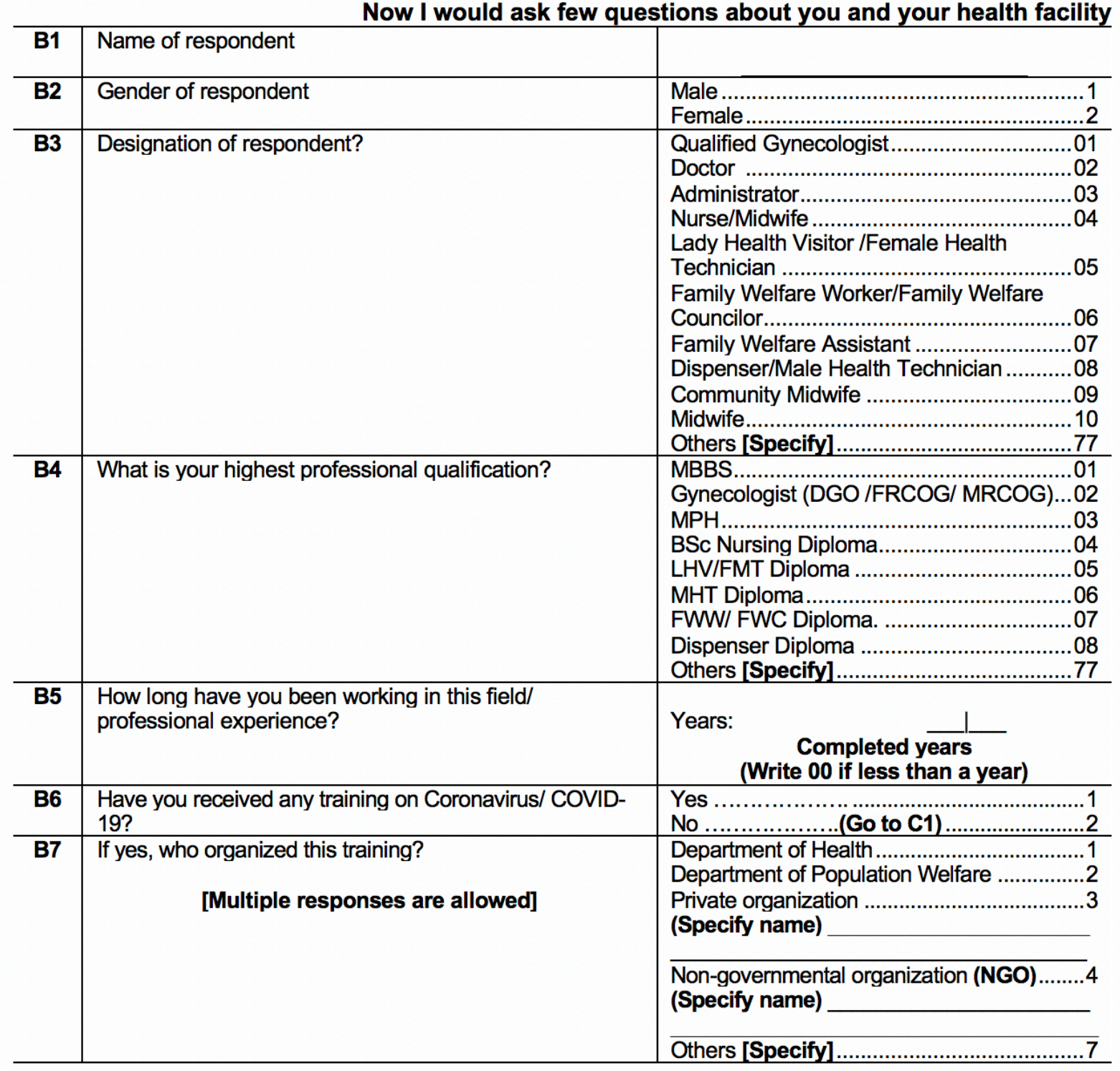




\section{SECTION - C \\ Knowledge of the service provider}

\section{Now I would like to ask you some questions that what do you know about this new disease of Coronavirus}

\begin{tabular}{|c|c|c|}
\hline C1 & $\begin{array}{c}\text { What are the main symptoms of Coronavirus? } \\
\text { Multiple responses are allowed }\end{array}$ & $\begin{array}{l}\text { Fever } \\
\text { Fatigue } \\
\text { Cough } \\
\text { Shortness of breath } \\
\text { Chills } \\
\text { Repeated shaking with chills } \\
\text { Muscle pain } \\
\text { Sore throat } \\
\text { Loss of smell or taste }\end{array}$ \\
\hline C2 & $\begin{array}{l}\text { How does this illness spread? } \\
\text { Multiple responses are allowed }\end{array}$ & 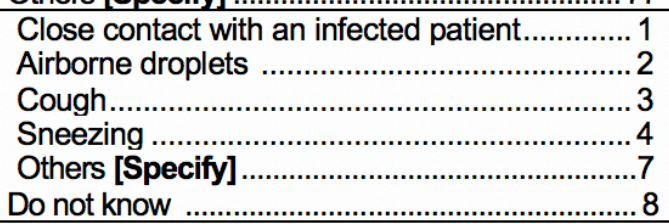 \\
\hline C3 & $\begin{array}{l}\text { What this COVID-19 leads to? / What can happen to a } \\
\text { person as a of result of COVID-19? } \\
\text { [Multiple responses are allowed] }\end{array}$ & $\begin{array}{l}\text { Pneumonia } \\
\text { Respiratory failure } \\
\text { Throat infection } \\
\text { Shortness of breath } \\
\text { Death } \\
\text { Others [Specify] }\end{array}$ \\
\hline C4 & $\begin{array}{l}\text { What is the current treatment for COVID-19? } \\
\text { [Multiple responses are allowed] }\end{array}$ & 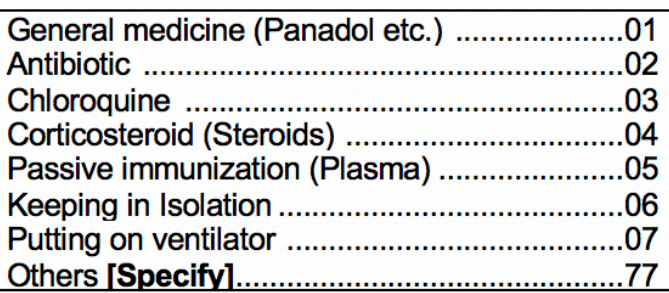 \\
\hline C5 & $\begin{array}{l}\text { What can help in the prevention of COVID-19 } \\
\text { transmission? } \\
\text { [Multiple responses are allowed] }\end{array}$ & 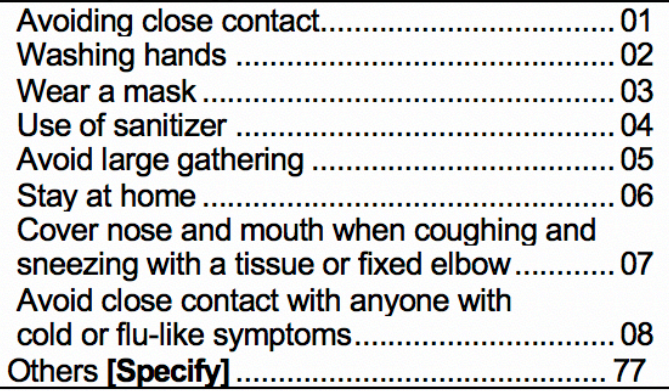 \\
\hline C6 & $\begin{array}{c}\text { What are your sources of information on Coronavirus? } \\
\qquad \text { Multiple responses are allowed }\end{array}$ & 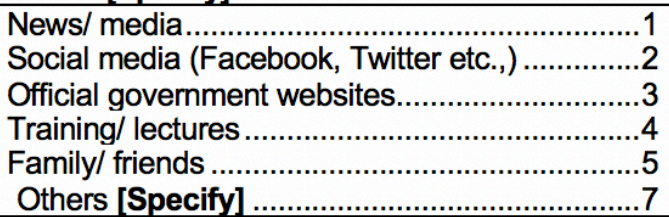 \\
\hline
\end{tabular}


Now I would read some statements regarding COVID-19, please answer as true or false

\begin{tabular}{|c|c|c|}
\hline C7 & COVID-19 symptoms appear in 2-14 days. & 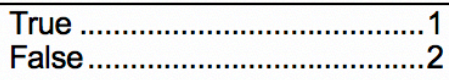 \\
\hline $\mathbf{C 8}$ & Flu vaccination is sufficient for preventing COVID-19 & 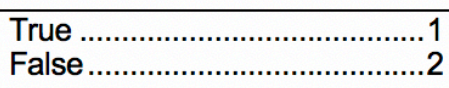 \\
\hline $\mathbf{C 9}$ & $\begin{array}{l}\text { During the outbreak, eating well-cooked and safely handled meat is } \\
\text { safe }\end{array}$ & 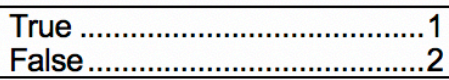 \\
\hline C10 & $\begin{array}{l}\text { Sick patients should share their recent travel history with healthcare } \\
\text { providers }\end{array}$ & $\begin{array}{l}\text { True .......................................... } \\
\text { False ............................... }\end{array}$ \\
\hline C11 & Disinfect equipment at least once a day & 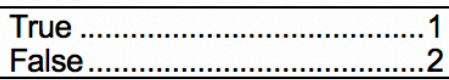 \\
\hline C12 & $\begin{array}{l}\text { Washing hands with soap and water can help in prevention of COVID- } \\
19 \text { transmission }\end{array}$ & 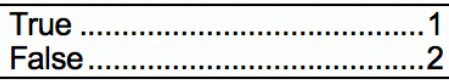 \\
\hline C13 & A woman who is positive for the virus can she breast feed her child & 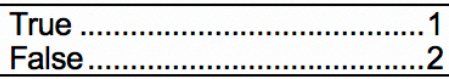 \\
\hline $\mathbf{C 1 4}$ & A COVID 19 positive woman can use modern contraceptives & 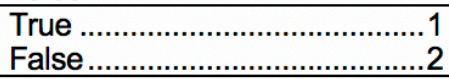 \\
\hline
\end{tabular}

\section{SECTION - D \\ Service Provision}

In case of closed facility, skip this section and Go to Section- E

Now I would like to ask some questions regarding services being provided at this facility

\begin{tabular}{|c|c|c|}
\hline D1 & $\begin{array}{l}\text { Does this facility provide services to corona positive } \\
\text { patients }\end{array}$ & 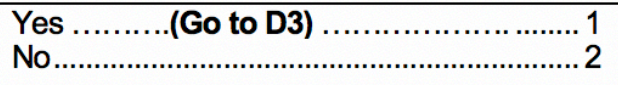 \\
\hline \multirow[t]{2}{*}{ D2 } & $\begin{array}{l}\text { If not providing COVID-19 services, what are the } \\
\text { reasons? } \\
\text { [Multiple responses are allowed] }\end{array}$ & 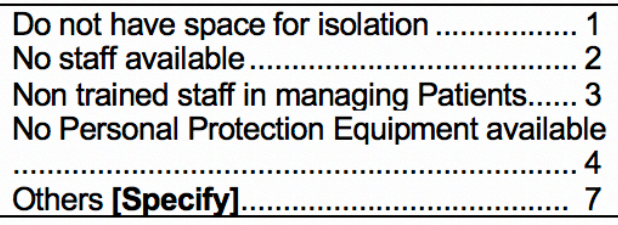 \\
\hline & \multicolumn{2}{|c|}{ Go to D7 } \\
\hline D3 & $\begin{array}{l}\text { Does this facility provide outpatient services or } \\
\text { inpatient for Corona positive patients? }\end{array}$ & 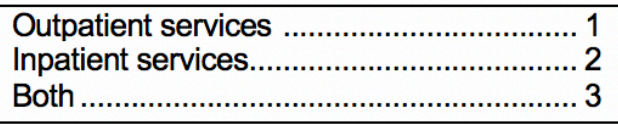 \\
\hline D4 & $\begin{array}{l}\text { What services your facility providing to Corona positive } \\
\text { patients? } \\
\qquad \text { [Multiple responses are allowed] }\end{array}$ & 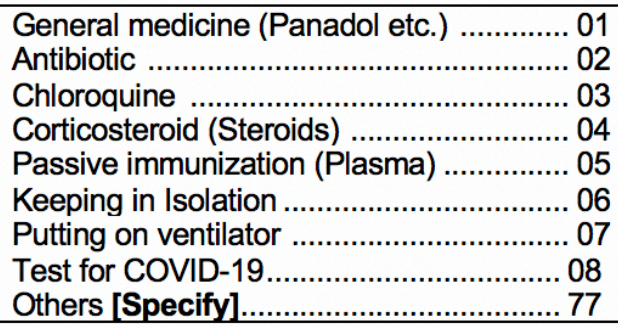 \\
\hline D5 & $\begin{array}{l}\text { How many beds are available for Covid19 patients in } \\
\text { this health facility/center? }\end{array}$ & 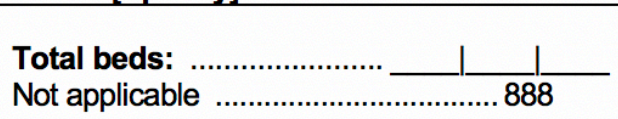 \\
\hline D6 & Is there any staff available on call for Covid19 patients? & 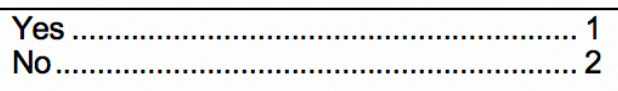 \\
\hline
\end{tabular}




\begin{tabular}{|c|c|c|}
\hline D7 & $\begin{array}{l}\text { Do you feel fear of catching coronavirus while serving } \\
\text { at the facility? }\end{array}$ & Yes \\
\hline D8 & $\begin{array}{l}\text { Do you recieve personal protection equipment to } \\
\text { avoid getting infected form the virus? }\end{array}$ & 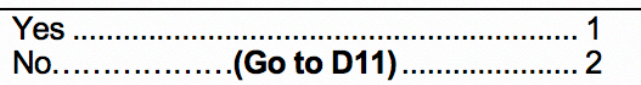 \\
\hline D9 & $\begin{array}{l}\text { If yes, what this personal protection equipement } \\
\text { include? } \\
\qquad \text { [Multiple responses are allowed] }\end{array}$ & 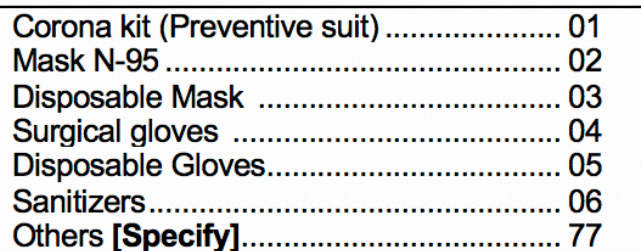 \\
\hline D10 & $\begin{array}{l}\text { From whom do you receive this personal protection } \\
\text { equipment? }\end{array}$ & $\begin{array}{l}\text { Department of Health ................................ } 1 \\
\text { Department of Population Welfare .............. } \\
\text { Private organization } \\
\text { (Specify name) } \\
\begin{array}{l}\text { Non-governmental organization (NGO) } \\
\text { (Specify name) }\end{array} \\
\begin{array}{l}\text { Self-purchase } \\
\text { Others [Specify] }\end{array}\end{array}$ \\
\hline D11 & $\begin{array}{l}\text { All patients who come to see you, do you provide them } \\
\text { any information about prevention from covid-19? }\end{array}$ & 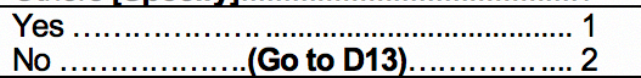 \\
\hline D12 & $\begin{array}{l}\text { What information you provide them regarding } \\
\text { prevention from covid-19? } \\
\text { [Multiple responses are allowed] }\end{array}$ & 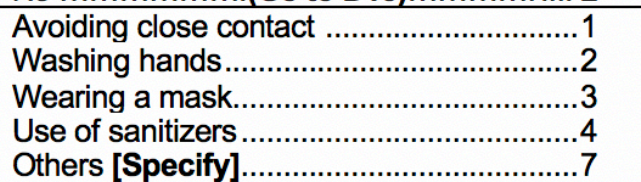 \\
\hline D13 & $\begin{array}{l}\text { Has your facility participated in any awareness } \\
\text { campaign regarding Covid-19? OR Have you done } \\
\text { anything individually? }\end{array}$ & Yes …......................................... 1 \\
\hline D14 & [Multiple responses are allowed] & 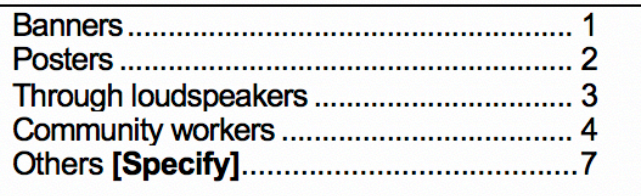 \\
\hline \multicolumn{3}{|c|}{ Now I would like to ask some questions regarding FP and RH services being provided at this facility } \\
\hline D15 & $\begin{array}{l}\text { What type of services do you usually provide at this } \\
\text { facility? }\end{array}$ & 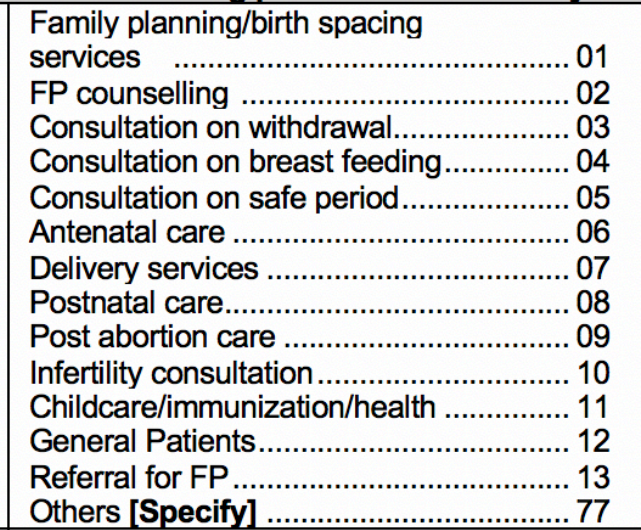 \\
\hline D16 & $\begin{array}{l}\text { Has any service provided here, been affected with this } \\
\text { current situation? }\end{array}$ & 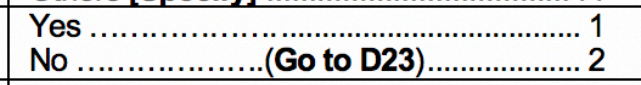 \\
\hline D17 & Which of the services got affected? & 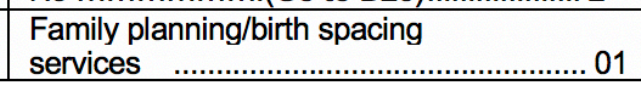 \\
\hline
\end{tabular}




\begin{tabular}{|c|c|c|}
\hline & [Multiple responses are allowed] & 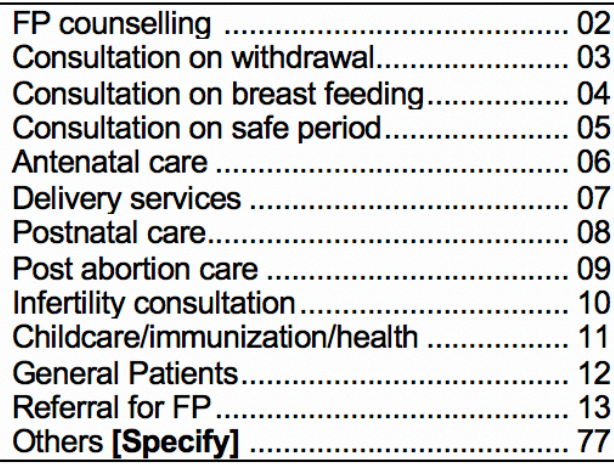 \\
\hline D18 & $\begin{array}{l}\text { In what ways these services got affected } \\
\text { [Multiple responses are allowed] }\end{array}$ & 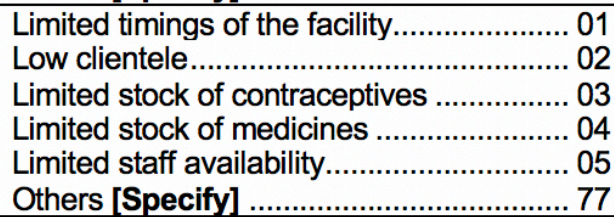 \\
\hline D19 & $\begin{array}{l}\text { Do you think that current limited services can effect } \\
\text { contraceptive use among women/ lead to } \\
\text { discontinuation? }\end{array}$ & 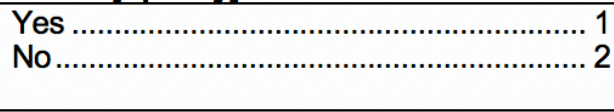 \\
\hline D20 & $\begin{array}{l}\text { Do you think that current limited service provision can } \\
\text { increase risk for pregnant women particulalry for } \\
\text { delivery services? }\end{array}$ & Yes \\
\hline D21 & $\begin{array}{l}\text { Do you have regular supply system for receiving } \\
\text { contraceptive in this COVID -19 situation? }\end{array}$ & Yes \\
\hline D22 & $\begin{array}{l}\text { If stock out, then what do you do? } \\
\text { [Multiple responses are allowed] }\end{array}$ & 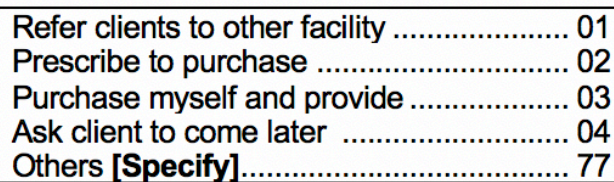 \\
\hline D23 & $\begin{array}{l}\text { As provider, what challenges do you face personally in } \\
\text { providing services at health facilities during this } \\
\text { Coronavirus situation? }\end{array}$ & 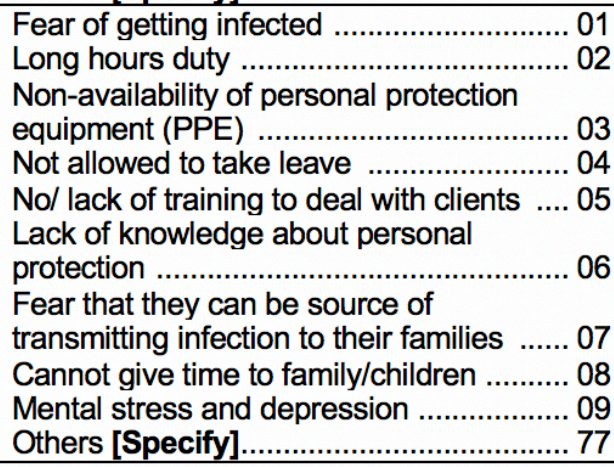 \\
\hline D24 & $\begin{array}{l}\text { In your observation/ experience do service providers } \\
\text { have to face any discriminating behavior these days at } \\
\text { they are at risk of getting infected? }\end{array}$ & 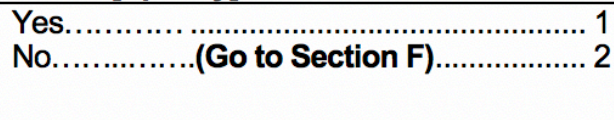 \\
\hline D25 & $\begin{array}{l}\text { What issues service providers have to face from } \\
\text { people around them? } \\
\text { [Multiple responses are allowed] }\end{array}$ & 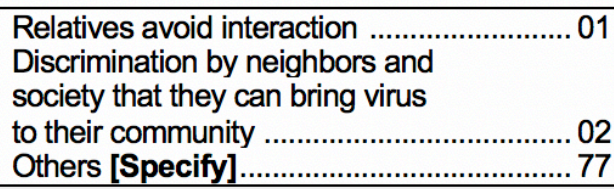 \\
\hline
\end{tabular}




\section{SECTION - E}

\section{Closure of the facility}

As you have mentioned that your facility is closed these days due to coronavirus situation, I would like to ask you some questions about the reasons of this closure and its impact on your life.

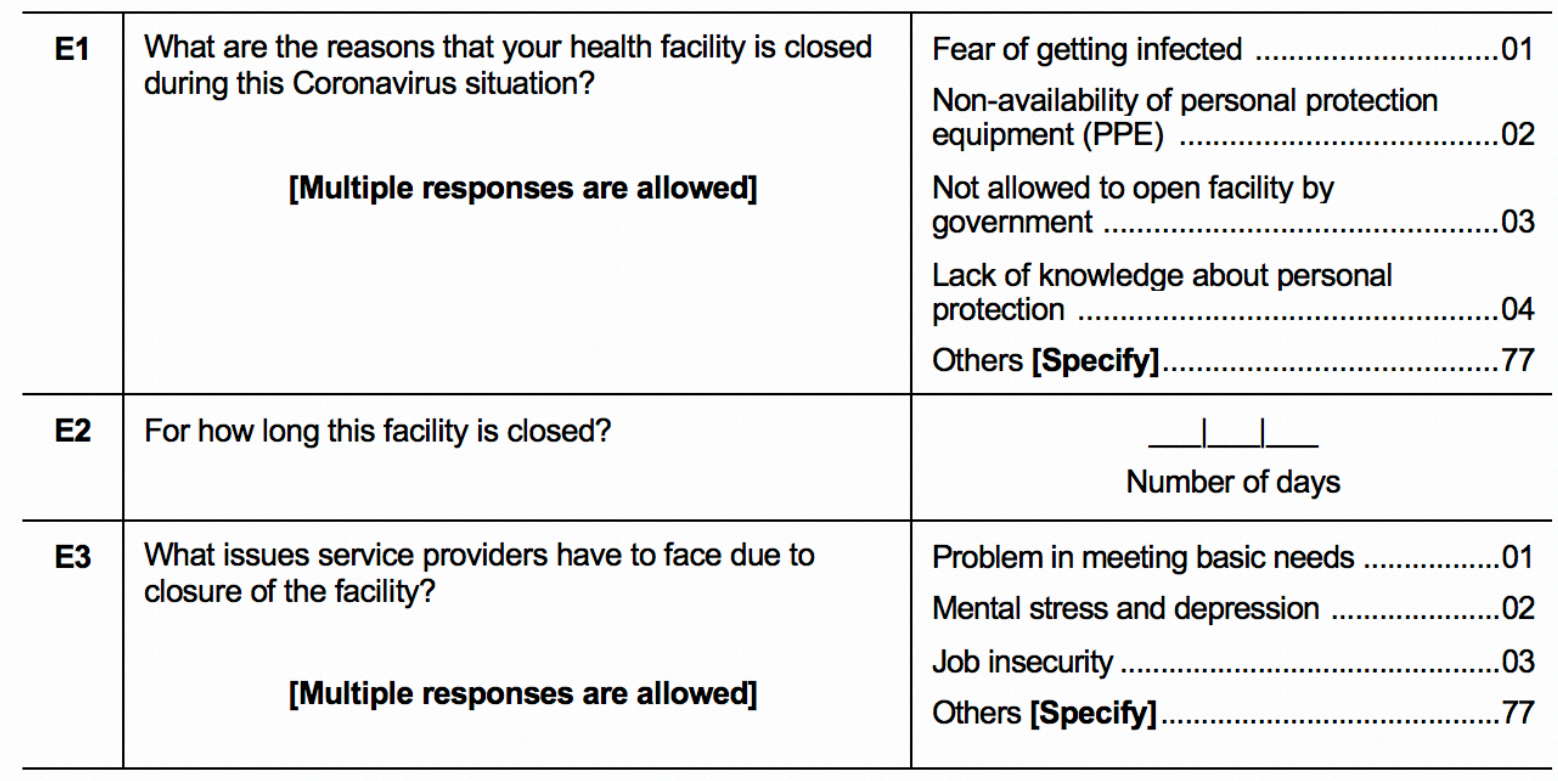

\section{SECTION - F}

\section{Permission for Revisit/ Re-tele visiting}

\begin{tabular}{l|l|l}
\hline \multicolumn{3}{l}{ It is possible that we may come/ call back after some time to interview you again. } \\
\hline F1 & Could we call/ visit this facility again? & Yes......................................................... \\
\hline F2 & $\begin{array}{l}\text { Would you like to give us any suggestion or ask any } \\
\text { question? }\end{array}$ & No ............................................................. \\
\hline
\end{tabular}

